\title{
Utility Advanced Turbine Systems (ATS) Technology Readiness Testing - Phase 3
}

\author{
Annual Report \\ October 1, 1996 - September 30, 1997
}

Work Performed Under Contract No.: DE-FC21-95MC31176

For

U.S. Department of Energy

Office of Fossil Energy

Federal Energy Technology Center

P.O. Box 880

Morgantown, West Virginia 26507-0880

By

General Electric Company

Power Generation Engineering

Schenectady, New York 12345

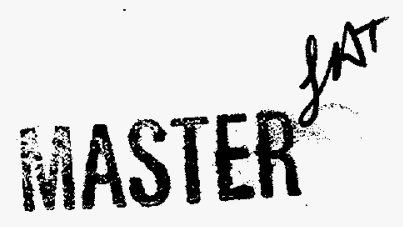

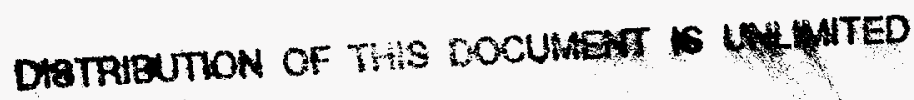




\section{Disclaim er}

This report was prepared as an account of work sponsored by an agency of the United States Government. Neither the United States Government nor any agency thereof, nor any of their employees, makes any warranty, express or implied, or assumes any legal liability or responsibility for the accuracy, completeness, or usefulness of any information, apparatus, product, or process disclosed, or represents that its use would not infringe privately owned rights. Reference herein to any specific commercial product, process, or service by trade name, trademark, manufacturer, or otherwise does not necessarily constitute or imply its endorsement, recommendation, or favoring by the United States Government or any agency thereof. The views and opinions of authors expressed herein do not necessarily state or reflect those of the United States Government or any agency thereof. 


\section{DISCLAIMER}

Portions of this document may be illegible in electronic inage products. Images are produced from the best available original document. 


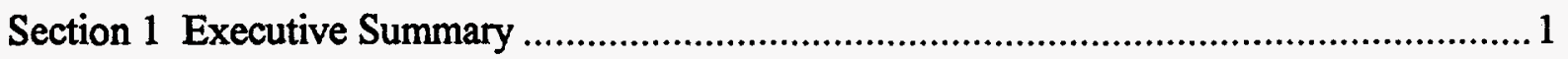

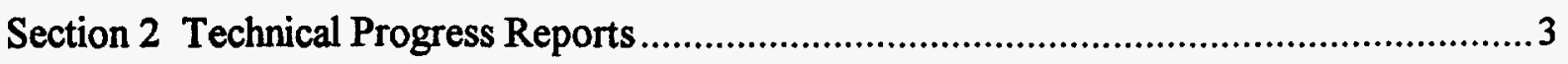

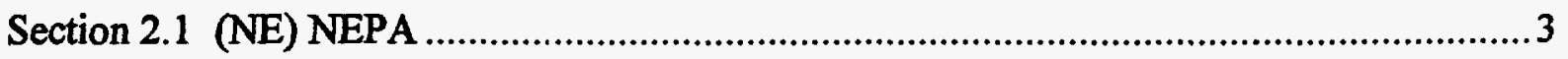

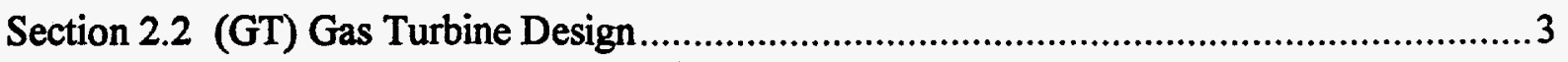

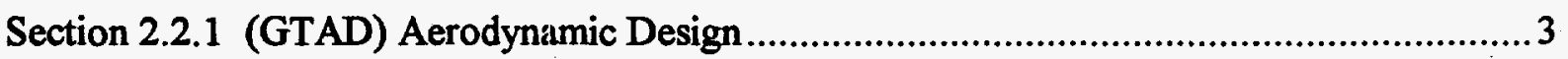

Section 2.2.2 (GTFF) Gas Turbine Flange-to-Flange Design ............................................... 4

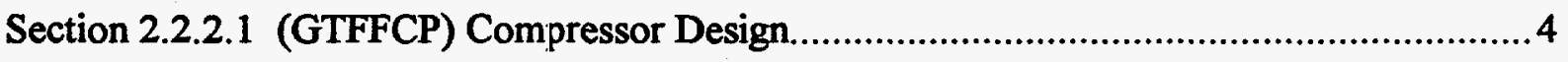

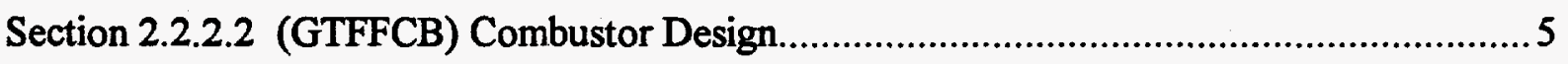

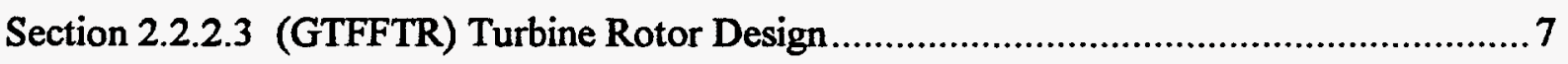

Section 2.2.2.3.1 (GTFFTR) Turbine Rotor Mechanical Analysis (Task Force)...................... 8

Section 2.2.2.3.2 (GTFFTR) Wheel Forging Residual Stress Analysis............................... 9

Section 2.2.2.3.3 (GTFFTR) Rotor Steam Circuit Analysis.........................................11

Section 2.2.2.3.4 (GTFFTR) Turbine Rotor Shaft Temperature Analysis - \#2 Bearing ........ 13

Section 2.2.2.3.5 (GTFFTB) Bucket Temperature Monitoring...................................... 13

Section 2.2.2.4 (GTFFTB) Turbine Bucket Design....................................................... 14

Section 2.2.2.4.1 (GTFFTB) S1B and S2B Wheel Dovetail Analysis ............................... 15

Section 2.2.2.4.2 (GTFFTB) S3B and S4B Tip Shroud Design Optimization...................... 16

Section 2.2.2.4.3 (GTFFTB) Bucket Wide Grain Sensitivity Analysis ..............................16

Section 2.2.2.4.4 (GTETIH) Bucket Tip Treatment Heat Transfer................................... 18

Section 2.2.2.4.5 (GTFFTB) S1B and S2B Air/Steam Coolant Transition Analysis............ 19

Section 2.2.2.4.6 (GTETEH) S॥B External Heat Transfer ..............................................20

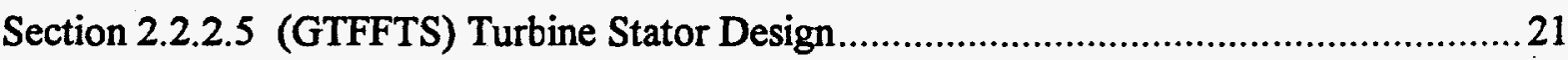

Section 2.2.2.5.1 (GTFFTS) Turbine Stator Robust Design ..........................................22

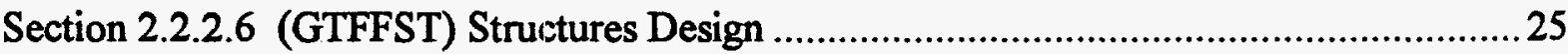

Section 2.2.2.6.1 (GTFFSTEF) Exhaust Diffuser Performance .......................................27

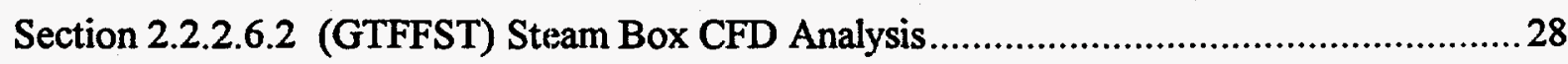

Section 2.2.2.7 (GTFFMS) Mechanical System Design...................................................2 29

Section 2.2.2.7.1 (GTFFMS) Transient Gas Turbine Cycle Model ....................................30

Section 2.2.2.8 (GTFFPP) On-Hase and External Piping Design ........................................31

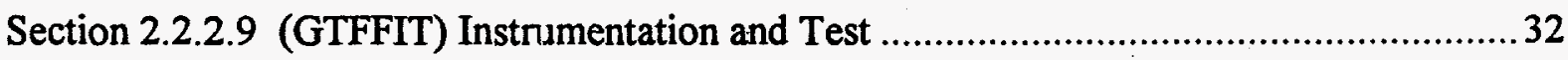

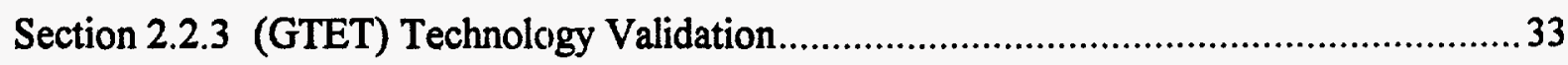

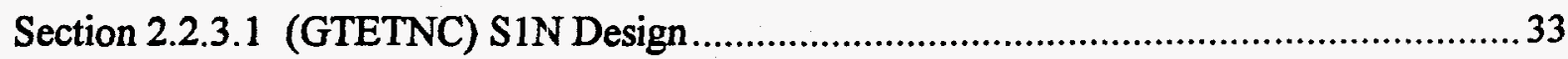


Section 2.2.3.1.1 (GTETNC) Nozzle Cascade CFD Analysis...........................................33

Section 2.2.3.1.2 (GTETEH) Combustion-Generated Flow Effects on Heat Transfer...........33

Section 2.2.3.2 (GTETRS) Rotor Steam Transfer..............................................................34

Section 2.2.3.3 (GTETSE) Rotor-Bucket Steam Transfer Spoolie .......................................35

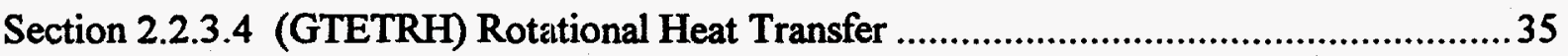

Section 2.2.3.4.1 (GTETRH) Rotational Effects on Bucket Mixing Ribs............................. 35

Section 2.2.3.4.2 (GTETRH) Bucket Cooling Circuit Rotational Pressure Drop Test ......... 36

Section 2.2.3.5 (GTETIH) Surface Enhanced Internal Heat Transfer ................................. 37

Section 2.2.3.5.1 (GTETS2NHT) S2N Trailing Edge Flow Test.......................................37

Section 2.2.3.5.2 (GTETIH) S213 Trailing Edge Heat Transfer Tests ...................................37

Section 2.2.3.5.3 (GTETIH) SIN Outer Band Liquid Crystal Heat Transfer Tests ...............40

Section 2.2.3.5.4 (GTETIH) S1N Convex Cavity Heat Transfer Tests.................................40

Section 2.2.3.5.5 (GTETIH) Bucket Tip Closed Circuit Cooling ................................... 41

Section 2.2.3.5.6 (GTETLE) Bucket Leading Edge Heat Transfer Testing .......................... 41

Section 2.2.3.5.7 (GTETIH) SIN Surface Enhanced Internal Heat Transfer .......................42

Section 2.2.3.5.8 (GTETIH) S1N Trailing Edge Heat Transfer Tests............................... 42

Section 2.2.3.5.9 (GTETBKHT) High Reynolds Number Turbulator Static Heat

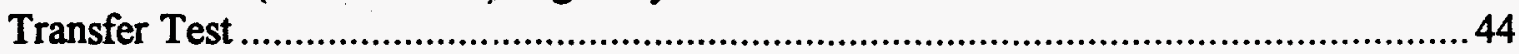

Section 2.2.3.5.10 (GTET) Impingement Degradation Effects ...........................................4

Section 2.2.3.5.11 (GTETIH) Production Airfoil Flow Checks ............................................45

Section 2.2.3.6 (GTETEH) Surface Roughness and Combustor-Generated Flow Effects on Heat Transfer.

Section 2.2.3.6.1 (GTETEH) SllN Heat Transfer for Production Aero with TBC Spall Effects. 48

Section 2.2.3.6.2 (GTETEH) Surface Roughness Effects on Heat Transfer..........................48

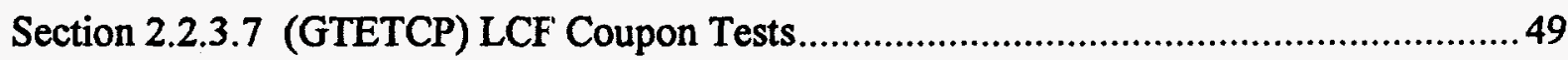

Section 2.2.3.7.1 (GTETCP) LCF and Crack Propagation Rate Tests...............................49

Section 2.2.3.8 (GTETSP) Steam Particulate Deposition..................................................51

Section 2.2.3.8.1 (GTETSP) Steam Particulate Deposition Rig Testing ..............................51

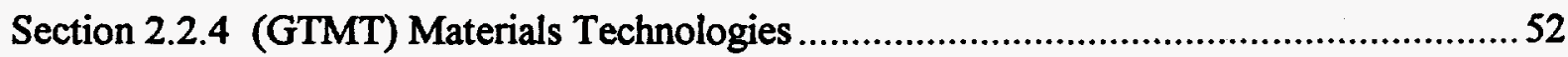

Section 2.2.4.1 (GTMTSE) Steam Effects on Mechanical Properties ...............................52

Section 2.2.4.2 (GTMTSO) Oxidation Due to Steam......................................................53

Section 2.2.4.3 (GTMTCE) Corrosion Rate Evaluations of Airfoil Overlay Coatings ..........54 
Section 2.2.4.4 (GTMTBV) Compressor Blades and Vanes Materials and Processes .

Section 2.2.4.5 (GTMTVG) Compressor Variable Guide Vane System Design Support

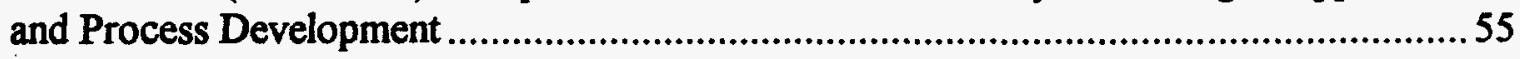

Section 2.2.4.6 (GTMTCS) Cornpressor Structural Materials and Processes...................... 55

Section 2.2.4.7 (GTMTRF) Turbine Rotor Forging Materials and Processes......................56

Section 2.2.4.8 (GTMTRS) Turbine Rotor Spoolies and Transfer Devices Materials

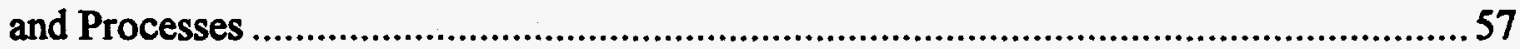

Section 2.2.4.9 (GTMTSB) Structural Bolting........................................................ 58

Section 2.2.4.10 (GTMTTA) Turbine Airfoils Materials and Processes.............................. 59

Section 2.2.4.11 (GTMTCB) Combustion Materials and Processes....................................60

Section 2.2.4.12 (GTMTST) Turbine Structures Materials and Processes ........................60

Section 2.2.4.13 (GTMTSH) Turbine Shells ..........................................................61

Section 2.2.4.14 (GTMTSR) Seal Technology............................................................ 61

Section 2.2.4.14.1 (GTFFTSESV) Hot Gas Path and Transition Piece Cloth Seals ............ 62

Section 2.2.4.14.2 (GTETBS) Siteam Gland Brush Seals...........................................63

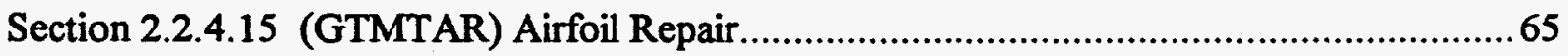

Section 2.2.5 (GTTT) Thermal Barrier Coating Technology .....................................65

Section 2.2.5.1 (GTTTSD) Coating System Development .......................................65

Section 2.2.5.2 (GTTTRR) TBC Risk Reduction.............................................. 73

Section 2.2.5.3 (GTTTDD) TBC Design Data and Life Analyses................................. 74

Section 2.2.5.3.1 (GTFFTB) Bucket TBC Roughness and Spall Characterization ..............76

Section 2.3 (CC) Combined Cycle Integration ....................................................... 77

Section 2.3.1 (CCUA) Unit Accessories ..................................................................77

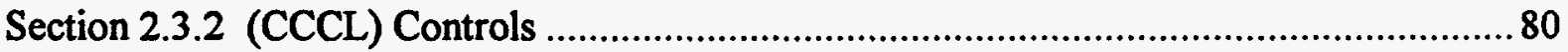

Section 2.3.3 (CCRA) Reliability, Availability, and Maintainability (RAM) Analysis...........81

Section 2.3.4 (CCSD) Combined Cycle Systems Design ...........................................82

Section 2.4 (MF) Manufacturing Equipment and Tooling........................................ 83

Section 2.5 (IG) Integrated Gasification and Biomass Fuel...................................... 84

Section 2.6 (DE) Pre-Commercial Demonstration.................................................. 84

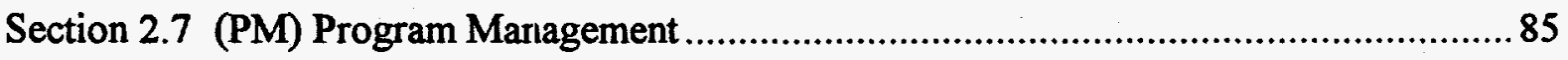

LIST OF FIGURES

Figure 1-1. Schematic of $\mathrm{H}$ machine cross section....................................................... 


\section{Section 1 Executive Summary}

The overall objective of the Advanced Turbine System (ATS) Phase 3 Cooperative Agreement between GE and the U.S. Department of Energy (DOE) is the development of the GE $7 \mathrm{H}$ and $9 \mathrm{H}$ combined cycle power systems. The major effort will be expended on detail design. Validation of critical components and technologies will be performed including: hot gas path component testing, sub-scale compressor testing, steam purity test trials, and rotational heat transfer confirmation testing. Processes will be developed to support the manufacture of the first system. 'Technology enhancements that are not required for the first machine design but will be critical for future ATS advances in performance, reliability, and costs will be initiated. Long-term tests of materials to confirm design life predictions will continue. A schematic of the GE H machine is shown in Figure 1-1.

This report summarizes work accomplished from $4 Q 96$ through $3 Q 97$. The most significant accomplishments are listed below:

\section{H/7H-common technology}

- Completed full-scale steam-cooled first-stage nozzle design validation heat transfer testing

- Completed initial tests of $\mathrm{H}$ combustor design at both component level and in full-scale reduced pressure burner tests

- Completed construction of a full-scale combustion test stand with combustor design pressure, flow, and temperature

- Developed single crystal casting technology for large-scale buckets and nozzles

- Completed testing of the $1 / 3$-scale $9 H$ compressor rig

- Continued testing elements of steam cooling system

- Improved forging process to allow production of largest gas turbine Inconel wheels

- Initiated thermal barrier coating (TBC) process trials for high deposition rate uniform application

- Tested ATS-type TBC-coated shrouds and buckets in utility customers' current gas turbines under actual conditions

- Developed nondestructive inspection techniques for single crystal airfoil production

- Developed statistical design methods for selected hot gas path components for better design control and reduced manufacturing variability and cost with increased yield

- Developed a transient operation analysis model to allow more accurate evaluation of transient gas turbine aerodynamic and thermal behavior in combination with other combined cycle components 


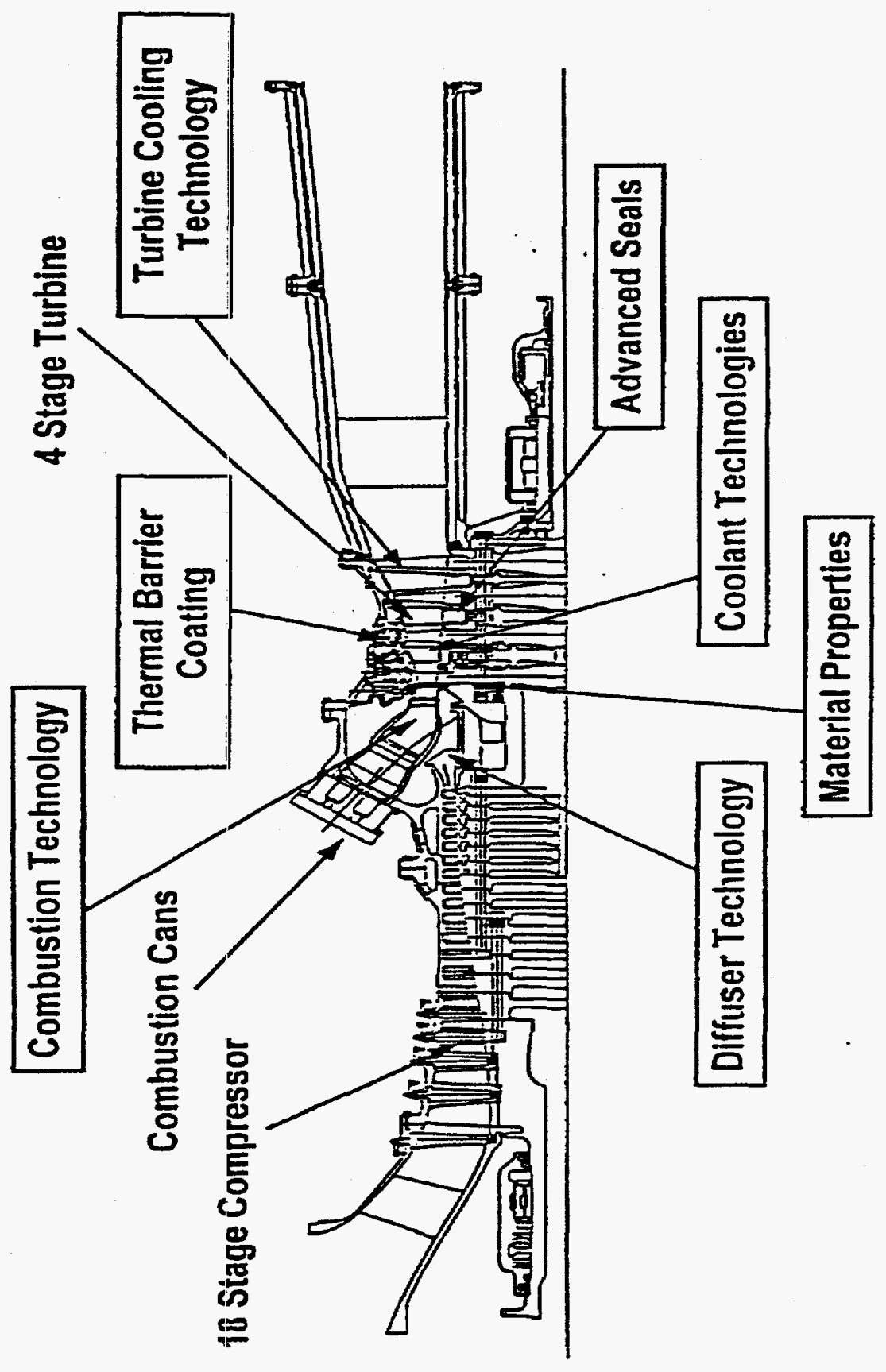

Figure 1-1. Schematic of $\mathrm{H}$ machine cross section 


\section{Section 2 Technical Progress Reports}

\section{Section 2.1 (NE) NEPA}

\section{Objective}

A draft topical report will be prepared which provides the environmental information associated with Phase 3, Technology Readiness Testing, as specified in the National Environmental Policy Act (NEPA). DOE will use this information to prepare the NEPA documentation for Phase 3. DOE will review the report and advise the participant of the acceptability of the report or the need for additional information. A final report will then be submitted.

A second draft topical report will be prepared which provides the environmental information associated with Phase 4, Pre-Commercial Demonstration, as specified in NEPA. DOE will use this information to prepare the NEPA documentation for Phase 4. DOE will review the report and advise the participant of the acceptability of the report or the need for additional information. A final report will then be submitted.

\section{Progress 4Q96 through 3Q97}

In accordance with GE's ongoing Cooperative Agreement with DOE, a draft topical report covering Safety and Health, Permits and Licenses, and Environmental Protection was prepared by International Technologies Corporation for the $7 \mathrm{H}$-related activities at the GE Power Systems manufacturing facility in Greenville, SC. DOE will use this NEPA information to prepare the Environmental Assessment (EA) documentation required for $7 \mathrm{H}$ full speed, no load (FSNL) testing activities.

\section{Plans for Next Quarter}

The DOE-produced draft EA will be reviewed to assist DOE in producing the final EA, and a Finding of No Significant Impact (FONSI) draft report will be amended, if necessary, to reflect the DOE review results.

\section{Technology Application}

The NEPA report provides documentation that GE Power Systems is in compliance with all applicable environmental, health, and safety laws and regulations, and has the required permits and licenses necessary for compliance.

\section{Section 2.2 (GT) Gas Turbine Design}

\section{Section 2.2.1 (GTAD) Aerodynamic Design}

\section{Objective}

To achieve ATS performance goals, a four-stage turbine will be designed. Advanced aerodynamic technology (sometimes called 3D aerodynamics) pioneered at GE Aircraft 
Engines (GEAE) will be applied to each stage to maximize performance and meet mechanical design requirements required by steam cooling technology.

The $7 \mathrm{H}(60 \mathrm{~Hz})$ and $9 \mathrm{H}(50 \mathrm{~Hz})$ turbines have similar flowpaths and a common rotor but require different aerodynamic designs. Performance requirements for the $7 \mathrm{H}$ and $9 \mathrm{H}$ turbine aerodynamics are the same.

\section{Progress 4Q96 through $3 Q 97$}

The final $7 \mathrm{H}$ turbine aerodynamic flowpath was completed, formally reviewed, and documented. All mechanical issues related to flowpath aerodynamics were resolved.

\section{Plans for Next Quarter}

This task has been completed.

\section{Technology Application}

Advanced aerodynamic technology (sometimes called $3 \mathrm{D}$ aerodynamics) pioneered at GEAE has been applied to each stage to maximize performance and meet mechanical design objectives required by steam cooling technology.

\section{Section 2.2.2 (GTFF) Gas Turbine Flange-to-Flange Design}

\section{Section 2.2.2.1 (GTFFCP) Compressor Design}

\section{Objective}

The objective of this task is to design $7 \mathrm{H}$ and $9 \mathrm{H}$ compressor rotor and stator structures with the goal of achieving lower cost and greater durability by applying proven GE Power Generation (GEPG) heavy-duty use design practices. The designs will be based on the GEAE CF6-80C2 compressor. Transient and steady-state thermomechanical stress analysis will be run to ensure compliance with GEPG life standards. Drawings will be prepared for forgings, castings, machining, and instrumentation for full speed, no load tests of the first unit.

\section{Progress 4Q96 through $3 Q 97$}

Component analysis for the $9 \mathrm{H}$ is complete, and all parts lives are calculated to meet product life requirements.

Drawings for the $9 \mathrm{H}$ compressor are complete for all components, and vendors for final part manufacture were selected. Manufacture began for all compressor parts including compressor rotors, blades, through-bolts, and spacers. Parts are in various stages of manufacture; all compressor components are scheduled for completion by the end of $4 \mathrm{Q} 97$.

The $9 \mathrm{H}$ sub-scale compressor test vehicle was assembled and tested. The preliminary test results indicate that the compressor met all design goals including efficiency, aerodynamic and aeromechanical performance, stall margin, and mechanical design integrity. The variable stator vane (VSV) schedule optimization is also complete. This optimized schedule will be used in the $9 \mathrm{H}$ production compressor. The post-test data reduction is still in progress. 
The compressor casings and VSV system completed all releases for modification instrumentation drawings. The inlet and compressor casings as well as many VSV components went through first piece qualification inspection and are arriving at the Greenville assembly facility. The VSV system hardware was updated to reflect the rig test rescheduling as closely as will be allowed with the ganged-actuation setup. The compressor discharge diffuser has experienced casting delay, thus slowing the progress of the overall compressor discharge casing (CDC) arrangement schedule.

The $7 \mathrm{H}$ preliminary aerodynamic design was completed for the new airfoil stages $0,1,2,14$, 15,16 , and 17. Initial aeromechanical evaluation of the airfoils is complete and acceptable. Stress analysis of forward stage blade dovetails is in progress. Initial results indicate that adequate design margins can be achieved in these new stages.

\section{Plans for Next Quarter}

With the completion of $9 \mathrm{H}$ hardware and instrumentation drawings, work for the $9 \mathrm{H}$ program will focus on releasing all assembly drawings for initial machine testing, and providing engineering support for manufacture and assembly of $9 \mathrm{H}$ components.

The $7 \mathrm{H}$ design work will accelerate during $4 \mathrm{Q} 97$ with release of components needed for subscale testing. Product definition will begin with initial life and product specification calculations. Detailed product definition and trade studies to define the basic geometry will begin with major compressor components.

\section{Technology Application}

The compressor design (aerodynamic and mechanical) and rig test results establish the basis for the $7 \mathrm{H}$ and $9 \mathrm{H}$ production hardware.

\section{Section 2.2.2.2 (GTFFCB) Combustor Design}

\section{Objective}

The objective of this task is to design a combustor based on the commercial DLN2 combustion system, with modifications made for improved use of available air, reduced cooling, and greater load turndown capability. This design will be similar for both the $7 \mathrm{H}$ and 9H machines. It will be configured to ensure the ability to use preheated fuel. Rig testing of full-scale and scaled components will be conducted at $7 \mathrm{H}$ and $9 \mathrm{H}$ cycle conditions. The final configuration will be validated in single-combustor, full-scale tests under full operating conditions.

The premixer-burner design will be optimized to use minimum pressure drop, achieve required fuel/air mixing, maintain stable flame, and resist flashback. The basic design will be developed and evaluated in full-scale single burner tests and then implemented in full-scale combustors. The ability to meet high cycle fatigue (HCF) life goals depends on understanding the effects and interrelationships of all combustion parameters. Existing dynamics models used in parallel with laboratory-scale and full-sicale testing will be used to predict combustor dynamic behavior. 
Chamber arrangement, casings, cap and liner assemblies, flame detectors, and spark plugs will be designed and analyzed to ensure adequate cooling, mechanical life, and aerodynamic performance. Fuel nozzles will be designed for operation on gas alone or on gas with distillate as a backup fuel. The transition piece will be designed and integrated with the design of the machine mid-section, transition cluct cooling, and mounting.

A full-scale, single-combustor test stand will be designed and fabricated to verify performance of the combustion system. Facility modifications will be made to support the test. These include installation of the test stand, installation of high-temperature stainless steel air piping, an additional air heater, control systems, upgrades to the combustion video system, and tooling.

\section{Progress 4Q96 through 3Q97}

Fuel staging studies were conducted to simplify the staging strategy of the DLN2 system and to eliminate operation in a manner that would put thermal streak loading on the combustor liners. This led to incorporation of a diffusion flame start and part-speed/part-load operation capability followed by piloted premix for an intermediate load range, and premix operation for the emission guarantee load range.

The fuel-air premixer was studied and a decision was made to base the combustion system on a pegless premixer denoted the swozzle (contraction of swirler and nozzle). Several different swozzle configurations with different swirl distributions were designed and fabricated for test.

The general combustion systen layout and chamber arrangement were designed. A liner diameter was chosen based on combustion stability considerations. All full-scale combustion system sub-components were fabricated for part-load evaluation in Stand 10 of the Schenectady GTDL and full-load evaluation in Stand A2 of the GEAE Evendale combustion test facility. In addition, a diffusion flame full speed, no load (FSNL) combustion system based on the 9E single nozzle configuration was designed and fabricated for first test of the gas turbine in the Greenville, SC, test facility. Casting trials were completed for the transition piece body and aft frame, and production of the transition piece assemblies began. In addition, thermal barrier coating programming and coating trials were completed, with the final methodology applied to the production parts.

First combustion testing was initiated in Stand 10 in April and first fire in Stand A2 occurred in August 1997. Stand 10 was fully commissioned and the first swozzle-based combustion testing was completed. Stand A2 commissioning will be completed in January 1998.

In addition to the test activities, numerous heat transfer, computational fluid dynamics, and finite element stress analyses were conducted on the sub-component parts. Early emphasis was directed at cap turn area and the end cover and swozzle assemblies as well as full-scale combusting flowfields contained by the liner.

Finally, the $7 \mathrm{H}$ combustion system and transition piece preliminary design was initiated.

\section{Plans for Next Quarter}

Most of $9 \mathrm{H}$ combustion system testing and substantiation will be completed in 1998. The $7 \mathrm{H}$ transition piece will be designed and casting trials completed. Testing of the $7 \mathrm{H}$ combustion 
system will begin at the end of $4 \mathrm{Q} 97$. This system is envisioned to be identical to the $9 \mathrm{H}$ system with the exception of the transition piece and any minor modifications necessary to meet performance objectives.

\section{Technology Application}

Design and development of the combustion system is required for the ATS gas turbine to meet the low emissions targets at the high cycle conditions of inlet temperature, pressure, air flow, and outlet temperature, all of which are greater than those of any of GE's developed products.

\section{Section 2.2.2.3 (GTFFTR) Turbine Rotor Design}

\section{Objective}

The objective of this task is the design of turbine rotor components (wheels, spacers, aft shaft, transition discs, coolant systems, and fastening devices). Transient and steady-state stress analyses will be used to calculate parts lives. Rotor and system vibratory characteristics will be evaluated. The coolant flow circuit for routing the cooling steam to and from buckets will be designed and performance calculated. Test results will be incorporated concurrently. Drawings and specifications will be developed in preparation for manufacturing.

\section{Progress 4Q96 through 3Q97}

The turbine rotor purge air system was set for the first test engine. Two axisymmetric subsystem models were built and run through a transient startup to steady state to a normal shutdown. These subsystem models included a compressor aft stub/transition disk/first-stage turbine wheel model and a fourth-stage turbine wheel/aft shaft model. These subsystem models allowed multiple iterations on the critical areas in the turbine rotor.

Several preliminary 3D analyses of the 1-2 spacer and the aft shaft, which consist of 3D mechanical with 2D swept thermals, were completed.

The final 2D axisymmetric systern model for final detail design analysis is underway.

The final 3D transient thermal mechanical analysis of the 1-2 spacer is underway.

All turbine rotor structural component designs and all component drawings were released and 9H components are being manufactured.

\section{Plans for Next Quarter}

The final 2D axisymmetric system model will be complete and design iterations will begin. Off-design conditions including boundary condition sensitivities will begin.

Several final 3D transient therrnal mechanical analyses of the second-stage turbine wheel, 2-3 spacer, aft shaft, and transition disk will be underway.

\section{Technology Application}

The turbine rotor analysis and design effort defined the basis for the $7 \mathrm{H}$ and $9 \mathrm{H}$ production hardware. 


\section{Section 2.2.2.3.1 (GTFFTR) Turbine Rotor Mechanical Analysis (Task Force)}

\section{Objective}

The objective of this task is to provide thermal and mechanical design and analysis support for rotor components of the ATS gas turbine. Analyses are run to determine temperature, displacement, and stress distributions for various components of the ATS gas turbine rotor. Initial designs and concepts are analyzed, compared, and modified to meet design specifications with respect to stress levels, low cycle fatigue (LCF) life, yielded volume, residual displacement, rabbet closure, etc.

\section{Progress 4Q96 through 3Q97}

Plane-stress analyses were performed on various cross sections of the 2-3 spacer to determine hoop stress levels near the steam and feed holes. A parametric study was completed assessing the effect of steam hole size and location for one of the cross sections. A minimum required ligament length between the steam hole and outer radius was established. Steam hole radius was determined to be less imporiant than the radial location of the steam hole. On the basis of these results, two other cross sections of interest were examined under centrifugal loading conditions. Both cross sections produced acceptable stress levels. Plane-stress analyses were also performed on the 2-3 spacer under combined centrifugal and thermal loading conditions simulating transient and steady-state thermal conditions. Three cross sections were examined for each case and all stress levels were found to be acceptable. The 2-3 spacer is expected to meet life requirements and no problems are foreseen.

Thermal and structural analyses of the end cap of the bore tube were run. A number of modifications to the end cap of the bore tube were evaluated, including the base design with a radial undercut, an axial hole at the center, and a combination of the two. Thermal as well as structural analyses were performed. The design with an axial hole at the center showed the best performance with respect to stress reduction because the vanes are freer to grow as a result of thermal expansion. This design was selected.

Nonlinear, 3D stress analyses of the axial tube spoolies for the steam delivery system were performed. These analyses included the contact interference to the wheel hole, the effects of thermal transients and initial interferences, as well as plasticity and creep. The analyses focused on stresses caused by angulation resulting from differential heating of the wheels.

Nonlinear, 3D stress analyses were also performed on the first- and second-stage bucket spoolies for the steam delivery system. The methodology developed for the axial tube spoolies was used. A design of experiments (DOE) approach was used to assess design variables with the model. The analyses established the proper interference fit to be used and indicated that the design was acceptable for drawing release to manufacturing. The current spoolie analysis methodology was also applied to a wear test specimen that survived 20,000 cycles at high interference and load. Acceptable assembly interferences to obtain required sealing and fatigue life were computed. The results are being used as design limits for the actual designs. A design study summary was begun to document work on the spoolies for the first- and second-stage bucket steam delivery system as well as the wear test specimen. 
Stress analyses were performed to determine the influence of steady-state thermal distributions as well as the bolt clamp load on the embossment flange opening/closing of the second-stage rotor. It was found that flange closing is not significantly affected by the amount of bolt clamp load. An increase to almost triple the normal bolt clamp load is required to close the gaps under steady-state thermal conditions. During steady-state thermal conditions, the flanges remain closed when no heat transfer takes place in the cooling holes. When heat transfer does occur, the amount of opening is acceptable.

A series of 3D stress analyses was performed on the manifold investigating ways of strengthening the walls to withstand the pressure loading while minimizing additional weight. Analyses were also performed to investigate the additional stress produced in the manifold caused by the centrifugal effect of the axial tube. The effects of isolating the through-tubes that feed steam to the first-stage buckets and of using a central support were investigated. Using this information a new 3D ANSYS finite element model of the feed manifold was built and analyzed. This model incorporates all the latest design changes. The model is detailed and includes the variations in wall thickness, fillet radii, and local thickening caused by stops. The analysis exhibited very reasonable stress levels.

Plane-stress analyses of four cross sections of the transition disk were performed. A review was conducted of the stress levels obtained in the transition piece based upon plane-stress; i.e., pie slices of various cross sections. The stress levels obtained from these analyses look good from both yielding and life perspectives.

Finite element analyses of conceptual designs for the steam delivery system axial tube end retention method were performed. Four concepts were modeled and analyzed with results guiding changes in the design.

A thermal system model of the rotor was created to perform a lumped fluid element (LFE) analysis. Two-dimensional meshes were created and the thermal and fluid boundary conditions were prepared. The system model includes the aft shaft, bore tube end cap, bearing and housing, exhaust frame, and steam box. The model was used to determine thermal distributions.

A 3D stress structural analysis of the aft shaft was completed reflecting recent design changes.

\section{Plans for Next Quarter}

Mechanical design and analysis support for rotor components will be provided as needed. Design reviews will be written documenting results.

\section{Technology Application}

The analyses performed and resulting design changes will be used in the final design of the ATS gas turbine rotor.

\section{Section 2.2.2.3.2 (GTFFTR) Wheel Forging Residual Stress Analysis}

\section{Objective}

The objective of this task is to determine the influence of residual stresses on overspeed design limits for IN706 and IN718 wheel forgings. Overspeed tests on a 7F first-stage wheel 
(IN706) indicated that there might be large residual stresses in the wheel forgings after heat treatment. These residual stresses may have an effect on fatigue life and will affect residual displacements. The effect on residual rabbet deflections is particularly important since this may affect rabbet opening/closure as well as rabbet loading and local plasticity. If residual stresses turn out to be significant in the ATS machine (IN718) as well, they will have to be included in the design calculations. The residual stress calculation will be done on the $7 \mathrm{~F}$ wheel first to correlate the analysis with available test data. The procedure will then be applied to the ATS wheels.

\section{Progress 4Q96 through $3 Q 97$}

The stress-strain data to be used for the stress analysis of the quenching process for the $7 \mathrm{~F}$ first-stage wheel were generated. These data, consisting of stress-strain curves for three different locations through the disk thickness, are used as input for the thermal stress analysis simulating the quenching process of the 7F first-stage wheel. This analysis was completed using temperatures obtained from earlier thermal analyses. Residual stresses resulting from the quenching process are on the order of $690 \mathrm{MPa}(100,000 \mathrm{psi})$.

A thermal stress analysis of the aging process of the $7 \mathrm{~F}$ first-stage wheel was completed ignoring creep effects. Stress and strain data as a function of time were obtained to determine appropriate test conditions for performing creep and stress relaxation tests.

Creep and relaxation tests began for the IN706 material. When these tests are completed, the thermal stress analysis of the aging process will be redone using this creep model to determine residual stress levels after aging. Creep strains and plastic strains will then be mapped onto the machined shape to determine the remaining residual stress levels in the wheel prior to the overspeed pre-spin. An overspeed analysis will then be performed that includes these residual stresses in order to determine their effect on residual growth, plasticity, and fatigue life.

A heat transfer analysis simulating the quenching and aging process of the ATS gas turbine second-stage wheel was completed. Tensile tests were performed on specimens undergoing the same thermal history seen in the quenching and aging process. Stress-strain curves were generated as a function of temperature for specimens that underwent just the quenching thermal cycle and for specimens that underwent both the quenching and aging thermal cycles. These stress-strain data are used as input for thermal stress analyses simulating the quenching and aging process of the ATS gas turbine second-stage wheel.

A thermal stress analysis simulating the quenching process of the ATS gas turbine secondstage wheel was completed. These levels are very similar to those seen in the $7 \mathrm{~F}$ first-stage wheel.

\section{Plans for Next Quarter}

A creep model will be fitted to the IN706 data, and the thermal stress analysis simulating the aging process of the 7F first-stage wheel will be redone. Residual strains will be mapped onto the final machined shape, and an equilibrium analysis will be performed to determine residual stress levels prior to pre-spin. An overspeed pre-spin analysis will be performed including residual stresses. Residual growth predictions including and excluding residual stresses will be compared to experimental results. 
Thermal stress analyses simulating the aging process of the ATS gas turbine second-stage wheel will be performed. Stress and strain levels will be obtained to provide test conditions for performing creep and stress relaxation tests on the IN718 material.

\section{Technology Application}

These residual stresses will affect the deformations of the wheel during overspeed. If they are found to be significant, they will have to be included in the design calculations for the ATS turbine wheels.

\section{Section 2.2.2.3.3 (GTFFTR) Rotor Steam Circuit Analysis}

\section{Objective}

The objective of this task is to assess rotational and 3D effects on the flow within the rotor steam circuit components whose performance is strongly dependent on these effects. The steam distribution into the buckets, for example, depends on the performance of the manifolds to ensure that the buckets are adequately cooled. Hydraulic losses can be better estimated when 3D effects are considered. The rotational and 3D effects will be assessed using computational fluid dynamics (CFF), and the results of the analyses will provide the basis for design modifications if necessary.

\section{Progress 4Q96 through 3Q97}

Solid models of the bucket supply manifold generated with Unigraphics were meshed for CFD computation using the unstructured-grid solver NOVAK3D. The models included a long section of the axial inlet tube and extensions for the spoolies to allow the flow to develop before boundary conditions are applied. In the early stages of the study, the buckets were not simulated. Many CFD models of the supply and return manifolds were created as the manifold designs evolved. The primary objective of the CFD simulations was to determine the magnitude of the flow maldistribution introduced by the manifolds in each bucket. The secondary objective was to verify the 1D pressure drop relations used in the overall steam delivery circuit YFT model.

The current baseline design, the T-design, was evaluated first. It displayed significant flow maldistribution to the buckets. The next design, the delta-wing concept, showed a significant improvement in flow distribution. The presence of the buckets, however, was expected to introduce a significant corrective factor.

Using 1D analyses, the geometric characteristics of orifices exhibiting pressure drops equivalent to those found in the first- and second-stage buckets were established and the NOVAK3D grid was updated. The original T-shape supply manifold was improved, using the lessons learned in the first phase of the project, and analyzed. The flow distribution showed slight deviations among the buckets. The maldistribution due to the return manifold was addressed next.

Because the actual return manifold design was not available at the beginning of $1 \mathrm{Q} 97$, the supply manifold CFD model, with appropriate boundary conditions, was used to estimate the flow maldistribution introduced by the combined effect of both supply and return manifolds. 
Concurrent with these CFD analyses, the definition of details in the supply and return manifolds was carried out using 1D analyses to assess trade-offs between performance and design robustness.

As the design of other components around the manifold evolved, constraints on the volume of the manifolds emerged. New models of the evolving designs were created and CFD results indicated a combined supply and return manifold impact on flow maldistribution that was somewhat larger than previously predicted.

The results of the CFD and $1 \mathrm{D}$ analyses were implemented in the design process, and the supply and return manifold detail designs are nearly complete. Preliminary pressure drop analyses indicate that an adequate safety margin is available in the YFT steam circuit model.

Further design constraints required a redesign of the supply and return manifolds. The most recent design of the supply manifold was meshed and its CFD analysis completed. Results of this supply manifold analysis show a slight improvement in flow distribution over the previous design. The combined effect of supply and return manifolds, which is the ultimate goal of this analysis, will be determined when the return manifold design is completed.

CFD analyses of the original bore inlet and supply end cap designs were completed. Results of these analyses confirmed flow swirl patterns previously predicted and pressure losses in the range predicted by the YFT analyses. A redesign of the end caps, driven by manufacturing and inspectability issues, was initiated and preliminary assessment of pressure drop penalties was performed using 1D analyses. CFD analyses of the alternate bore tube inlet section were performed. In addition to the baseline inlet design, a larger opening was also considered. The larger opening did not exhibit any undesirable back-flows through the inlet area and did improve the hydraulic performance of the bore inlet section (lower pressure drop, improved cross-sectional velocity distribution in the annulus, and slightly lower swirl angle). The results were transmitted and designers will incorporate the new design as the baseline. Analysis of the supply end cap was completed.

Results of CFD simulations of the bore inlet tube static test geometry show excellent agreement with test results. With no flow swirl, both approaches predict virtually the same loss coefficient for the inlet into the bore tube.

\section{Plans for Next Quarter}

The return bore tube and return manifold CFD analysis will be completed. Post-processing of the supply end cap results will be performed. Further comparison with test data is also planned.

\section{Technology Application}

The results of this task define the hydraulic performance and help guide the design of the overall steam distribution circuit and critical individual components it comprises. Performance predictions of various designs are used in trade-off and optimization studies to select the baseline concept of the overall steam distribution strategy and the specific design of the scroll, the supply and return manifolds, and supply and return bore tube and end caps. 


\section{Section 2.2.2.3.4 (GTFFTR) Turbine Rotor Shaft Temperature Analysis - \#2 Bearing}

\section{Objective}

The objective of this task is to investigate design options that would result in a minimum temperature of the shaft surface in contact with oil and/or air oil mist, and a maximum thermal gradient in the area of the oil seals in the $\# 2$ bearing.

Allowable temperatures in the seal forward of the $9 \mathrm{H}$ turbine $\# 2$ bearing are limited due to the accelerated decomposition of lubricating oil at high temperatures. Thermal gradients are also limited in that uneven thermal expansion of the shaft will adversely affect seal clearances and performance.

\section{Progress 4Q96 through 3Q97}

A detailed lumped fluid element (LFE) transient thermal model of the fourth-stage turbine wheel/aft shaft area was developed. The model included the fourth-stage turbine wheel, aft shaft, exhaust frame, bearing, and steam box. Multiple iterations were run evaluating various secondary flow circuits as well as blower schedules and bearing oil schedules.

\section{Plans for Next Quarter}

This model will be exercised to optimize the aft shaft secondary and oil flow system. The model will then be added to the final system model.

\section{Technology Application}

All the design options evaluated in this study are being considered for ATS turbine rotor design in a detailed follow-up study using a fluid element analysis (FEA) approach to better simulate the heat transfer boundary conditions in the current modeling effort.

\section{Section 2.2.2.3.5 (GTFFTB) Bucket Temperature Monitoring}

\section{Objective}

The objective of this task is to provide the steam-cooled rotor buckets with protection against a loss-of-steam-coolant event. The protection system will provide a timely signal enabling the turbine to be shut down with minimal damage.

\section{Progress 4Q96 through 3Q97}

Pyrometers were chosen as the primary means of steam-cooled bucket protection. Several other technologies were investigated (e.g., tracer leaks, vibrational signatures, steam pressures, and steam flowrates) but were discarded in favor of monitoring the bucket temperatures using pyrometers attached to the outer casing of the turbine with a direct line-ofsight view of the buckets. Pyrometers offer significant advantages: (1) they respond to the bucket parameter of most concern (i.e., temperature); (2) all the buckets in a stage come into the field of view of a single fixed pyrometer; and (3) the detection system has a rapid response time. Line-of-sight was recognized as the method of achieving long-term pyrometer stability.

A test pyrometer system was installed at a test site. The gas turbine is now running under normal operating conditions, and the pyrometer is generating data indicative of bucket surface 
temperature. The data will be used to help design the control and monitoring systems of the ATS gas turbine.

\section{Plans for Next Quarter}

Pyrometer data will continue to be monitored and analyzed at the test site. An additional test site, at which several of the buckets to be monitored will have TBC coatings, will be added to the program.

\section{Technology Application}

Pyrometers will be used in the ATS gas turbine to monitor steam-cooled turbine blade temperature during operation. This will allow for timely detection of insufficient steam coolant flow into the buckets.

\section{Section 2.2.2.4 (GTFFTB) Turbine Bucket Design}

\section{Objective}

The objective of this task is the design of buckets for the four rotating stages. The heat transfer and material databases for steam-cooled first- and second-stage buckets continue to expand and will be integrated concurrently with the design. Cooling passages will be sized consistent with manufacturing practicalities and the bucket life requirements. Flow variation and consistency will affect life calculations and will be considered. Current practices for thermomechanical steady-state and transient analyses, dynamics and vibration analysis (which can deal with anisotropy), and corrosion/oxidation analysis will apply throughout. Drawings and specifications will be developed in preparation for manufacturing.

\section{Progress 4Q96 through $3 Q 97$}

The frozen aerodynamic design was approved, allowing detail design of the $7 \mathrm{H}$ turbine airfoils. Analysis began with detailed 2D and 3D models of the first-, second-, and third-stage dovetails and the first-, third-, and fourth-stage shanks. Preliminary modal analysis was completed on all stages as well as detailed analysis on the first and fourth stages in order to refine vibratory margins. Detail design of the $7 \mathrm{H}$ airfoils was slowed midway through the reporting period in order to focus resources on detail design issues on the similar $9 \mathrm{H}$ turbine airfoils.

Design of the 9H turbine airfoils continued. Detail design was completed on all four stages of airfoils. Casting and machining drawings were issued on all stages. Casting and post-cast tooling was completed. Casting trials were conducted on all stages of hardware. The first set of castings was shipped on the first and third stages; a portion was shipped on the second and fourth stages. Bench testing is in progress on all stages for experimental confirmation of predicted bucket frequencies and damper effectiveness. Highly detailed finite element models were completed on steam-cooled first and second stages for detailed life assessment and robust design activities through which the design is refined. Lessons learned in these activities are being incorporated into the $7 \mathrm{H}$ airfoil designs. 


\section{Plans for Next Quarter}

Detail design of the $7 \mathrm{H}$ airfoils vill be accelerated. The focus will be on items with long lead times, including shank and dovetail definition for the third and fourth stages for increased rotor and bucket life.

Detailed analysis of the $9 \mathrm{H}$ airfoils will continue with the completion of transient analysis and the continuation of robust design activities targeted at increasing life and yield on future castings. Bench testing will continue on all four stages of buckets. Casting of the first set of airfoils will be completed, and post-cast operations will continue on all stages.

\section{Technology Application}

The design and development of turbine buckets are required for the ATS turbine to ensure that the buckets deliver power to the turbine shaft and the buckets meet the stated part life requirements.

\section{Section 2.2.2.4.1 (GTFFTB) S1B and S2B Wheel Dovetail Analysis}

\section{Objective}

The objective of this task is to perform 3D thermomechanical analyses of ATS gas turbine rotor dovetails, bolt holes, and steam-cooling holes. The dovetails are highly stressed and, in addition, there are severe thermal gradients in the dovetail region. Detailed 3D stress analyses are required to ensure that the dovetails and the wheels meet design guidelines.

\section{Progress 4Q96 through 3Q97}

A detailed 3D finite element model of a $9^{\circ}$ sector of the second-stage wheel was built. The sector contained approximately 28,000 brick elements. The finite element model of the bucket contained approximately the same number of elements. This model included the internal cooling channels. A 3D steady-state thermal analysis of the assembled wheel/bucket was performed as a coupled thermomechanical analysis. The mechanical loading was due to the centrifugal effects. The thermal boundary conditions were applied on all external surfaces as well as on the internals of the bucket cooling channels. The thermomechanical coupling was used because of the heat transfer from the bucket to the wheel.

Effective and principal stresses were plotted for mechanical as well as steady-state thermomechanical loadings. The areas of focus in the buckets were in the dovetail region. The stresses due to the centrifugal loading were further increased by the thermal stresses due to the temperature difference between the cooling steam on the input and output side. On the wheel, the areas of focus were in the dovetail, in the dovetail slot bottom, and at the center of the bolt hole.

\section{Plans for Next Quarter}

This task has been completed. 


\section{Technology Application}

The dovetails are highly stressed and, in addition, there are severe thermal gradients in the dovetail region. Detailed 3D stress analyses are required to ensure that the dovetails and the wheels meet design guidelines for the ATS turbine rotor.

\section{Section 2.2.2.4.2 (GTFFTB) S3B and S4B Tip Shroud Design Optimization}

\section{Objective}

The objective of this task is to optimize stresses and creep deflections in the ATS third- and fourth-stage bucket shrouds. Detailed 3D creep analyses are needed to ensure that the stresses are within the required limits for creep life.

\section{Progress 4Q96 through 3Q97}

The scope of this task was to analyze the ATS third- and fourth-stage buckets and compare the stresses in the shrouds with the stresses in a bucket that has been running in the field for an extended period of time (the "reference" shroud). The third-stage bucket shroud was analyzed in 1996, but at that time the model did not include a full-length model of the airfoil. This was corrected in the present analyses. The models for the three buckets contained 15,000-20,000 3D hex elements each. The nurnber of elements had to be limited because of the time that would be consumed in 3D creep analyses.

A lot of time was spent in determining the correct boundary conditions between buckets at the shroud/shroud contact. Four different boundary conditions were examined, from no contact at the shroud/shroud contact area to modeling three consecutive contacting buckets with no friction in the contact areas. Elastic analyses of the three buckets were performed with all four boundary conditions. The results showed that the ATS fourth-stage shroud had higher stresses than the reference shroud. However, since the fourth-stage shroud is operating at a lower temperature than the reference shroud, the stress levels were acceptable. The stresses in the third-stage shroud were relatively high and the shroud is operating at a relatively high temperature. It was therefore recommended to Engineering Design that the height of the rail on the third-stage shroud be increased.

\section{Plans for Next Quarter}

This task has been completed.

\section{Technology Application}

The analysis performed here will be incorporated into the shroud designs of the ATS gas turbine third- and fourth-stage buckets.

\section{Section 2.2.2.4.3 (GTFFTB) Bucket Wide Grain Sensitivity Analysis}

\section{Objective}

The objective of this task is to show the effect on natural frequency of the variations in grain size and orientation of $9 \mathrm{H}$ fourth-stage buckets. If the variations in natural frequency can be shown to be non-critical, bucket yield can be improved. 


\section{Plans for Next Quarter}

This task has been completed.

\section{Technology Application}

The results of this study will be used on the ATS gas turbine design primarily as a means of improving bucket yield.

\section{Section 2.2.2.4.3.1 (GTFFTB) Bucket Robust Design and Life Assessment \\ Objective}

The objective of this task is to use finite element analysis and Design of Experiments (DOE) techniques to quickly estimate bucket life, identify optimized bucket critical-to-quality criteria (CTQs), and statistical distributions of bucket CTQs given statistical distributions of bucket parameters. The main reason for doing this work is to obtain robust bucket designs that are minimally sensitive to manufacturing tolerances and will therefore meet all life requirements.

\section{Progress 4Q96 through 3Q97}

The DOE analyses for the first-stage bucket robust design and life assessment and secondstage bucket life assessment are complete. The factors included in the DOE analyses are metal wall thickness, airfoil TBC thickness, bond coat thickness, TBC thickness in the leading edge, secondary orientation angle, primary orientation angle about the axial axis of the machine, and primary orientation angle about the tangential axis of the machine. These DOE analyses yield prediction equations for alternating pseudo-stress, temperature, and low cycle fatigue (LCF) life in a spreadsheet-based life assessment tool that is currently being used to assess the life of production buckets. Robust design and probabilistic analyses were performed using the firststage bucket equations to determine optimum wall thickness and reliability curves for LCF life in critical first-stage bucket locations given current production parameters. Similar analyses are currently underway for the second-stage bucket. A series of DOE analyses focused on increasing life in critical regions of the second-stage bucket is also being performed.

\section{Plans for Next Quarter}

Work will continue on the robust design of the second-stage bucket that will include internal and external heat transfer parameters and variability in the TBC conductivity in addition to the factors that were considered.for the first-stage bucket.

\section{Technology Application}

The results of this study will be used on the ATS gas turbine in order to assess bucket performance and obtain optimized factor settings and statistical distributions of the CTQs given the distributions of the factors. The results of this study will be used on the ATS gas turbine design primarily as a means of improving bucket yield. 


\section{Section 2.2.2.4.4 (GTETIH) Bucket Tip Treatment Heat Transfer}

\section{Objective}

The bucket tip regions of the ATS turbine remain a critical design issue affecting both turbine performance and life. Since the blades utilize no external film cooling, a tip design must be verified that minimizes both the tip hot gas leakage and the tip external heat loading, while also providing some shroud rub protection for the internal steam-cooling circuit. Standard squealer tip geometries are thought to provide inadequate rub protection and can be difficult to cool without film, while a plain tip geometry will not provide adequate leakage sealing.

This task continues design verification and design improvement for the first- and second-stage blade tips. A Blade Tip Heat Transfer Cascade will be used with new or modified blade tip geometries to design and verify the appropriate tip heat transfer and seal arrangements in conjunction with manufacturing and cooling requirements. Specifically, this task will determine the external heat transfer coefficient distributions on the blade tip and on the airfoil surface near the blade tip using transient liquid crystal techniques in a blade tip cascade.

\section{Progress 4Q96 through 3Q97}

At the beginning of this reporting period, Texas A\&M University was constructing a blade tip cascade to model the tip heat transfer for the first-stage blade of the ATS turbine. The cascade was composed of two flow passages and three airfoils scaled so that the appropriate Reynolds number and Mach number distributions would be obtained. Heat transfer testing was to be based on transient liquid crystal methodology, using a blowdown test capability. During 4Q96, $1 \mathrm{Q} 97$, and 2Q97, Texas A\&M concentrated on completion of the required test scope from 1996 , including tip heat transfer for two geometries with high and low freestream turbulence intensity, near-tip surface heat transfer, shroud pressure measurements, and freestream turbulence intensity measurements. The final report for the work being performed at Texas A\&M was completed. This report contains the minimum work scope requested by CRD to close out GE's contract with them. This effort was concluded with the attainment of test results for tip heat transfer coefficients. They provided two sets of tip heat transfer results for two geometries at two freestrearn turbulence intensity levels.

During 2Q97, a rebuilding of the Texas A\&M cascade within CRD's test facilities was begun. This cascade is now completed and is being installed. It includes features added for more flexibility in testing. To avoid problems encountered in the past with flow and thermal boundary conditions, this blade tip cascade will use a steady-state heat flux method with surface heaters to establish the heat transfer conditions rather than the transient blowdown method used by Texas A\&M. All safety reviews have been cleared and testing will be started as soon as possible, first for establishing the flow characteristics in and around the blade tip, and then tip heat transfer testing.

\section{Plans for Next Quarter}

The CRD blade tip cascade will be tested to determine the tip heat transfer coefficients at the non-dimensional ATS turbine condition design point. Both plain tip and rub-strip tip geometries will be tested with nominal design tip clearance. Results will be reduced to tip heat transfer maps for application to the blade design. 


\section{Technology Application}

The results from the testing performed under this task will be used directly in the design of the first- and second-stage bucket tips to improve tip performance and provide more accurate assessments of tip life. Tip geometries shown to have lower heat loads or less gap leakage, or both, will be incorporated into the design process.

\section{Section 2.2.2.4.5 (GTFFTB) S1lB and S2B Air/Steam Coolant Transition Analysis}

\section{Objective}

The objective of this task is to determine the time required for switching from air cooling to steam cooling to keep thermal stresses in the ATS gas turbine first-stage and second-stage buckets within acceptable levels. Three-dimensional transient thermomechanical analyses of the first- and second-stage buckets will be run during the transition from air to steam cooling. Predicted temperature and stress responses will be used to evaluate the effect of the coolant change on the bucket lives and to recommend control system modifications, if necessary.

\section{Progress 4Q96 through 3Q97}

The automation process for steady-state thermomechanical analyses, using ANSYS/LFE, of the ATS gas turbine first-stage bucket was completed and validated at full speed, full load (FSFL) conditions. Comparisons of temperature predictions between ANSYS/LFE and previous YFT and ANSYS iterative calculations show good agreement. A computer program was also developed to scale the bucket external heat transfer boundary conditions ( $\mathrm{h}$ and $\mathrm{T}$ ). The boundary condition scaling was based on the FSFL heat transfer predictions as well as the firing temperature, core flowrate, and air properties at the desired operating condition. This procedure was later used to generate boundary conditions for the ATS gas turbine first-stage bucket robust design activities. The analysis process was then used to evaluate the steadystate performance of the first-stage bucket at part load, where the air-to-steam transition occurs. The gas path thermal boundary conditions were obtained by scaling the FSFL convective film coefficients and temperatures, while the internal boundary conditions were evaluated using ANSYS/LFE.

The details of the air-to-steam transition process were defined using the transient cycle predictions for a cold start and the transient rotor performance. The transient rotor predictions of temperature at the bucket inlet and pressure drop across the bucket during the air-to-steam transition were used in the analyses. The bucket inlet temperatures and flowrates were obtained from the rotor model and step-changed from the steady-state air values to the steady-state steam values. The transport properties of the internal coolant were also stepchanged from air to steam at the transition time. The computed temperature distributions were used as thermal loading for structural analyses to determine the time, location, and magnitude of the peak component stress from which life estimates were made. Bucket exit conditions may serve as refined boundary conditions for future rotor design iterations.

The ANSYS/LFE model of the first-stage bucket was modified to include updated platform cooling and geometry modifications. Steady-state analyses of the first-stage bucket at FSFL conditions were run again to include the effects of updated rotor cooling configuration 
changes as well. These results were bench-marked against design calculations and provided heat transfer boundary conditions for the robust design analyses.

The ANSYS/LFE model was also used to predict the effect of loss of steam cooling on the bucket. Steady-state and transient thermomechanical analyses were run to evaluate the impact of reduced coolant flow on bucket performance, and to estimate the required shutdown time in the event of a total loss of coolant.

The ANSYS/LFE model of the second-stage bucket was completed. Surface elements were created in the bucket internal cooling passages, and the LFE elements were generated. The ANSYS/LFE model of the second-stage bucket airfoil was completed and bench-marked against the design basis ANSYS model at FSFL conditions. Transient and loss of coolant analyses were performed.

The results for both first- and second-stage buckets showed that the stresses during the normal air-to-steam transients were within acceptable levels. However, the buckets would only survive a loss-of-cooling condition for a very brief period.

\section{Plans for Next Quarter}

This task has been completed.

\section{Technology Application}

The air-to-steam transition requirements during startup will have to be controlled so that the LCF life of the buckets will meet design guidelines.

\section{Section 2.2.2.4.6 (GTETEH) S1B External Heat Transfer}

\section{Objective}

The ATS turbine first-stage bucket is highly loaded both aerodynamically and thermally. It is crucial that the external heat loading for this component be predicted accurately. A nonconservative design heat load may result in a low life part design, while a too conservative heat load will lead to overutilization of steam coolant. As the heat load distribution is a major contributor to the bucket cooling design and its effectiveness, an accurate determination of the external heat transfer distribution is required to minimize the impact of other variable factors in the design.

This task will provide external heat transfer coefficient distributions for the pitch section of the ATS turbine first-stage bucket. Cascade slave hardware will be manufactured by CRD for installation into the Transonic Blade Cascade facility at NASA Lewis Research Center, Cleveland. NASA will perform flow and heat transfer tests with a smooth airfoil and report heat transfer distributions at the design Reynolds number. Rough surface testing is optional in this program. This task is being carried out in conjunction with CRD's Research Alliance with NASA Lewis (no funds are exchanged in this Alliance).

\section{Progress 4Q96 through 3Q97}

During this reporting period, material raw stock was purchased for the required cascade slave airfoils for NASA's facility. The aluminum airfoil mold to be used by NASA in fabricating the 
heat transfer test airfoil was completed. The stainless steel ingot, which furnishes the slave airfoils, was heat treated and machined to parallel surfaces prior to wire-EDM of the airfoil. All drawings for instrumentation placement and dimensioning were completed. No slave airfoils have been machined as yet.

Operating conditions within the NASA facility were reviewed with NASA test engineers. The proper blade Reynolds number requires an inlet cascade pressure of 25 psia. The NASA cascade is currently operated to a maximum of approximately 20 psia. NASA will explore the possibility of using higher pressure within their facility. If this option is not viable, the test Reynolds number for the first-stage bucket hardware will be reduced to approximately $80 \%$ of the desired value. This reduction is considered minor, as the results may be reliably scaled up to the desired conditions.

In 3Q97, this task was halted due to other program priorities. It is unlikely that NASA will be able to test this blade design in their facility until 1998. The present task may therefore be taken up again and completed at that time.

\section{Plans for Next Quarter}

No activity is planned for this task.

\section{Technology Application}

The results of this task will be used to verify or alter the predicted design external heat loading for the first-stage bucket. Where the experimental results deviate significantly from the design predictions, changes in the blade coolant flow can be made to achieve a more efficient design.

\section{Section 2.2.2.5 (GTFFTS) Turbine Stator Design}

\section{Objective}

The inner and outer turbine shells will be designed, including a turbine stator cooling system to provide rotor/stator clearance control. A closed circuit coolant delivery and return system for the turbine flowpath stator components will be designed. Component, sub-assembly, and assembly flow tests will be incorporated concurrently. Implications for handling equipment (crane and manipulators ) will be included in design considerations.

Steam-cooled turbine nozzles will be designed. Thermomechanical transient and steady-state analyses will be run to determine parts lives. Material, manufacturing, and heat transfer database expansion is planned and will be integrated concurrently.

Shrouds will be designed. Sealing systems will be selected for minimum leakage. Thermal and structural analyses of equiaxed or anisotropic materials will be applied as appropriate.

Calculations will be made of all flow in the cooling systems, including leakage flows, to support performance, thrust balance, and component temperature calculations.

Design of hot gas path seals will be based on laboratory tests. Seals developed for transitionpiece-to-nozzle-segment and intersegment interfaces will be evaluated in cascade tests. Both sealing and wear performance will be assessed. Manufacturing drawings and specifications will be produced. 


\section{Progress 4Q96 through $3 Q 97$}

A 3D finite element analysis of the outer turbine shell was run to determine detailed stresses and deflections. Casing out-of-round was optimized through saw cutting of the horizontal joint bolt holes. A 3D inner shell transient analysis was performed to determine stresses and optimize turbine tip clearances during transient operation. Detailed 3D modeling was completed on the turbine shrouds, including 3D creep analysis and modal analysis. Flow calculations were updated on the turbine nozzles.

\section{Plans for Next Quarter}

A 3D transient analysis will be completed on the outer turbine shell. A detailed 3D shell system model will be completed to determine the loading on the pins supporting the inner shell within the outer shell as a result of distortion of the inner and outer shells. A transient analysis of the first-stage nozzle and shroud will be completed. Detailed sub-modeling of critical areas will continue.

\section{Technology Application}

The turbine stator analysis and design effort defined the basis for the $7 \mathrm{H}$ and $9 \mathrm{H}$ production hardware.

\section{Section 2.2.2.5.1 (GTFFTS) Turbine Stator Robust Design}

\section{Objective}

The objective of this work is to develop and apply robust design methods for the development of steam-cooled components of the advanced gas turbine. The goal of this effort is to achieve high standards of performance, quality, and reliability for these components by performing the following tasks during the product development cycle: (1) apply, and develop as needed, the robust design methodology to first- and second-stage nozzles; (2) apply the robust design methodology to some of the steam- and air-cooled stator components (e.g., first-stage shroud and turbine inner shell); (3) provide consulting and support for applying the robust design methodology to some of the critical rotor components (e.g., manifold, steam tube bushings, and spoolie); (4) provide consulting and support for integration of design, manufacturing, and assembly; and (5) train the GEPS staff on the concepts, methods, and tools for achieving robust design.

A "robust design" is a design that satisfies the product performance requirements in an optimal manner and also exhibits minimal sensitivity to variabilities arising from various sources, such as manufacturing processes and tolerances, material behavior, operating environment, in-service damage, and maintenance and repairs. The methodology consists of the following key steps: (1) identification of critical-to-quality (CTQ) characteristics, key control parameters (KCPs), and key noise parameters (KNPs); (2) definition of the Design of Experiment (DOE) matrices for KCPs and KNPs; (3) execution of the DOE matrices through analysis, testing, prototyping, and/or manufacturing; (4) statistical analysis of the DOE data to develop response surfaces, (5) optimization using response surfaces to determine optimal KCPs that meet the CTQ requirements and minimize sensitivity to variations; (6) performing Monte Carlo analysis to quantify the likelihood of meeting CTQ requirements under various 
noise conditions; (7) improving the part's producibility and assembly by specifying wide manufacturing and assembly tolerances; and (8) validating the design developed through analysis and/or testing. The methodology was demonstrated successfully on a number of reallife complex applications and is being applied in the present project to steam-cooled components of the ATS gas turbines.

\section{Progress 4Q96 through 3Q97}

Robust design efforts were focused on (1) generating new finite element models (FEMs); (2) parameterizing and updating the existing FEMs; (3) developing robust design formulations by identifying performance critical-to-quality characteristics (CTQs), key control parameters (KCPs), and key noise parameters (KNPs); (4) developing design of experiments (DOE) matrices and executing them through finite element analyses; (5) carrying out statistical analysis of the DOE results, developing response surfaces and optimizing the CTQs for their means and variances; (vi) performing Monte Carlo analysis using response surfaces and a probabilistic analysis code; (6) documenting progress made in this reporting period; and (7) providing consulting services to GEPS staff on robust design.

\section{First-Stage Nozzle}

Statistical analyses were run for the second-phase DOE to develop response surfaces at each FE node for stress, temperature, and life. Response surfaces were validated against independent DOE runs. Robust design studies were performed by optimizing the variances and mean values of LCF life at critical nodes using response surfaces and an in-house optimization code. Monte Carlo analysis was also carried out to calculate the probability of meeting LCF life requirements at various nodes.

A third-phase DOE study, which includes variabilities in gas path and coolant temperatures, convective heat transfer coefficients, and crystal orientations, in addition to metal wall and TBC thicknesses, was executed. The data obtained were analyzed, and response surfaces for stress, temperature, and life at each node were developed and verified. Monte Carlo analysis was performed to calculate the probability of attaining certain LCF life value in the presence of different types of variabilities. Robust design studies were performed to maximize mean LCF life at each FE node and to minimize life sensitivity with respect to variations, including manufacturing tolerances. The finite element model was further updated to incorporate certain design changes and to refine the mesh in certain critical areas of interest including adding new features.

A fourth-phase DOE was designed and executed for lifing the castings received from the vendor. Response surfaces were developed using the FE results from these runs, and were also verified using independent DOE runs. A spreadsheet tool was developed based upon these response surfaces that enables rapid estimation of LCF lives given the coordinate measuring machine (CMM) data for various castings at the vendor site.

\section{Second-Stage Nozzle}

A FEM comprising airfoil, inner and outer sidewalls, inner and outer fillets and covers, diaphragm, and hook portion was developed. FEMs of individual singlets were combined to create a doublet per design requirements. Boundary conditions were applied to the FEM. A thermal-structural analysis was performed to ensure that the model gives adequate results. 
A DOE study for improving LCF life was completed. The results thus obtained for stress, temperature, and life were statistically analyzed.

\section{First-Stage Shroud}

A first-phase DOE study was performed. This required developing macros for updating the FE model to implement changes in geometry, boundary conditions, and other analysis parameters of interest. Statistical analysis of the DOE results was carried out to identify parameters that have significant influence on life. A follow-on second-phase DOE study is planned for $4 Q 97$.

\section{Rotor Components}

Spoolie Design: Robust design analysis was developed. DOE matrix and parameters were defined; analysis of the DOE data was performed; DOE runs resulted in reduced stresses, thus improving the part life.

Main Steam Tube: Several DOE matrices and their parameters were defined and executed. As a result of the analysis, stresses were significantly reduced, thereby improving part life to meet requirements.

Manifold: DOE matrix and parameters were defined. Analysis runs were performed. The results were used to evolve the design concept/configuration. A design was identified that analytically meets the requirements related to design as well as manufacturing.

Flanges: DOE matrix and parameters were defined using mixture design concepts. Analyses of the DOE runs were performed. The results were analyzed to minimize the flange openings. Based upon these findings, the flow circuit was modified to ensure that the flanges remain closed.

\section{Turbine Inner Shell}

A robust design approach was defined. DOE matrices and parameters were identified. ANSYS analyses were carried out for both mechanical and thermal conditions. Data were analyzed to identify parameters that have a significant influence on the performance variables. 2D thermal results were substantiated with 3D analyses.

\section{Plans for Next Quarter}

\section{First-Stage Nozzle}

Updating of the FE model will be completed. Further studies on Monte Carlo analysis and robust design will be carried out to improve the part producibility and the probability of meeting LCF life requirements. Sensitivities to gas path temperature, steam temperature, and steam flowrate will be computed for optimizing system efficiency with minimal effect on LCF life. Work performed thus far will also be documented.

\section{Second-Stage Nozzle}

Results of the first-phase DOE and details of the FE model generation will be documented.

First-Stage Shroud

A second-phase DOE will be designed, executed, and analyzed to evolve a robust design. 


\section{Rotor Components}

Documentation of work performed on the design of spoolie, manifold, steam tube, and rotor flanges will be completed.

\section{Turbine Inner Shell}

3D mechanical DOE analysis will be carried out, and response surfaces will be developed for active tip clearance control.

\section{Technology Application}

Results will be used in the development of part drawings in terms of nominal dimensions and manufacturing tolerances, LCF life assessment of as-cast parts to be received from vendors, quantifying the confidence level in meeting the CTQ requirements under various sources of variations, and improving part producibility by widening manufacturing tolerances.

\section{Section 2.2.2.6 (GTFFST) Structures Design}

\section{Objective}

The objective of this task is to design the exhaust frame and diffusers, steam gland, and aft bearing housing. Instrumentation and test plans for component model, factory, and field testing will be prepared.

\section{Progress 4Q96 through 3Q97}

\section{Exhaust Frame and Diffuser}

The exhaust structures progressed from the engineering preliminary design and initial material release phase to detailed hardware production and prototype instrumentation drawing releases for analysis verification. The details for the concepts of steam introduction to the rotor through the steam gland, aft bearing cooling and exhaust tunnel service routing through the exhaust frame struts, and integrated internally-insulated aft diffuser duct have been completed and all work progressed with positive results. Design analysis and test including the computational fluid dynamics (CFD) and diffuser flow and acoustic tests showed promising enough results to justify proceeding with the mechanical design release, and all hardware is on schedule to meet the 9H full speed, no load (FSNL) testing.

In 3Q97, the exhaust frame and diffuser supplier completed welding/fabrication to produce the first exhaust frame. The final arrangement drawing releases of the exhaust frame and forward diffuser were completed. Final modification instrumentation drawing releases of the exhaust frame and forward diffuser are in process. An exhaust structures assembly design review was held for final release of all detail drawings and all action items are nearly complete. The aft diffuser duct completed internally-insulated performance tests and showed promising results (for minimal loss on pressure recovery) at CRD. Therefore, the outer aft diffuser will be combined with the diffuser duct (and will be internally insulated) for best cost advantage to the system. 


\section{Steam Gland}

The steam gland progressed through casting, machining, and detail assembly releases and design reviews. CFD analysis established the steam input scroll geometry and detailed flow and mechanical analysis confirmed that all design requirements will be met for performance, strength and life, and cost. The delivery of the steam gland is on schedule to the 9H FSNL test pending final machining completion and seal manufacture.

In 3Q97, the vendor completed the casting and rough machining for the first unit after a repair and the steam gland is being final machined. Modification instrumentation machining and assembly drawings for the steam gland were issued. Detailed labyrinth seal drawings and all assembly component drawings were issued, including modifications to reduce swirl interaction features.

\section{\#2 Bearing Housing}

The \#2 bearing housing progressed through casting, machining, and detail assembly releases and design reviews through the past year. Journal bearing and oil detail flow analysis and mechanical analysis confirmed that all design requirements will be met for performance, strength and life, and cost. Final transient soakback condition thermals and deflections are still pending to examine the effects of machine trip or power plant "blackout" conditions. The delivery of the \#2 bearing housing is on schedule to the 9H FSNL test pending final machining and seal manufacture.

The casting vendor completed the casting for the first unit. Flow analysis of the oil and air seals was updated with the assumptions of holding rotor temperature and delta temperature across seals to within GE experience levels. The assembly and supporting seal and component drawings were issued. Transient thermal (machine trip) and flow analysis work will continue on the heat rejection at the bearing due to steam supply through the rotor bore and on acceptable deflections. A detailed deflection and thermal analysis of the bearing seals and journal surface for steady-state and normal shutdown conditions with machine trip and blackout conditions will follow. The prototype test instrumentation modification machining drawing was issued. Standard bearing instrumentation (for radial rotor vibration, bearing pad $\mathrm{T} / \mathrm{C}$ 's, and stator vibration sensors) and the prototype instrumentation assembly drawings were started.

\section{Plans for Next Quarter}

\section{Exhaust Frame and Diffuser}

With the completion of $9 \mathrm{H}$ hardware and instrumentation drawings, work for the $9 \mathrm{H}$ program will focus on releasing all instrumentation assembly drawings for initial machine testing, and providing engineering support for manufacture and assembly of $9 \mathrm{H}$ components. The exhaust frame and forward diffuser assembly will be completed at the vendor's site, including the internal instrumentation lead-outs.

\section{Steam Gland}

The prototype instrumentation assembly drawings will be issued and the vendor will have completed the machining first piece qualification (FPQ). The steam gland design will be 
examined for possible cost reduction/design optimization using brush seals in place of the labyrinth seals for the first $7 \mathrm{H}$ unit.

\section{\#2 Bearing Housing}

The bearing housing machining vendor will complete the first unit. All interfacing conditions with the rotor and bearings will be established for off-design conditions (e.g., power turndown and machine trip). Any special requirements for safe soakback thermals in the journal bearing area will be designed and released. The $7 \mathrm{H}$ application will be examined for oil flow requirement and the lack of capability to increase the oil flow passage sizes.

\section{Technology Application}

The analysis and design effort establish the basis for the $7 \mathrm{H}$ and $9 \mathrm{H}$ structure designs.

\section{Section 2.2.2.6.1 (GTFFSTEF) Exhaust Diffuser Performance}

\section{Objective}

The requirements for the ATS gas turbine exhaust diffuser include (1) improved baseload pressure recovery performance compared with earlier GE exhaust diffuser designs and (2) operation without acoustic resonance at any operating point of the gas turbine. The objectives of this task are to test potential ATS gas turbine exhaust diffuser geometries for pressure recovery performance and to verify that the design selected does not excite acoustic resonances.

The test program includes the installation and test of a scale-model diffuser with flowpath geometries and components compatible with the ATS gas turbine. Specifically, the cost-saving idea of internal insulation will require axial ribs in the walls of the diffuser flowpath. Impact on pressure recovery will be measured. Several other tests will be performed, each with the aim of maximizing performance. These tests include examining variations in flowpath, centerbody length and termination shape, steam pipe locations and fairings, and other diffuser features that affect performance. The final exhaust diffuser design will be tested to verify that no acoustic resonances are excited, particularly at full speed, no load (FSNL) conditions.

\section{Progress 4Q96 through $3 Q 97$}

Testing of an existing 1/9-scale exhaust system model was completed as planned, in both baseline and improved configuration. The improved configuration eliminated off-baseload acoustic resonances and will be used in the ATS gas turbine diffuser. This baseline scalemodel exhaust diffuser was then instrumented for pressure recovery measurements. It was tested with smooth internal surfaces and with internal surface strips to evaluate the effect of internal insulation on diffuser performance. Tests at both full speed, no load (FSNL) and full speed, full load (FSFL) conditions showed that internal insulation could be used in the advanced gas turbine diffuser without significantly degrading performance.

A new model was then designed and built. This model was a 1/13.2-scale representation of the ATS gas turbine exhaust system that incorporated the reduced-resonance design tested earlier. The model was instrumented both for pressure recovery and for detection of acoustic resonances. Its performance was mapped over two different inlet swirl angles (including axial 
flow) and a variety of inlet Mach numbers both with and without the internal surface strips. The tests verified that the design meets performance objectives even with the internal insulation. No acoustic resonances were observed at either FSFL or FSNL conditions.

\section{Plans for Next Quarter}

Analysis and tests will be performed to answer any remaining questions about acoustics in the ATS gas turbine exhaust system. Final analysis of the technical results from this task will be completed.

\section{Technology Application}

The results from this series of scale-model gas turbine exhaust diffuser tests will be used to establish several diffuser design features. One of these features is the feasibility of an internally insulated exhaust frame, a less expensive option than external insulation. Data will be used to design a diffuser with the required pressure recovery, enhancing the overall combined-cycle plant efficiency. These tests will verify that the final design is free from acoustic resonances.

\section{Section 2.2.2.6.2 (GTFFST) Steam Box CFD Analysis}

\section{Objective}

The objective of this task is the design of a steam delivery system as part of the $9 \mathrm{H} / 7 \mathrm{H}$ steam cooling design. A steam gland is being designed to bring the cooling steam from a stationary inlet pipe onboard a rotating shaft. Steam will enter the steam gland through an axial inlet pipe. The pipe turns $90^{\circ}$ so that the resulting flow is traveling tangent to the rotor shaft and into an inlet scroll. The inlet scroll cross-sectional area is sized to match the steam velocity to the rotor tangential velocity. As the steam travels around the scroll circumferentially, some steam is being extracted into rotor slots. A 3D computational fluid dynamics (CFD) analysis is required to define the appropriate geometry of the steam gland inlet scroll that will result in a nearly uniform radial outflow from the scroll circumference.

\section{Progress 4Q96 through 3097}

To confirm the results obtained thus far with NOVAK3D and to assess the effect of the constant exit static pressure assumption required by NOVAK3D, TfC (another CFD code) was used to solve both the original and "continuous scroll outlet" concepts. Both TfC and NOVAK predict a better performance for the modified design, as measured by the standard deviation of the velocity profiles about their mean. Although the comparison between the NOVAK and TfC solutions is satisfactory, the root of the differences was investigated and found to be the differences in the flow predictions in the elbow region of the design. The NOVAK flow pattern indicates a stronger recirculation downstream of the elbow than predicted by TfC. The effect of the exit static pressure on the solution was evaluated by running TfC in the "uniform exit pressure" mode (similar to NOVAK's) and then again with the "non-uniform exit pressure" option. The results of this effort were documented and presented in a design review of the steam gland design. No outstanding issues in this area were identified. The proposed continuous scroll outlet concept is the current baseline design. 


\section{Plans for Next Quarter}

This task has been completed.

\section{Technology Application}

The results of this study have had an impact on the design of the scroll geometry and confirmed its proper performance in meeting the desired uniform flow distribution. The analysis of the entrance to the rotor serves three purposes: (1) it incorporates rotational effects and confirms the 1D analyses of the YFT study of the steam distribution system; (2) it points to the relative insensitivity of the current design to variation in the inlet conditions of the flow; and (3) with the prediction of the relative swirl angle, obstacles in the annular passage will be designed to be aligned with the incoming steam.

\section{Section 2.2.2.7 (GTFFMS) Mechanical System Design}

\section{Objective}

The objective of this task is to perform system level studies to optimize cost and performance. Performance, cost, weight, and other system level integration issues will be monitored and tracked. A flange-to-flange cross-section drawing will be maintained, and all mechanical interfaces will be controlled. All gas turbine systems, as well as the technical requirements for accessories, will be defined and specified.

\section{Progress 4Q96 through 3Q97}

The focus of work in this reporting period was on $9 \mathrm{H}$ detail design and supporting technology development that benefits both the $9 \mathrm{H}$ and $7 \mathrm{H}$ turbines. Performance estimations were updated to reflect the current component designs. Engineering milestone and manufacturing schedules were updated, reflecting the current cycles and customer requirements.

System level studies continue to be performed to optimize cost, performance, weight, size, maintainability, reliability, and manufacturability. Performance, cost, weight, and other system level and integration issues are being monitored and tracked. The systems review team, which includes engineering, manufacturing, sourcing, and maintainability personnel, continues to meet to review the merit of system issues and determine whether incorporation of ideas meets system goals such as cost, schedule, and performance.

The maintainability, reliability, and serviceability team continues to work to ensure that all of the "lessons learned" for field operation are being incorporated into the 9H/7H design. RAM and FMEA studies were completed, and goals were established for the $\mathrm{H}$ machines consistent with the Product Specifications.

A full-scale mockup of the miclsection including the compressor discharge casing (CDC), combustion transition piece, and steam piping was completed and is being used for assembly and maintainability trials, with feedback to Engineering to ensure that assembly and maintainability issues are incorporated into designs prior to hardware procurement.

The $9 \mathrm{H}$ mechanical interface drawing, which includes the internal and external interfaces, was updated and modified. The $7 \mathrm{H}$ aero flowpath drawing was completed, establishing a basis for the initial cross-section drawing. 


\section{Plans for Next Quarter}

Work effort will shift to focus on the $7 \mathrm{H}$. The $9 \mathrm{H}$ mechanical interfaces will be confirmed and updated. The $7 \mathrm{H}$ engineering milestone schedule will be integrated with the manufacturing schedule and released as a working document. Performance estimations for both the $7 \mathrm{H}$ and $9 \mathrm{H}$ will continue to be updated as ideas are incorporated and component designs mature. The cross-section drawings will be upidated for both machines.

\section{Technology Application}

The cross-functional systems review team will ensure that field experience "lessons learned" are incorporated into the component designs, thus optimizing performance, cost, weight, size, maintainability, reliability, and manufacturability.

\section{Section 2.2.2.7.1 (GTFFMS) Transient Gas Turbine Cycle Model}

\section{Objective}

The objective of this task is to create a more detailed transient model of the flange-to-flange ATS gas turbine for use in the overall plant transient simulation. The plant simulation in turn is used to define the gas turbine internal boundary conditions for parts design and analysis and overall plant control strategies. A real time simulation is used to test the actual control for the ATS gas turbine.

\section{Progress 4Q96 through 3Q97}

The state of transient modeling for the ATS gas turbine was reviewed and end user requirements were noted. These requirements are described in the Technology Application portion of this Section. GE Aircraft Engines transient modeling methods and practices were reviewed and their experience was applied where practical. The steady-state cycle model was modified to operate in a transient mode as a subroutine callable from the larger overall plant transient simulation. Component calculations and maps were extended to model performance at part speed conditions. The model has been exercised within the overall plant simulation over all required speed ranges and runs at an acceptable computer execution time. The model must be simplified by the Advanced Controls group to run as a real time model in their simulation.

A model to estimate the temperature and clearance of critical metal parts (heat soak model) has been completed and coded in FORTRAN. The objective is to model the metal temperature of key metal parts and create a stress and clearance model for critical locations that utilizes the model metal temperatures. The heat soak model currently operates in a stand-alone mode and will be integrated into the transient cycle model in 4 Q97. The stress model will be worked on in 1 Q98.

A study to validate modeling methods in the low speed to full speed, no load range is near completion. The validation was accomplished by utilizing the same modeling methods for an older GE gas turbine for which low speed test data were available and comparing model predictions to actual data. The model compares very well with test data. 


\section{Plans for Next Quarter}

Comparison of the heat soak model to more detailed analysis will be completed, and the model will be integrated into the ATS gas turbine transient model. The stress model will be developed during 1Q98 and added to the heat soak model. The gas turbine cycle model will be updated to represent current status performance levels.

\section{Technology Application}

The plant transient model is used in the design of the ATS gas turbine control system as well as the overall plant control and equipment. Simulation results of contemplated equipment configurations and control strategies define the operating environment and design condition of the ATS gas turbine.

The safe and reliable operation of the ATS gas turbine is critically dependent on off-base systems whose actions do not necessarily follow or result from operation of the gas turbine. For instance, the pressure and temperature of the cooling steam supplied to the ATS gas turbine must be maintained within an allowable band to preserve hot parts life. These issues and many others, such as failure modes effects analysis (FMEA), are studied through use of the transient plant model.

The steam/gas process group (CCST) combined cycle plant transient simulation requires a model that has good fidelity with the steady-state ATS gas turbine cycle model and a reasonable computer execution time. The combined cycle model is used to define overall plant control strategies and design conditions for plant and balance of plant equipment. The simulated operation of the ATS gas turbine and its control within the overall plant then provides information on transient design conditions for the design of the gas turbine itself. The current CCST plant transient model runs on a PC with the OS2 Operating system using the PC-Trax program.

The controls design group (ACSE) requires a real time ATS gas turbine transient cycle model with an accuracy of $\pm 1 \%$ of the steady-state cycle model. The requirement for a real time transient model is due to the need to connect the computer model input/output electronically to the ATS gas turbine control for design and checkout. The real time requirement means that the model calculation time must be less than the sampling time of the actual control. ACSE models run on a UNIX workstation using the EASY5 program.

\section{Section 2.2.2.8 (GTFFPP) On-Base and External Piping Design}

\section{Objective}

The objective of this task is to design piping for fuel, air, steam, water, and oil transfer. A turbine base will also be designed for securing the ATS gas turbine to the foundation.

\section{Progress 4Q96 through 3Q97}

Developments of preliminary designs for turbine base and piping systems progressed. System requirements were developed and refined. Major hardware design reviews were held and plans were laid out to address action items. A final design review of the $9 \mathrm{H}$ turbine base was held. 
No technical issues were found. All issues from previous reviews were closed. The final documentation was released to build.

Preliminary design reviews for all piping systems were completed. Several action items were generated for each system, with a plan put in place to address each item. Design activity will continue toward completing final piping designs and releasing build documentation.

\section{Plans for Next Quarter}

System requirements will continue to be addressed and reviewed. Work on final piping designs will continue. Present plans are to release completed build documentation for air extraction, exhaust frame cooling air, clearance control, second-stage nozzle cooling, cooled cooling-air, and cooling and sealing air piping systems.

\section{Technology Application}

The turbine base and piping designs require the consideration of new ideas in this technology application. The turbine base must be capable of handling and transferring much larger loads than in previous gas turbine designs. This requirement is complicated by the limited space available to the turbine base because of the machine shipping envelope, the increased number of systems requiring piping for fluid transport, the piping size and quantity, and the foundation interface limits. In summary, the piping design challenge is driven by the increase in size and quantity of fluid systems support required by the turbine and the limited space around it.

\section{Section 2.2.2.9 (GTFFIT) Instrumentation and Test}

\section{Objective}

The objective of this task is to instrument and conduct field tests that validate the ATS gas turbine design for mechanical integrity and operating performance of the unit and establish emissions performance. Test plans will be formulated and instrumentation will be specified. Compressor and turbine rotor telemetry systems will be developed and acquired.

\section{Progress 4Q96 through 3Q97}

The telemetry system approach was selected as a front end system for transmitting signals from all sensors mounted on the rotor including the compressor and turbine sections. The telemetry systems will be mounted in the load coupling. The telemetry vendor selection is in process.

The preliminary number of sensors required for a full speed, no load (FSNL) and full speed, full load (FSFL) gas turbine, including power plant skids, was established.

Work is in progress on the instrumentation drawings, including compressor rotor, turbine buckets, nozzles, and casings. The preliminary FSNL test plan was prepared and provided to various engineering organizations for reviews and comments. 


\section{Plans for Next Quarter}

The number of sensors required for the flange-to-flange gas turbine unit and power plant components for FSNL and FSFL tests will be established. Work on the test plan, instrumentation drawings, and telemetry system design will continue.

\section{Technology Application}

These are test plans to establish the instrumentation requirements for $7 \mathrm{H}$ and $9 \mathrm{H}$ FSNL and FSFL tests.

\section{Section 2.2.3 (GTET) Technology Validation}

The overall objective of this task is to provide confirmation of critical component design and technology. The validations include hot gas path component testing, sub-scale compressor testing, steam purity test trials, and rotational heat transfer testing. Technology enhancements that are not required for the first machine design but will be critical for future ATS advances in performance, reliability, and costs will be conducted.

\section{Section 2.2.3.1 (GTETNC) S1N Design}

\section{Section 2.2.3.1.1 (GTETNC) Nozzle Cascade CFD Analysis}

\section{Objective}

The objective of this task is to apply a fully viscous 3D computational fluid dynamics (CFD) analysis to predict the flow and aid in the generation of heat transfer boundary conditions for the first-stage Nozzle Cascade Test. Such a validated CFD tool then becomes the vehicle to apply the Nozzle Cascade Test data to the actual machine design problem.

\section{Plans for Next Quarter}

This task has been completed.

\section{Technology Application}

The validation of NOVAK3D predictive capabilities provides a valuable tool to evaluate the impact of design modifications and off-design performance of ATS nozzles in particular. It also contributes to a more realistic calculation of heat transfer coefficients and consequently enhances the heat transfer predictions in complex geometries.

\section{Section 2.2.3.1.2 (GTETEH) Combustion-Generated Flow Effects on Heat Transfer}

\section{Objective}

The objective of this task is to evaluate the freestream turbulence intensity incident upon the ATS first-stage nozzle airfoil, and the effect of this turbulence level on the airfoil heat load. This turbulence intensity level and its character have a major and direct bearing on the heat load for the nozzle airfoil and endwall. 


\section{Plans for Next Quarter}

This task has been completed.

\section{Technology Application}

The ATS cascade test results were incorporated directly into the ATS first-stage nozzle design. Comparison of results with both high-turbulence-generating perforated plates and a DLN combustor system cold-flow mockup verified the applicability to design of heat transfer results from the former method.

\section{Section 2.2.3.2 (GTETRS) Rotor Steam Transfer}

\section{Objective}

For stable cooling of the turbine buckets, static flow tests will be conducted to validate the steam flows in the circuit to and from the buckets, through the rotor. These will establish flow losses for the unique components in the steam delivery circuit.

\section{Progress 4Q96 through $3 Q 97$}

Flow tests were completed for various steam inlet geometries, where the steam first comes on board the rotor. These have helped to characterize the pressure losses with various configurations and establish a preferred design compromise. The results show good agreement with analytical model results.

Downstream of this steam inlet the flow splits into multiple passages, at the same time turning and changing the flow area. Again, for the flow losses in this region to be accurately represented, a rig test was required. This part of the circuit has now been added to the flow rig and run with favorable results.

The various components of the steam system are connected together with "spoolie" seals. These components offer both forward- and backward-facing lips that provide additional sources of pressure loss to the system. These components were also flow tested for pressure loss, and the results were used to validate the analytical system flow model.

\section{Plans for Next Quarter}

The flow testing for the first flow split was analyzed with flow coming straight down the tube, but analytical flow modeling predicts that the rotor rotation will cause the steam to be swirling as it flows down the tube. The next test will be to swirl the flow in the rig to establish the influence on pressure drop at the flow split.

Construction of a further rig will begin in order to model the flow losses in the manifolds that distribute the steam to the buckets.

\section{Technology Application}

Rotor steam transfer tests are used to evaluate the design optimum for the $7 \mathrm{H}$ and $9 \mathrm{H}$ turbine bucket cooling. 


\section{Section 2.2.3.3 (GTETSE) Rotor-Bucket Steam Transfer Spoolie}

\section{Objective}

Rotating air test rig tests will be performed to validate the steam transfer spoolie design concept. (Spoolies are the hollow, spool-shaped ducts that bridge the gap between the steam delivery channels in the turbine rotor and cooling channels in the buckets.) A stationary steam test rig will be used for evaluation of durability and alignment effects on leakage.

\section{Progress 4Q96 through 3Q97}

A new test rig was completed and installed so that wear testing of larger spoolies at simulated engine operating conditions of temperature, pressure, G-field, and environment (steam) could take place. Preliminary testing in air successfully demonstrated the spoolie wear rates with the largest spoolies showing consistency with the previous, successful small spoolie results. Initial wear testing in steam demonstrated good leakage results, and opportunities to adjust additional coating parameters that could lead to further improvements in leakage and durability.

Separate wear-coating screening tests were completed for a number of candidate coatings, confirming the superiority of the selected production coating and identifying an additional wear/friction lubricant to further enhance wear performance.

\section{Plans for Next Quarter}

A wear-coating coupon test matrix is being developed to investigate the influence of various coating manufacturing parameters on wear rate in order to optimize wear, leakage, and durability in a steam environment. The testing is currently planned to begin early in 1Q98.

Further tests are planned for the spoolie steam wear/leakage rig, investigating alternate coating manufacturing parameters, in the pursuit of optimum wear and leakage.

An additional rig was constructed to investigate the endurance capability of the spoolie coating to small movements between the components that are experienced when the rotor is on turning gear, when there is no rotational G-force to rigidly lock the components in position. This low rpm rotational rig has just started running, initially investigating the lock-up rpm.

\section{Technology Application}

These tests will validate the rotor bucket steam transfer spoolie design.

\section{Section 2.2.3.4 (GTETRH) Rotational Heat Transfer}

\section{Section 2.2.3.4.1 (GTETRH) Rotational Effects on Bucket Mixing Ribs}

\section{Objective}

The addition of mixing ribs to turbine blade radial cooling passages was found to provide a more robust thermal design, without the severe reduction in performance measured previously, when evaluated in sub-scale models at low Reynolds numbers. Since this design 
improvement is scheduled for use in the ATS gas turbine, design data that incorporate this change need to be obtained at full-scale conditions in the operating range of interest.

A full-scale turbulated test passage of the appropriate aspect ratio will be constructed that will be identical to the one tested previously except for the addition of the new mixing rib geometry. This passage will be evaluated in the full-scale rotational test rig over the range of dimensionless parameters presert in the ATS gas turbine.

\section{Progress 4Q96 through 3Q97}

The full-scale test passage, incorporating mixing ribs in addition to the previously tested turbulator configuration, was designed, constructed, and installed. An unheated passage of the same cross section as the heated passage was installed upstream of the test passage and connected with the test passage by a $180^{\circ}$ turn. This arrangement provides a realistic inlet velocity distribution to the test passage. Like the passage tested without mixing ribs, the four passage sides were independently heated electrically with enough thermocouples to allow the evaluation of the local heat transfer coefficient on each passage side. The thermocouples on the leading and trailing sides provide the radial variation of the heat transfer coefficient over fourteen equal radial lengths.

A test duct was installed in the test rig, instrumented, and calibrated for heat losses and local conduction effects. Initial data were obtained and are currently being analyzed. Further test conditions will include Reynolds numbers and Buoyancy numbers over the range of interest to the application.

\section{Plans for Next Quarter}

The data acquisition on the full-scale test passage with mixing ribs will continue. The results will be correlated in dimensionless form.

\section{Technology Application}

The new turbulator and rib design, which has to-date only been demonstrated in small-scale tests, is being employed to reduce the bucket cost and to yield a more robust design with improved performance at high Buoyancy numbers. This design will be validated by the fullscale data to be generated under this task.

\section{Section 2.2.3.4.2 (GTETRH) Bucket Cooling Circuit Rotational Pressure Drop Test}

\section{Objective}

The objective of this task is to determine the effect of rotation on the pressure drop in a radial bucket cooling passage. The computational fluid dynamics (CFD) computations of the effect of rotation on bucket cooling passage heat transfer and pressure drop indicate a significant effect of the Buoyancy number on pressure drop. Since the bucket pressure drop is a major fraction of the total system pressure drop involving the coolant, it was deemed necessary to measure this effect using the full-scale test rig.

The high aspect ratio turbulated duct assembly was instrumented to measure the pressure drop between the inlet and outlet manifolds. Appropriate heaters were employed on the pressure 
measurement lines to avoid condensation of the working fluid and to minimize the density corrections required due to temperature differences between the measurement lines and the test duct. This allowed the differential pressure transducer to be mounted near the rotational axis, where no transducer correction for centrifugal effects was required. The pressure drop for both outflow and radial inflow was measured.

\section{Plans for Next Quarter}

This task has been completed.

\section{Technology Application}

The new pressure drop correlation, which includes the effect of the Buoyancy number, is now in use in the evaluation of alternate coolant passage designs and in the evaluation of the flowpressure drop characteristic of the ATS turbine bucket cooling system.

\section{Section 2.2.3.5 (GTETIH) Surface Enhanced Internal Heat Transfer}

\section{Section 2.2.3.5.1 (GTETS2NHT) S2N Trailing Edge Flow Test}

\section{Objective}

The objective of this task is to perform heat transfer tests in the trailing edge region of the second-stage nozzle using a Plexiglas ${ }^{\mathrm{TM}}$ model built in 1995. The purpose of the work is to generate a cooling scheme that will (1) even out the coolant side heat transfer coefficients along the channel and (2) yield results that are comparable to or better than the turbulent pipe flow correlation predictions.

The model keeps the important geometric variables of the passage close to the actual design. It has thin-foil heaters on both the suction and pressure sides, and liquid crystals to determine the temperature distributions. Tests were planned to investigate the triangular passage performance with several turbulator designs.

\section{Plans for Next Quarter}

This task has been completed.

\section{Technology Application}

The test results for cooling passages in the second-stage nozzle trailing edge cooling circuit provided the necessary design information and turbulator configurations for the ATS secondstage nozzle. This allows the design to obtain the desired heat transfer enhancement for the passages and to channel the cooling flow near the apex of the triangular flow passage near the trailing edge region effectively.

\section{Section 2.2.3.5.2 (GTETIH) S.2B Trailing Edge Heat Transfer Tests}

\section{Objective}

The task objective is to provide adequate experimental data to verify the performance of the second-stage bucket trailing edge cooling circuit. Because film cooling and trailing edge bleed 
cooling are incompatible with the ATS gas turbine objective of closed circuit cooling, the bucket trailing edge must be cooled completely by convection in the trailing edge cavity. The geometry and flow conditions in the trailing edge cavity are different from any analyzed and tested previously. The heat transfer coefficients in the cavity are determined experimentally using a scale model. The experimental results are used to guide and improve the design of the bucket.

\section{Progress 4Q96 through 3 Q97}

The trailing edge cavity of the ATS gas turbine second-stage bucket presents a challenge to designers because the trailing edge is very thin. The resulting low aspect ratio cooling circuit cavity cannot use film cooling or trailing edge coolant bleed because of the closed-circuit cooling in the advanced gas turbine. Turbulators are required in this cavity, both to increase the coolant heat transfer coefficient and to distribute the flow in the cavity so that all regions of the trailing edge are adequately cooled.

Cooling the $180^{\circ}$ turn at the bucket tip end of the trailing edge cavity also presents a challenge because film cooling cannot be used. The tip cap must be adequately cooled by internal cooling alone, with the trailing edge portion of the tip cap presenting a special challenge.

Thin-foil heaters, thermochromic liquid crystals, and liquid crystal video thermography (LCVT) were used to measure the heat transfer coefficient distributions. This type of liquid crystal changes color with temperature, which allows temperature distributions to be measured by using the LCVT digital image processing system to convert the color distributions to temperature distributions.

The computational fluid dynamics (CFD) part of this task was completed.

A scale model of the two cooling cavities of the ATS gas turbine second-stage bucket nearest the trailing edge was used. It models half of the span of the bucket, from the pitch line to the tip. The model has a constant included angle for both cavities that is very close to the angle of the actual bucket. The tip geometry was modeled very carefully to match the same locations and relative angles of the ribs, tip cap, and turning vane.

Five sets of tests were performed during the reporting period. The first set evaluated a change to the trailing edge cavity turbulator configuration. The next three sets were aimed at determining the effect of the turn guide vane on bucket tip heat transfer. The fifh set was done to verify repeatability of the experiments. In all tests, a single flowrate was tested. The heater flux was increased incrementally to enable mapping of temperatures at the trailing edge tip.

The results were scaled to the actual ATS gas turbine conditions using the Dittus-Boelter correlation for smooth wall fully-developed pipe flow:

$$
N u_{\mathrm{db}}=h_{d b} D_{h} / k=0.023 \cdot \operatorname{Re}_{\mathrm{Dh}}^{0.8} \cdot \operatorname{Pr}^{0.4}
$$

Assuming that the flow distributions in both the model and the bucket are the same and follow the same dependence on $\operatorname{Re}$ and $\operatorname{Pr}$ as the Dittus-Boelter correlation, the model results are scaled using: 


$$
N u_{\text {bucket }}=N u_{\text {model }} \cdot R e_{\text {bucket }}^{0.8} \cdot P r_{\text {bucket }}^{0.4} / R e_{\text {model }}^{0.8} \cdot P r_{\text {model }}^{0.4}
$$

The scaled predictions for heat transfer coefficients were presented in previous reports.

In the first of the three sets of tests to evaluate the effect of the turn guide vane, the model was modified to remove the turn guide vane from the trailing edge cavity. The model tested included separate cooling circuits to remove excess energy from the overlap region of the heater. The results showed a decrease in trailing edge tip heat transfer coefficient compared to the results observed with the turn guide vane present. In the second set of tests, the model was modified so that the turn guide vane in the trailing edge cavity matched the turn guide vane in the second-stage bucket core die. The results showed a decrease in trailing edge tip heat transfer coefficient compared to the results observed with the original turn guide vane design. In the third set of tests, the turn guide vane in the model was modified so that the ratio of passage areas on both sides of the turn guide vane matched the ratio of passage areas in the turbine bucket cooling circuit. The results show heat transfer coefficients at the trailing edge that are similar in magnitude to those observed with the original turn guide vane design. The model was refurbished after the turn guide vane tests and the liquid crystals were replaced. The last turn guide vane test wasi repeated to ensure repeatability of results.

The trailing edge cavity of the ATS gas turbine second-stage bucket can be modeled by a smooth duct of narrow cross section. Experiments were planned to determine the effect of rotation on heat transfer in such a duct, oriented at oblique angles to the axis of rotation. In the experiments, a high-molecular-weight gas (Refrigerant-134A) at ambient pressure and temperature conditions will be used to match the dimensionless parameters at engine conditions. Thin-foil heaters were used to produce a constant heat flux at the long sides of the duct; the narrow sides were unheated. Three duct cross-section orientations will be evaluated: $0^{\circ}, 45^{\circ}$, and $60^{\circ}$ to the axis of rotation. The test results will show the effect of rotation and orientation angle on duct leading and trailing side heat transfer. The test ducts for the $0^{\circ}$ and $45^{\circ}$ configurations were constructed and instrumented. An existing rotating rig will be used for the testing. The rotating disk was modified for use with the test ducts.

The first cross-section orientation $\left(0^{\circ}\right)$ was tested and data recorded. A finite element model was built to evaluate the measurement error due to heat loss through the thermocouples. Thermocouple measurement correction and data reduction are in progress.

The test duct for the second cross-section orientation $\left(45^{\circ}\right)$ was installed into the rotating disk.

\section{Plans for Next Quarter}

The computational fluid dynamics (CFD) and liquid crystal heat transfer portions of this task have been completed.

Experiments will be conducted to determine the effect of rotation on heat transfer in ducts of narrow cross section, oriented at $30^{\circ}$ and $45^{\circ}$ angles to the axis of rotation. The finite element model for thermocouple heat loss will be used to determine temperature corrections for all of the test points of the first experiment. A finite element model for thermocouple heat loss will 
be created for the test duct oriented at $45^{\circ}$ to the axis of rotation. The results of the rotating duct experiments will be analyzed and reduced to a useful form.

\section{Technology Application}

The results of the tests conducted as part of this task were used directly in the design of the second-stage bucket for the ATS gas turbine.

\section{Section 2.2.3.5.3 (GTETIH) S1N Outer Band Liquid Crystal Heat Transfer Tests}

\section{Objective}

The objective of this task is to perform heat transfer tests with a representative outer band impingement configuration and measure the heat transfer coefficient distributions underneath the impingement jets. The data will be compared with the design calculations and expectations. A test rig is used to simulate the design impingement jet plate geometry as closely as possible. The test section walls are instrumented with three etched thin-foil heaters and a liquid crystal layer to measure the local wall temperature distributions as a function of flowrate and heat flux. The temperature data are then converted into heat transfer coefficient values.

\section{Plans for Next Quarter}

This task has been completed.

\section{Technology Application}

The test results obtained with the flow and heat transfer tests showed that the design calculations and models were able to successfully predict the flow directions and heat transfer coefficients for the complicated impingement pattern of the ATS first-stage nozzle outer band. The tests also showed that the heat transfer is dependent on the leading and trailing edge cavity discharge pressure levels. In addition, the data showed that an impingement design without a separating rib is more effective than a design with a separating rib on the suction and pressure sides.

\section{Section 2.2.3.5.4 (GTETIH) S1N Conver Cavity Heat Transfer Tests}

\section{Objective}

The objective of this task is to perform flow and heat transfer tests in a simple test rig representative of a first-stage nozzle convectively cooled passage geometry with two different turbulator designs to determine the effect of corner radius on the heat transfer enhancements obtained with the turbulators. Two simplified plastic models of the cooling channel were constructed with the important geometric variables kept as close as possible to the actual design. An additional test section was also constructed to model the exact geometry of the convectively cooled cavity, which incorporated the area changes along the radial distance. The inside surfaces of the test pieces were coated with liquid crystal paint or a liquid crystal sheet, and transient and steady-state tests were run to determine the friction factors and local heat transfer coefficient distributions. The results were also compared with the CRD database. An 
additional flow test was conducted with a metallic test section manufactured with exactly the same dimensions as the prototypical passage to verify the flow models of the design.

\section{Plans for Next Quarter}

This task has been completed.

\section{Technology Application}

The results of these tests with rectangular and filleted turbulated tubes provided the designer with information on the differences between the two and showed that the database can be used to predict the friction and heat transfer. The results with various turbulator heights changed the design requirements to prevent large variations in the local heat transfer coefficients. The test data also showed that the heat transfer enhancements are not reduced at the high Reynolds numbers of interest for the present design.

\section{Section 2.2.3.5.5 (GTETIH) Bucket Tip Closed Circuit Cooling}

\section{Objective}

The objective of this task is to measure non-rotating heat transfer and pressure drop in the $180^{\circ}$ tip turn region of a two-pass serpentine bucket tip, and to evaluate the ability of an enhanced surface in the tip region to enhance the tip cooling without a substantial pressure drop penalty.

\section{Plans for Next Quarter}

This task has been completed.

\section{Technology Application}

These results were used by the designers of the ATS gas turbine buckets to design the tip turn regions of serpentine cooling circuits.

\section{Section 2.2.3.5.6 (GTETLE) Hucket Leading Edge Heat Transfer Testing}

\section{Objective}

The objective of this task is to evaluate turbulator geometries for the first-stage bucket leading edge passage by performing non-rotating heat transfer and pressure drop tests at high Reynolds numbers on scaled models of the leading edge passage.

\section{Plans for Next Quarter}

This task has been completed.

\section{Technology Application}

The heat transfer and pressure drop results from this task were used in the design of the firststage bucket in the ATS gas turbine. 


\section{Section 2.2.3.5.7 (GTETIH) S1N Surface Enhanced Internal Heat Transfer}

\section{Objective}

The objective of this task is to investigate and determine the heat transfer coefficient enhancements that could be generated under impingement jet cooling modules by adding surface roughness elements without increasing the total system pressure drop. The effect of bumps missing in some regions due to manufacturing problems will also be investigated.

The test section used for impingement heat transfer tests is enclosed in a high-pressure enclosure that can be operated at pressures up to 10.2 atm (150 psia) by means of a backpressure control valve. The impingement air is fed to a supply chamber equipped with a square impingement jet plate that can accommodate several hole configurations. The impingement test surface is in intimate contact with a copper block that is heated by four cartridge heaters. The impingement test plates, positioned at a controlled distance from the impingement jet plates, are instrumented with four embedded thermocouples that measure the plate temperature. Tests are conducted at various jet Reynolds numbers and several jet plate geometries. To investigate the effect of bumps missing in some regions, the high-pressure containment is modified so that a window can be attached at one end. A thin-foil heater and a liquid crystal assembly are glued onto the impingement test plate and the color changes are observed with the liquid crystal video thermography (LCVT) system.

\section{Plans for Next Quarter}

This task has been completed.

\section{Technology Application}

The ANSYS analysis results provide the increases in wall temperature expected for various numbers of bumps missing. The acceptable temperature rise will determine the quality control criteria and the nondestructive testing technique for the missing bump number determination. The transient technique provides a nondestructive technique to check the non-uniformity of the cooling and the number of missing bumps.

\section{Section 2.2.3.5.8 (GTETIH) S1N Trailing Edge Heat Transfer Tests}

\section{Objective}

The first-stage nozzle trailing edge triangular cavity is air cooled and uses a combination of several cooling techniques. The turbulated main passage feeds several trailing edge slots whose heat transfer is enhanced by pin fins and high-solidity turbulators. The root region includes a $180^{\circ}$ turn that feeds three trailing edge cooling slots. The flow and heat transfer inputs for the design are complex and need verification testing.

The objective of the task is to build a representative model of the trailing edge cavity and measure the local heat transfer coefficients to ensure that (1) the heat transfer coefficient correlations used in the design are appropriate and (2) there are no flow recirculation or uneven distribution regions where the heat transfer coefficients are lower than the expected values. 


\section{Progress 4Q96 through $3 Q 97$}

A design change was incorporated near the root of the first-stage nozzle to improve castability. This change required additional trailing-edge cavity flow checks to the base case studies performed in 1996 in order to answer two questions: (1) how much does the cooling flowrate increase? and (2) can the pressure margin for the film holes in this region be maintained? To provide answers, the aluminum flow model used in 1996 was modified by eliminating the rib at the root $180^{\circ}$ turn and polishing off the last four turbulators. Flow tests were then conducted with the modified geometry. The detailed static pressure distributions measured were compared with the original model tests conducted in 1996. The results showed that the flowrate increased by $15 \%$ and there was a region at $30 \%$ span from the root section where the film pressure margin was still higher than the design requirement.

For the heat transfer tests, a conceptual design of the test section was prepared based on cross sections provided by Design Engineering. The model divides the cavity into several regions and matches the wetted perimeters and flow areas as closely as possible. These discrete cross sections were then connected with a linear variation of the passage geometry. A tool path program for a numerically controlled machine was prepared by the machine shop and an acrylic model of the test section was manufactured. Measurements were made on the acrylic model and compared with the model dimensions. After the dimension checks, one wall of the model was covered with a liquicl crystal sheet and a thin-foil heater. The flow separation ribs, the pin fins, and the balsa wood turbulators were attached to the opposite wall with a clearance allowing for a gasket between the two faces.

Two series of heat transfer tests were conducted with the instrumented test section at two flowrates. The trailing edge holes were discharging to atmospheric pressure. The measured static pressure distributions agreed with the flow model predictions and showed a constant pressure all along the turbulated cavity that feeds the trailing edge holes. The calculated flowrates for both test pressure ratios were within $5 \%$ of the measured values.

The heat transfer tests were conducted by setting the flowrate and then setting the uniform heat flux to the thin-foil heater to a given value that started the color changes in the liquid crystal. Once steady state was reached, an image of the surface was recorded by liquid crystal video thermography (LCVT) for future analysis. The heat flux was then increased in preset steps and the surface temperature distributions were recorded for each case. Twelve images were recorded and saved for analysis. The liquid crystal color versus temperature calibration was performed in the calibrator. The surface temperature results with the known uniform heat flux values were then used to convert them to heat transfer coefficient distribution data. The local heat transfer coefficients in the turbulated supply cavity and in the pin fin and turbulated trailing edge holes were measured.

\section{Plans for Next Quarter}

This task has been completed. 


\section{Technology Application}

The flow and heat transfer results obtained will verify the design tool predictions and ensure that the predictions are correct and that there are no regions that have friction and heat transfer coefficient values different from the design assumptions.

\section{Section 2.2.3.5.9 (GTETBKHT) High Reynolds Number Turbulator Static Heat Transfer Test}

\section{Objective}

The objective of this task is to investigate and determine the heat transfer coefficient enhancements possible in the first-stage nozzle. Internal cooling will be supplied by two different types of convection: one using impingement heat transfer within the internal airfoil cavities, the other using high Reynolds number turbulated heat transfer within the aftmost convective channel of the airfoil. This task will concentrate on the latter type of heat transfer. Experimental work reported in the open literature on turbulator heat transfer enhancement and friction factors is limited to passage Reynolds numbers below 80,000. This task will supply data and correlations to be used for advanced machine design conditions. Heat transfer and pressure drop data are required at far higher Reynolds numbers than previously tested with common turbulator geometries and passage aspect ratios.

\section{Plans for Next Quarter}

This task has been completed.

\section{Technology Application}

The results from this task are applicable to any non-rotating components in the ATS gas turbine that use turbulated passages for cooling. As long as rotational effects are accounted for, these results are also applicable to turbulated passage cooling of rotating components.

\section{Section 2.2.3.5.10 (GTET) Impingement Degradation Effects}

\section{Objective}

The internal nozzle design verification tests conducted in 1996 with various impingement jet plates and test plates showed that the impingement heat transfer coefficients measured under the first and second rows of the impingement jets were lower than the open literature correlation predictions (Metzger). Although this difference was not significant in some regions, it was important in others where accurate knowledge of the heat transfer coefficients under the first two impingement jets is important. The differences between the design verification test results and the correlation predictions were attributed to the fact that in those tests the first row of jets was near a wall with zero velocity boundary conditions while in the correlation tests the first row was adjacent to a constant pressure boundary condition.

The objective of this task is to understand the physical phenomenon that causes the observed difference. The local static pressure distributions along the cross flow regions of the impinging jets will be measured for two inlet boundary conditions, one with a wall and the other with a constant pressure. Tests will also be conducted with the cross flow discharging in one 
direction across the impingement jets and discharging in two directions symmetrically from the center row.

\section{Progress 4Q96 through $3 Q 97$}

A series of tests was conducted to investigate the effect of the distance between the jet plate and the impingement test plate on the jet flowrate for a given constant pressure ratio. The results showed that, for the given pressure ratio, the flowrate increases and reaches an asymptotic value as the distance between the plates increases. The impingement program developed for the design calculations appears to calculate the correct flowrates as long as the jet-to-plate distance is larger than 0.75 .

To investigate the effects of the location of the first row of jets (i.e., near a wall with zero velocity boundary conditions or adjacent to a constant pressure boundary condition), the impingement test rig used in the enhanced surface heat transfer tests was modified to accommodate static pressure taps along the jet cross flow regions. The impingement test plate was instrumented with a liquid crystal and a thin-foil heater. In addition to the impingement heat transfer coefficients distribution, the static pressure distributions were also measured along the side wall at the jet injection locations and in between jets. The first series of tests was conducted with the first row of jets impinging near a wall with a zero velocity boundary condition. A second series of tests was also conducted for comparison where the jet and test plates are left as above except that the first row of jets is moved away from the wall by $1 \mathrm{~cm}$. An air cavity is left (with no flow) between the first row and the wall. Static pressure and heat transfer coefficient distributions were again measured.

Once again the data agree with the model predictions. The heat transfer coefficients measured during these tests showed that the highest impingement heat transfer was occurring underneath the first jet and not the second jet as observed in 1996. The results confirmed the applicability of the Metzger impingement heat transfer coefficient correlations and the model predictions for the design calculations. The difference between the 1997 and 1996 results may be due to some instability in the jet formation that was not manifested during the 1997 tests.

\section{Plans for Next Quarter}

The project results were transmitted to GEPS staff by means of technical reviews. The project is complete.

\section{Technology Application}

The results obtained will clarify the discrepancy between prior test results and those from open literature correlation predictions (Metzger). The new data will improve the design of the first-stage nozzle internal cooling scheme.

\section{Section 2.2.3.5.11 (GTETIH) Production Airfoil Flow Checks}

\section{Objective}

The cooling flow circuits of the first- and second-stage nozzles and buckets of the ATS gas turbine have complicated flow configurations. Design flow models involve several empirical 
friction factors and flow element head loss coefficients that were taken from the best knowledge available. The models need experimental verification with typical cast components.

The objective of the flow checks, conducted with air, is to check the flowrates and static pressure distributions of typical cast first- and second-stage nozzle and bucket components. The results will be compared with the design flow model predictions. The measured overall coolant flowrates for a given overall inlet-to-exit pressure ratio will also form the basis for future quality flow tests to ensure that every component fulfills the flow design requirements.

\section{Progress 4Q96 through 3Q97}

As part of this airfoil flow checks task, two first-stage nozzles to be used in the GEAE cascade low cycle fatigue (LCF) tests were flow checked. The two nozzles are similar to the ones which were flow checked in 1995 for the GEAE cascade heat transfer tests. The nozzles have steam circuits and two air-cooled cavities near the trailing edge. The flow checks were conducted in air, and the static pressure distributions were compared with the flow models and the 1995 data.

The comparison of data shows that the steam circuits of the LCF test nozzles and heat transfer test nozzles are similar. The air flow cavities differed somewhat but those differences were corrected before the LCF test nozzles were installed.

The full-scale first-stage nozzle test setup in Evendale, used for heat transfer and LCF tests, has two fully instrumented airfoils which are air and steam cooled. Two water-cooled copper airfoils constitute the side walls of the test facility. These water-cooled airfoils form the pressure and suction side walls of the cascade facility. The water-cooling circuitry was flow tested to generate flowrate versus pressure drop data and compare them with the original design. The results showed that the overall measured flowrates were lower than the design intent for the given pressure differences. The test results obtained in the laboratory were also compared with the test data obtained at Evendale.

Although the original plans called for the flow testing of cast first- and second-stage nozzle and first- and second-stage bucket components, the only cast component to be flow tested in 1997 is the second-stage bucket. In preparation for these flow tests, the SLA model of the bucket-cooling circuit was used to determine the location of the static pressure taps. The second-stage bucket design staff transferred the YFT cooling-circuit flow model, and the model was run for the low-pressure air flow test conditions to evaluate the relative pressure drops and the flowrates involved in the testing. The vendor supplying the cast sample bucket will EDM-drill the static pressure taps.

\section{Plans for Next Quarter}

The necessary flow tests and static pressure distribution measurements for the second-stage bucket will be performed.

\section{Technology Application}

The flow and static pressure distributions results obtained with the cast components will verify the design flow model predictions and ensure that the predictions are correct and that there are no regions that have friction and head loss factors different from the design assumptions. 
Section 2.2.3.6 (GTETEH) Surface Roughness and Combustor-Generated Flow Effects on Heat Transfer

\section{Objective}

The effects of TBC surface roughness on external heat transfer will be characterized using flat plates tested in an atmospheric wind tunnel. An advantage of flat plates over airfoils is that TBCs can be applied easily and polished to uniform thickness and surface finish. Full mapping of the TBC surface topography will be performed. Reynolds numbers will span those expected in the ATS turbine inlet nozzle surface away from the leading edge. Tests will include plates with and without leading edge step heights to model the effects of component interface misalignments. Verification tests on airfoil replicas will be performed.

\section{Progress 4Q96 through 3Q97}

Six test plates were prepared. Each stainless steel test coupon was instrumented with several pairs of thermocouples arranged to form heat flux gauges. The test plates were installed in a cold-flow wind tunnel and heated from the backside via embedded cartridge heaters. The test side of each plate was coated with the baseline TBC system, consisting of MCrAlY bond coat and air-plasma-sprayed (APS)YSZ top coat. One plate was left as an uncoated metal surface and served as the smooth baseline test piece.

The test wind tunnel was designed and fabricated so that the test plates could be removed easily for detailed surface preparation and/or polishing. In addition, the design allowed for the provision of an adjustable step in the flowpath to simulate the expected component interfacial steps in the ATS turbine. Cold air flow was provided over the heated test plates inducing a heat flux through the thickness of the plates, including the TBC, which was transferred to the air via convective heat transfer. An imaging infrared camera system was used to capture the steady-state surface temperature map of the entire plate, either metal or TBC surface. Separate calibration tests determined the individual heat flux gauge responses as a function of temperature level. The convective heat transfer coefficients were obtained for TBC surfaces of various roughnesses using the measured heat fluxes, the measured surface temperatures, and the measured air pressure, temperature, and mass flowrate.

Test conditions were varied to cover a representative range of flow Reynolds numbers, surface roughness, and step height-to-momentum boundary layer thickness ratios. Two TBCcoated plates and one hydraulically smooth metal plate were tested. Plate average Reynolds numbers ranged from 400,000 to $3,000,000$. TBC surface roughness levels ranged from 1 to 10 microns (40 to 400 micro-inches). Step height-to-momentum boundary layer thickness ratios from 0 to 20 were tested for each roughness level. Repeatability was found to be very good for the metal plate results, and satisfactory for the TBC-coated plate results.

\section{Plans for Next Quarter}

The experimental data will be analyzed and reported. A summary of design recommendations will be presented to the turbine design team, including any suggested follow-on efforts. 


\section{Technology Application}

Data obtained from this task affects the design of turbine airfoils in two ways. Tests that measure the effect of TBC surface roughness on external heat transfer will be used to determine the extent of necessary polishing for new parts, and detailed quantification of the magnitude of heat transfer associated with actual, not modeled, TBC roughness will allow for greater accuracy in the initial design of airfoils. The data obtained on flowpath steps will be used directly in the design of the turbine nozzle sidewalls to assess the impact and consequences of heat transfer enhancement due to steps, including the effect of TBC roughness as a possible mitigating factor.

\section{Section 2.2.3.6.1 (GTETEH) S1N Heat Transfer for Production Aero with TBC Spall Effects}

\section{Objective}

The objective of this task is the quantification of the external heat transfer coefficient distribution for the production aerodynamic design definition of the ATS turbine inlet nozzle airfoil.

A previous task begun in Phase 2 and completed under Phase 3 quantified the external heat transfer distributions for the original aerodynamic design, including effects due to roughness and turbulence intensity. The production aerodynamic design is sufficiently different in crucial regions to warrant a new series of tests, again including roughness and turbulence intensity effects. The new aerodynamic definition for the nozzle is specifically designed to lower the heat load on the airfoil. Results from the previous cascade tests are being used on the new airfoil design, but with the assumed validity of local Reynolds number scaling of heat transfer coefficients. Since such scaling of results has no experimental basis for airfoils that deal with complex flows, it was necessary to verify the new design.

\section{Plans for the Next Quarter}

This task has been completed.

\section{Technology Application}

The results from this series of tests yielded external heat transfer load validation on the production first-stage nozzle design.

\section{Section 2.2.3.6.2 (GTETEH) Surface Roughness Effects on Heat Transfer}

\section{Objective}

The external heat loading for the ATS first-stage nozzle airfoil is heavily dependent upon the nonlinear effects of surface roughness, especially as the nozzle design cannot rely upon film cooling. Given the current state of turbine cooling technology, the only viable method for determining the nozzle heat load with roughness effects is experimental validation of the heat transfer distribution under non-dimensional engine-representative conditions. 
The ATS Turbine Inlet Nozzle Cascade has been used to provide data on external heat transfer coefficients on airfoils with surface roughness. The cascade incorporates instrumented airfoils with flow conditions representative of the ATS inlet nozzle geometry. The appropriate non-dimensional parameters for dynamic similarity are close to those of the engine inlet nozzle. External heat transfer coefficient distributions are measured through the use of embedded thermocouples, with a constant surface heat flux condition supplied by thin-foil heaters. Surface roughness elements of the appropriate size and distribution were bonded onto the surface heaters. Data inclucle various roughness levels, distributions, and types to allow the calibration of predictive methods. Characterization of surface roughness effects includes the interactive nature of roughness with fluid dynamic conditions such as acceleration. The cascade has also been used to assess the effects of transition piece wake shedding on airfoil heat transfer, the effect of extreme surface roughness representative of as-sprayed thermal barrier coatings, and the effect of modeled coating spallation on heat transfer enhancements.

\section{Plans for Next Quarter}

This task has been completed for the current cascade airfoil configuration.

\section{Technology Application}

The test results were used directly in the design of the ATS first-stage nozzle airfoil. Thus the cascade conditions for an appropriate rough surface condition, with elevated freestream turbulence intensity from a DLN combustor mockup, were used as the convective heat load definition for the nozzle airfoil. Since modeled spallation heat transfer enhancements were equal to or below the assumed enhancement levels for the nozzle design, the conservative nature of this portion of the design was verified. Cascade testing verified the requirement to polish the thermal barrier coating on the Full Scale Nozzle Cascade instrumented airfoils, thereby avoiding potential test problems in that task. The optimal relative location for the transition piece endwall segments, as determined through cascade testing, was incorporated into the turbine design.

\section{Section 2.2.3.7 (GTETCP) LCF Coupon Tests}

\section{Section 2.2.3.7.1 (GTETCP) $\amalg$ CF and Crack Propagation Rate Tests}

\section{Objective}

The E-beam high thermal gradient test facility will be used to test several nickel-based superalloy (N5) coupons for low cycle fatigue (LCF) durability. The coupons will be geometrically representative of a section of the turbine inlet nozzle airfoil containing hot and cold sides. Coupons will be instrumented for the evaluation of thermal conditions during testing. Tests will be performed to evaluate metal durability under conditions of temperature, thermal gradient, and stress representative of the ATS turbine inlet nozzle. Testing will be cyclic, developing cycles of exposure on the test coupons considered representative of engine cycles. Post-test evaluations of the TBC and metal conditions will be performed. Data will provide a basis for LCF life evaluations. 
In addition to the high thermal gradient testing of superalloy coupons for LCF durability, this task will also assess the crack propagation rate of N5 in the presence of steam. This will be done in two ways: (1) isothermal, mechanically loaded testing of tubular specimens through which steam is passed and (2) high thermal gradient testing of a tophat specimen in the presence of steam. Post-test evaluations of the metal conditions will be performed. Data will provide a basis for LCF life

\section{Progress for this Quarter from 4 Q96 report}

The E-beam high thermal gradient test rig was brought back on-line after a lengthy down period resulting from power problems within the transformer array of the rig. An additional problem was encountered in the high voltage supply cable connecting the rig transformers to the E-beam gun. A replacement cable was installed after a short downtime.

\section{LCF Testing}

Testing of LCF tophat specimens was resumed during this period with the first two of a set of specimens to be processed without single-point turning or other machining; i.e., the tophats are cast-to-dimensions and the TBC applied as in the turbine design process. The conditions for LCF testing in this facility exceed the ATS turbine inlet nozzle design conditions for substrate/bond-coat interface stress but fall short of causing the quick plastic deformation seen in early specimens. Both specirnens completed well over 3000 cycles of exposure with no apparent damage to the metal or TBC.

An analysis was run to determine test conditions for a tophat fillet specimen. The analysis is a pre-test prediction of thermal boundary conditions required to match design temperature and stress levels in the fillet. The analysis required that the tophat fillet specimen design be modified. The fabricated fillet specimen was instrumented with thermocouples. The specimen was given a coating that was found in previous tests to be a good qualitative guide to the location and magnitude of the strain pattern developed in the specimen. Tests were conducted that verified the strain pattern. E-beam cyclic testing of this specimen was initiated.

Superheated steam can now be supplied to the tophat test rig as coolant. All facility work to enable this upgrade is complete.

\section{LCF Metallographic Evaluations:}

Evaluation of an LCF specimen that completed approximately 1850 cycles of E-beam testing was completed. One purpose of the evaluation was to help understand a mechanism that was proposed for the loss of TBC. Metallurgical examination of other tophat specimens is underway.

\section{Plans for Next Quarter}

Cyclic testing of the fillet specimen will continue. Metallurgical evaluations of completed specimens will also continue.

\section{Technology Application}

The results of the tests conducted as part of this task will be used as a basis for LCF life evaluation of the first-stage nozzle and first-stage bucket for the ATS gas turbine. 


\section{Section 2.2.3.8 (GTETSP) Steam Particulate Deposition}

\section{Section 2.2.3.8.1 (GTETSP) Steam Particulate Deposition Rig Testing Objective}

The objective of this task is to measure the rate and location of steam particulate deposition in bucket tip turns and in two heat transfer structures to be employed within the ATS gas turbine nozzles and buckets. The information is to be translated into a steam purity specification and full-filter specification for the ATS gas turbine. The approach employed is to use gas turbine combined cycle (GTCC) steam flowing in series through a special filter specified for the ATS gas turbine, then through the tip turns in a specially constructed centrifugal deposition rig, and finally through two static specimens consisting of turbulated and impingement-cooled specimens. Amounts and locations of deposits in these specimens will be used to verify the predicted time-between-outages results from ATS Phase 2 studies.

\section{Progress 4Q96 through 3Q97}

\section{Steam Filter Performance}

The steam filter exposure continued through $2 \mathrm{Q} 97$ when it was taken off-line for another examination after the centrifuge startup trials. The filter cartridge remained unchanged, and there was no change in its filtration performance after over 8,000 hours of steam exposure. In general the element had a mild discoloration due to thermal exposure, but there was no observable material degradation. Earlier the filter had been shown to be resilient to small deformations, even after exposure. This filter design was carried forward to steam system design.

\section{Static Specimen Results}

The static specimens, impingement and turbulated, installed in 1996 were on-line for 31 and 38 weeks, respectively, with few outages. The specimens were again taken off-line at the end of 1Q97, when the steam system to which they were connected was shut down for a 7-year overhaul.

During 2Q97 the specimens were examined by borescope and sampled using remote manipulators in order to leave the specimens available for further exposure and to avoid disturbing any deposits as much as possible. The borescope analyses were recorded to videotape, and any removable deposits were analyzed for $\mathrm{Cr}, \mathrm{Mo}$, and $\mathrm{Fe}$, since the plant superheater tubes were $2.25 \mathrm{Cr}$, $1 \mathrm{Mo}$, balance $\mathrm{Fe}$.

The impingement specimen (portion of first-stage nozzle cooling) was very clean with no removable deposit observed at all. Only a slight darkening of the target wall adjacent to the distributor holes showed any relationship between the holes and the adjacent wall; that slight darkening was approximately the same diameter as the holes and was not removable.

\section{Centrifuge Startup Attempts}

The centrifuge apparatus went through three startup attempts with seal modifications before the last two. In the first case, the steam leakage was much too high to allow continuous running; in the second, the steam leakage was lower, but the machine rotating resistance was 
too high when steam was applied to the shaft. This resistance behaved as if the shaft was expanding to the carbon gap seals, forcing them to rotate until the steam pressure locked them to the stator. It was decided to make the system available for brush seal tests (reported on in Section 2.2.4.14.2, Brush Seals Development for Steam Box) in 3Q97 and 4Q97. The deposition tests may resume with brush seals used in place of the carbon clearance seals.

\section{Plans for Next Quarter}

The steam seal test will be completed. A decision will then be made whether or not to refit the centrifuge with new brush seals on both sides of the rotor and restart the deposition test series. At the conclusion of the testing program, the piping facility will be removed from the power plant and stored for possible future use. Consultation with the ATS plant systems design team will continue through $4 \mathrm{Q} 97$.

\section{Technology Application}

Data from tests under this steam particulate deposition task will allow for the necessary steam filter specifications to be established. The proper particulate filtering of steam used for bucket and nozzle cooling is critical to the reliable long-term operation of the ATS gas turbine.

\section{Section 2.2.4 (GTMT) Materials Technologies}

\section{Section 2.2.4.1 (GTMTSE) Steam Effects on Mechanical Properties}

\section{Objective}

The objective of this task is to evaluate the candidate turbine materials for any effects due to operation in a steam environment. Tests of materials that are exposed to steam will be performed to measure fatigue crack propagation, low cycle fatigue (LCF), and creep. Additional tests deemed necessary to meet design criteria will be performed. Comparisons will be made to data collected in air. Where necessary, the program will evaluate the roles of alternate heat treatments and/or surface treatments.

\section{Progress 4Q96 through $3 Q 97$}

An internal, interim report was issued that documents a disk and wheel lifing criterion based upon smooth bar low cycle fatigue (LCF) test results collected on IN718 for this program. A number of mechanical property behavior curves were assembled for IN718 and prepared for official communication to Design Engineering. Fatigue crack growth rate (FCGR) testing of the first piece qualification (FPO) turbine wheel material was conducted. Optical microscopy, scanning electron microscopy (SEM), transmission electron microscopy (TEM), and auger analysis continued to be used to examine the fracture surfaces of the various test specimens.

Work was initiated and conducted throughout the reporting period on studying the effect of environmental conditions on the welded and brazed joints that will be used with the hot gas path materials. Slow strain rate tests (SSRT) were used to discriminate between various joint processing options. Test matrices to provide handbook data were completed. Construction of test specimens was initiated as sample material became available. Additional material to support test specimen fabrication was expedited from the investment casting foundries. 
SSRT tests were conducted with the rotor steam delivery materials to permit discrimination of various manufacturing process options. Optimum conditions were identified. Testing in steam was impeded by some test rig issues. Modification of the test specimen permitted collection of an initial sampling of LCF data.

Various types of mechanical test specimens for the hot gas path materials were machined during this reporting period. They included: crack growth, creep, and LCF specimens for the second-stage bucket material; crack growth, creep and LCF specimens for the first-stage bucket material; and crack growth, creep, and LCF specimens for the second-stage nozzle material. The LCF specimens made from the first-stage bucket material were machined from cast slabs intentionally produced with casting defects. Testing was initiated on many of these specimens. Initial data were analyzed to identify any unique trends.

\section{Plans for Next Quarter}

Machining of mechanical test specimens from the third-stage nozzle material will be initiated, and the following activities will continue:

- Steam dynamic crack growth rate threshold testing of additional samples of IN718 designated "Ingot 4"

- Fabrication of high priority welded and brazed joints to permit characterization of mechanical properties hot gas path material joints

- SSRT tests of these joints to identify areas of subsequent analysis and initiate LCF testing

- Crack growth, creep, and LCF testing of hot gas path material specimens in steam

- LCF testing of rotor steam delivery material specimens

\section{Technology Application}

This task will evaluate the behavior of turbine materials in a steam environment in order to account for the introduction of steam cooling.

\section{Section 2.2.4.2 (GTMTSO) Oxidation Due to Steam}

\section{Objective}

Testing of ATS materials in steam will be performed to evaluate the long-term oxidation responses to this environment. Specimens will be subjected to steam exposure in an autoclave and removed at specified intervals for examination of oxidation characteristics.

\section{Progress 4Q96 through 3Q97}

Tests of four point bend specimens were conducted very early in this reporting period. No unique anomalies were identified in the results. Preliminary results were found to be adequate.

\section{Plans for Next Quarter}

This task has been completed. 


\section{Technology Application}

This task was designed to evaluate the static behavior of turbine materials in a steam environment in order to take into account the introduction of steam cooling.

\section{Section 2.2.4.3 (GTMTCE) Corrosion Rate Evaluations of Airfoil Overlay Coatings}

\section{Objective}

The objective of this task is to evaluate the performance of ATS materials in potentially corrosive environments with various overlay coatings and substrate materials. Initial evaluations will be performed in small burner rigs with known contaminants. This will allow ranking of the corrosion rates of materials and coatings. Subsequent testing will be performed in facilities that better simulate gas turbine service conditions, including high gradients, for confirmation of burner rig results.

\section{Progress 4Q96 through 3Q97}

During each quarter of this reporting period, approximately 2000 additional hours of exposure time accumulated on the coated samples still running in the high-temperature oxidation burner rigs. Metallographic evaluations were performed on the few pins that were removed from test. Strain-to-crack tests continued, with the objective of permitting relative ranking of the oxidation results and subsequent comparison with field performance results to validate this testing approach to new coatings.

\section{Plans for Next Quarter}

Burner rig testing will continue. Strain-to-crack testing at various temperatures on all coating compositions of interest will continue. Test data will be analyzed and the results correlated with observations made on field-tested parts.

\section{Technology Application}

This task will evaluate potential airfoil coatings in environments that reflect planned ATS turbine operating conditions.

\section{Section 2.2.4.4 (GTMTBV) Compressor Blades and Vanes Materials and Processes}

\section{Objective}

Although material selections have been completed, this task will examine potentially less expensive materials for use in blades and vanes in the latter stages of the ATS compressor. These evaluations of alternate materials will be based on results of tests of mechanical properties, with emphasis on high cycle fatigue (HCF) properties. For the materials that have been selected, tests of critical properties will be conducted under ATS-specific conditions. Component tests of select parts will be conducted for life verification purposes and establishment of final manufacturing parameters. 


\section{Progress 4Q96 through 3Q97}

Two remaining creep tests were concluded very early in this reporting period. Handbook property curves were issued for all of the blade and vane materials that will be used in the ATS turbine. All metallurgical work in support of this activity was completed.

\section{Plans for Nert Quarter}

This task has been completed.

\section{Technology Application}

This task characterized the mechanical behavior of existing and new blade/vane materials in more aggressive environments than past compressor operation.

\section{Section 2.2.4.5 (GTMTVG) Compressor Variable Guide Vane System Design Support and Process Development}

\section{Objective}

Information to support selection of materials for the variable guide vane (VGV) bushings and thrust washers will be gathered to ensure a robust and reliable design. Testing will be conducted to confirm materials selections, cover any parameters outside of existing data, and gather data for new materials.

\section{Progress 4Q96 through 3Q97}

The candidate bushing and washer materials completed the impact tests and oscillating wear tests. A report was written and the results were discussed with Design Engineering.

\section{Plans for Next Quarter}

This task has been completed.

\section{Technology Application}

This task provided operational test data on ancillary materials used in the variable guide vane system. Potential bushing and sleeve materials will be screened.

\section{Section 2.2.4.6 (GTMTCS) Compressor Structural Materials and Processes}

\section{Objective}

Mechanical and physical property tests will be performed on ATS compressor structural materials to provide an expanded mechanical and physical property database for design validation and enhancement. Material processing parameters for prototype manufacturing of the components will be selected based on design requirements and discussions with vendors. When necessary, material and processing specifications will be modified or new ones written. 


\section{Progress 4Q96 through $3 Q 97$}

High cycle fatigue (HCF) testing of one of the compressor rotor wheel materials was conducted over a range of ternperatures of interest. Smooth and notched bar tests were conducted at two mean stress levels. The test program was completed and the first draft of the final report was submitted to Design Engineering. GE continued technical support of the diffuser supplier to address manufacturing issues discovered during the casting of the prototype diffuser. Over the course of this reporting period significant progress was made in enhancing the process to improve the internal soundness of the castings. A test matrix to evaluate low cycle fatigue (LCF) of material that reflects modified processing of the diffuser casting was defined.

\section{Plans for Next Quarter}

The final compressor rotor wheel material HCF report will be submitted to Design Engineering. Refinements in the diffuser casting process will be supported, as warranted. The LCF test matrix for diffuser casting material will be completed and a report issued to Design Engineering.

\section{Technology Application}

This task will continue characterization of compressor structural materials in test conditions that reflect service environments.

\section{Section 2.2.4.7 (GTMTRF) Turbine Rotor Forging Materials and Processes}

\section{Objective}

Processing parameters of forged large turbine rotor components will be optimized to achieve the desired forging attributes. These parameters include chemistry and processing temperatures as well as post-processing surface treatments. Sub-size and full-size forgings will be produced to verify and evaluate the processing approaches, and forging supplier process plans will be developed for all components. Forging acoustic properties will be determined by ultrasonic testing on test block and prototype parts. The attenuation, anisotropy, frequency bypass, and signal-to-noise ratio will be measured and used in fracture mechanics analyses to support rotor design. Optimized inspection methods, any necessary software, and scan plans will be developed based on the work with prototype parts. Property evaluations will be conducted to ensure that material behavior models used for design accurately reflect those achieved in parts made by the manufacturing process selected.

\section{Progress 4Q96 through 3Q97}

GE ultrasonic evaluation of the rotor forgings was completed. Work was initiated to correlate the ultrasound results to specific features in the forgings. Analyses of these test results and subsequent disposition of each of the forgings were completed. Sensitivity studies on the machining of the wheel material were completed and the results were used to modify the processing to be more robust.

Smooth bar low cycle fatigue (LCF) tests with two hold times and at two different temperatures were conducted. Handbook LCF curves were issued to Design Engineering. 
Additional creep, tensile, crack growth rate, and static and dynamic crack growth rate tests were conducted on samples of the wheel material that were taken from various forgings. Relaxation tests were completed on material removed from several locations in the forgings. Test results were communicated to Design Engineering.

\section{Plans for Next Quarter}

Exploration of the correlation of ultrasound results to features in the forgings will continue. Crack growth rate tests, creep rupture tests, LCF tests, and static and dynamic crack growth rate tests will continue. As appropriate, the Handbook curves will be updated on the basis of the results of these tests.

\section{Technology Application}

This task will enhance process capabilities for manufacture of turbine rotor forgings.

\section{Section 2.2.4.8 (GTMTRS) Turbine Rotor Spoolies and Transfer Devices Materials and Processes}

\section{Objective}

Although material selections for the cooling system delivery systems have been completed, this task will perform testing to verify properties and identify potentially better materials. Any applicable or needed coatings or joint materials will also be identified. Procedures for joining delivery components together and inspecting them will be evaluated.

\section{Progress 4 Q96 through $3 Q 97$}

Machining of sheet specimens intended for tubing material property evaluation was completed. Tensile, creep, and fatigue specimens for both the parent and welded material were machined. Sheet specimens for spoolie material property evaluation were obtained from the spoolie vendor and were machined. Tensile testing of tubes was completed. The results confirmed earlier work conducted on sheet specimens. An evaluation of various surface treatments to enhance the properties of the steam delivery tubes was completed. The tests highlighted the incremental benefit that could be obtained with each of these treatments. The results will be used to fine tune the manufacturing processes for these parts.

Manufacturing Process Plans (MPPs) were reviewed for the various rotor steam delivery components. Comments were forwarded to the suppliers and the processes refined. New part specifications were written for several components.

Block-on-shoe wear testing of eleven candidate spoolie coating systems was completed. Initial shakedown testing was completed in an air environment. Eleven coating systems were tested in conditions representative of the planned operating environment. Good performers in this group exhibited a significant reduction in the frictional forces in the first 10,000 cycles of the test. They also had well-developed wear scars and little galling. Poor performers had frictional forces as high as the uncoated base metal. The top five performing coating systems from this initial screening test were tested in more rigorous conditions to permit discrimination of the wear behavior. In this second round of tests, only two coating systems were able to reduce the frictional forces through the course of the test. As a result of this work, these two materials 
were selected to reduce friction and wear in the rotor steam delivery system. Material and process specifications were issued for these materials. Supplier qualification efforts were initiated.

Block-on-shoe fretting testing of five candidate coating systems was initiated. The fretting rig was assembled and an initial shakedown test was completed in an air environment. Adjustments were made to the test parameters.

\section{Plans for Next Quarter}

Mechanical property tests will continue on specimens made to simulate the final configuration of the processing of the steam delivery hardware. A test program to define the sensitivity of material properties to specific options in the thermal processing of the parts will be initiated. Discussions will continue with suppliers to refine processes in accordance with metallurgical requirements to optimize the processes. Supplier qualification support will continue. Fretting tests will be completed. Options for attaining desired surface finishes on coated parts will be examined.

\section{Technology Application}

This task will develop processes and mechanical property data to optimize steam delivery hardware manufacture and subsequent operation.

\section{Section 2.2.4.9 (GTMTSB) Structural Bolting}

\section{Objective}

Mechanical and physical property tests on two high-strength bolting materials will be conducted at ATS turbine conditions. If required, manufacturing trials will be conducted to optimize forming processes.

\section{Progress 4Q96 through $3 Q 97$}

Stress relaxation tests were conducted on several heats of three different bolting materials. The final set of specimens was recently loaded in the test rigs. Additional baseline material was ordered for the stress relaxation program. Preliminary results on the influence of preconditioning on the subsequent stress relaxation response of one of the compressor bolting materials were obtained.

\section{Plans for Next Quarter}

Collection of long-term stress relaxation data will continue, and the influence of preconditioning on stress relaxation response will be investigated further.

\section{Technology Application}

This task will increase the database for flange/flange and wheel/wheel bolting applications. 


\section{Section 2.2.4.10 (GTMTTA) Turbine Airfoils Materials and Processes}

\section{Objective}

Microstructure and mechanical properties will be evaluated for full-sized castings processed in this program. A comprehensive program will yield final specifications with appropriate heat treatments and will quantify the effects of ATS airfoil geometry and structure/property variability. Casting processes will be developed for all airfoils by employing developmental casting trials. Critical nozzle and bucket long-term material properties will be measured at elevated temperatures. Metallic coating systems will be developed for internal and external oxidation protection of the airfoils. Samples will be coated using various techniques for optimization studies and process verification.

\section{Progress 4Q96 through $3 Q 97$}

Low cycle fatigue (LCF) tests on first-stage bucket material containing casting defects were conducted at five selected temperatures. Creep and high cycle fatigue (HCF) tests on firststage bucket material containing casting defects were conducted at one selected temperature. The defect types tested included low- and high-angle boundaries at various angles of misorientation. LCF tests were also conducted on second-stage bucket material containing casting defects. The defect types being evaluated in this material include emergent grains and misoriented grains. LCF tests were initiated on hot isostatically pressed (HIPed) second-stage bucket material at two selected temperatures. The effect of HIPing will be compared with baseline data from un-HIPed material. HIPing evaluations were also initiated on the secondstage nozzle material.

Tensile, creep, and LCF tests were initiated on the third-stage nozzle material at various temperatures and stresses. These tests are part of a full-scale design data program that includes testing of various physical properties, oxidation and hot corrosion testing, and crack growth testing. Additional cast slabs of this material are on order.

Preliminary design curves were issued for first- and second-stage bucket materials with defects.

A test matrix was agreed upon to evaluate the material behavior of welded and brazed airfoil joints. The material was not received for testing until late in $3 Q 97$.

\section{Plans for Next Quarter}

Additional LCF tests on defect-containing first- and second-stage bucket material will be conducted. Creep and LCF tests on the third-stage nozzle material will continue. Long-term creep tests on various bucket and nozzle alloys will continue. Tests will be concluded and analysis of results of HIPing evaluations on the second-stage bucket and second-stage nozzle materials will be completed. Fabrication of welded and brazed airfoil joints for mechanical testing and testing of the high priority joints listed in the test matrix will be initiated.

\section{Technology Application}

This task will enhance the database of mechanical properties at service conditions for bucket, nozzle, and shroud materials. 


\section{Section 2.2.4.11 (GTMTCB) Combustion Materials and Processes}

Objective

Properties of materials for combustion components will be evaluated at ATS conditions.

\section{Progress 4Q96 through 3097}

Discussions were held with Design Engineering to determine test needs. A test matrix for evaluation of sheet material with tensile, creep, and low cycle fatigue (LCF) of welded structures was agreed upon. Two materials were selected for evaluation. Test material arrived very late in this reporting period and did not support the original test plan schedule.

\section{Plans for Next Quarter}

Test material will be sent to machining and, subsequently, to testing suppliers. Tensile and LCF testing will be initiated.

\section{Technology Application}

This task will enhance processes and mechanical property data to optimize combustion hardware manufacture and subsequent operation.

\section{Section 2.2.4.12 (GTMTST) Turbine Structures Materials and Processes}

\section{Objective}

Producibility evaluations for the turbine structures will include selection of materials processing parameters and chemistry, and preparation of material and process specifications. Processing trials will be used to confirm producibility and verify capabilities of suppliers. Testing will be conducted where necessary to evaluate the materials under ATS conditions.

\section{Progress 4Q96 through 3Q97}

Several producibility reviews were held with suppliers. A number of process specifications were revised to include acceptance requirements for the ATS turbine components. Process refinements were evaluated and pursued with suppliers as need warranted. Iterative evaluation of supplier capabilities with Design Engineering was concluded. Special attention was given to manufacturing process selection for the manifold adapter castings and the torque shaft. All outstanding issues related to process, establishment of acceptance requirements, and qualification requirements were resolved. Drawings for all major turbine structure components, including the third-stage diaphragm machining drawing, third-stage inducer machining drawing, and fourth-stage shroud, torque shaft, and steam gland were reviewed and approved.

\section{Plans for Next Quarter}

Support of the suppliers' metallurgical activities will continue and first piece qualification (FPQ) results will be reviewed as they become available. 


\section{Technology Application}

This task will continue characterization of turbine structure materials in test conditions that reflect service environments.

\section{Section 2.2.4.13 (GTMTSH) Trurbine Shells}

\section{Objective}

Materials and processes will be identified for production of the turbine shells. Specifications will be defined after material property testing and process verification/optimization trials are conducted to achieve the best quality part to meet all design criteria.

\section{Progress 4Q96 through 3Q97}

Several producibility reviews were held with suppliers. Various process specifications were revised to include acceptance requirements for the ATS machine components. Process refinements were evaluated and pursued with suppliers as needs warranted. Iterative evaluation of supplier capabilities with Design Engineering was concluded. Manufacturing Process Plans (MPPs) were reviewed for the inner turbine shell and the outer turbine shell. Work was done with the supplier on needed refinements to welding procedures.

\section{Plans for Next Quarter}

The final weld and inspection plans from the supplier will be reviewed and a determination made as to whether any additional development work is required.

\section{Technology Application}

This task will enhance characterization of turbine shell materials in test conditions that reflect service environments.

\section{Section 2.2.4.14 (GTMTSR) Seal Technology}

\section{Objective}

Improved gas path seals will be developed for the ATS turbine utilizing seal technology developed for aircraft engine components where applicable. The technology will be evaluated using developmental hardware and samples.

\section{Progress 4Q96 through 3Q97}

All metallurgical work on this activity has been completed.

\section{Plans for Next Quarter}

This task has been completed.

\section{Technology Application}

This task optimized seal attachment processes focused on airflow leakage restrictions to enhance performance. 


\section{Section 2.2.4.14.1 (GTFFTSESV) Hot Gas Path and Transition Piece Cloth Seals}

\section{Objective}

Seals between the hot gas path turbine components are required to help meet the ATS combined cycle efficiency target. One objective of this task is to develop and test hot gas path seals that meet both leakage performance and life requirements. Specifically, improved sealing performance that reduces the equivalent gap of the seal is sought by replacing the current Q-tip seals with a cloth sealing system. The cloth seals also need to meet the same full-life requirement.

Seals between the combustor transition piece and the first-stage nozzle are required to help meet the ATS combined cycle efficiency target. The other objective of this task is to develop and test transition piece cloth seals that meet both leakage performance and life requirements. Specifically, advanced cloth seals will be developed for the transition piece/first-stage nozzle junction. Life consistent with the prescribed inspection interval is required.

\section{Progress 4Q96 through $3 Q 97$}

\section{Hot Gas Path Cloth Seals}

Extensive testing was done to identify the best cloth material and weave with respect to wear, sealing, and formability considerations, and detailed FEM analysis of various shim designs was done. Based on test and analysis results, a particular weave of a cobalt-based superalloy cloth and a nickel-based shim were selected for the seal. Typically, a cloth seal comprises a pair of high-strength shims sandwiched between two layers of cloth. The high-temperature "Shoebox" rig at CRD was used to test various seal designs over a range of controlled gap, offset, and mismatch conditions typical of those encountered between mating members in a turbine. After a number of designs were evaluated under controlled conditions of pressure and misalignment, a single-shim, crimped cloth seal was selected.

The relatively stiff strip (dogbone) seals now used for hot gas path sealing cannot be bent or curved easily for comer leakage applications. In current turbine designs, a typical inner+outer shroud arrangement uses straight seal segments that meet at corners, and there is usually leakage between segments. Because of their flexibility, cloth seals permit the design of continuous, curved sealing sections. Tests at ATS gas turbine conditions of temperature, pressure, and pressure drop were conducted on corner junctions using both continuous curved cloth seals and segmented straight seals. The continuous curved seals performed better than the straight two-piece corner junctions in all tests.

High-temperature oxidation tests of the seal material were also conducted. Many candidate superalloy samples were tested in both wire and sheet forms. A few of the materials that appear to work well under ATS gas turbine conditions will have to be investigated to evaluate seal producibility.

\section{Transition Piece Cloth Seals}

The first-stage nozzle undergoes large (thermal) motion relative to the transition piece end frame under various machine conditions (e.g., fire-up; full speed, no load; steady-state). The cloth seal is required to maintain contact at the joint under all these conditions without yielding. In addition, under repeated load-unload cycling, the seal materials (cloth, shim) are 
expected to retain their functional properties (wear resistance, elasticity). The seal and shelf contour geometries were carefully selected to achieve these objectives. Finite element analyses were conducted to ensure that there will be no material failure.

Extensive high-temperature wear tests were conducted between standard cloth samples and corresponding solid surfaces representing the mating surface (shelf). On the basis of the results of these tests, materials were selected for the cloth and shim portion of the seal.

The tests that were performed were used to aid in selecting appropriate seal materials. Hightemperature low cycle fatigue (LCF) testing and high-temperature material characterization testing are being done on the fabricated seals to evaluate their performance. A special hightemperature rig and oven were fabricated for the LCF test.

High-temperature leakage tests were conducted on the outer cloth seal using the Shoebox rig, which measures seal leakage under controlled conditions of pressure, pressure drop, and temperature of a "standard" length seal sample. Seal leakage was considerably lower than the leakage measured with conventional "Floating Seals."

\section{Plans for Next Quarter}

\section{Hot Gas Path Cloth Seals}

The seal/slot thermal analysis will be completed. Detailed reports on all seal testing and analysis will be written.

\section{Transition Piece Cloth Seals}

The LCF tests will be completed. Detailed reports on seal design development, analysis, hightemperature leakage tests, and material characterization tests will be written.

\section{Technology Application}

A turbine stator (shroud) is built up of several annular segments that are packed together at circumferential and axial junctions. The junctions between these segments need to be sealed in order to minimize leakage and maintain high efficiency. Typically such junctions have slots on the mating edges. Seals are used in the slots, bridging adjacent members, to block off any leakage. Current turbine designs do not have any seals for the curved, circumferential junctions. Straight, axial junction (dogbone) seals are used in some newer machines. Cloth seals provide the capacity to reduce seal leakage significantly.

\section{Section 2.2.4.14.2 (GTETBS) Steam Gland Brush Seals}

\section{Objective}

Brush seals will be developed to minimize steam leakage in the steam gland. Leakage reduction will increase the efficiency of the ATS gas turbine. The successful implementation of brush seals in the steam gland will also allow for a reduction in the axial length of the steam gland. The shorter length will result in a manufacturing cost reduction. 


\section{Progress 4Q96 through $3 Q 97$}

There are two seal locations to be considered: aft of the steam scroll is a leakage flow with a low-pressure drop; forward of the scroll is a leakage flow with a high-pressure drop. A singlestage brush seal design was developed for the first location and a two-stage brush seal for the second. Static leakage tests were used to determine the leakage performance under operating conditions. Computational fluid dynamics (CFD) modeling was used to design the geometry of the two-stage seal. Since most wear is assumed to occur during transients, the wear life is being determined by testing under conditions based on extreme transient conditions. The design will be validated by sub-scale rotary tests under operating conditions.

The objective of the interstage geometry design for the two-stage seals is to ensure that the flows exiting the first stage do not damage the second-stage seal. The jet velocity must be attenuated and the flow along the upstream bristles of the second stage must be radially inward rather than outward.

The CFD modeling work has shown that a space of at least $38.1 \mathrm{~mm}$ (1.5 inches) between the last labyrinth tooth and the second-stage brush is enough to ensure favorable flows into the second-stage brush. The seal is designed with a space of $44.5 \mathrm{~mm}$ (1.75 inches) between the last labyrinth tooth and the second-stage brush. Since the flow pattern appears to be insensitive to the number of labyrinth teeth, similar flow patterns are expected in the $\mathrm{H}$ machine with 20 teeth and the steam deposition rig, which has 4 teeth.

The layout of the brush seal in the H-machine steam gland is in progress. Definition of the brush seal cross section geometry, bristle and backing plate materials, and bristle diameter is complete.

The objective of the sub-scale wear test is to determine the wear characteristics of the brush seal at machine operating conditions. The brush seal vendor completed a 20-hour sub-scale wear test of the brush seal. The predicted transient conditions in the turbine call for wear conditions that exceed the capability of the test rig. The seal-to-shaft interference in the test rig was increased in order to partially compensate for the lower pressure difference across the seal. The larger interference increases the contact pressure between the bristles and shaft. Wear rate on the brush seal was very low. No wear was observed on the IN718 rotor.

The material of the $\mathrm{H}$ machine aft stub shaft has changed to a $\mathrm{Cr}-\mathrm{Mo}-\mathrm{V}$. This will result in reduced wear rate on the brush seal bristles and a slightly increased wear rate on the shaft.

The objective of the dynamic leakage test is to measure seal leakage during rotation and to determine the durability of the two-stage seal design in a high-pressure steam environment. The steam deposition test rig was modified to accommodate a total of 4 brush seals: one brush seal set consists of unsegmented seals; the other set is segmented, with the segment end design similar to that of the $\mathrm{H}$ machine. Both sets of brush seals have 4 labyrinth teeth between the brush seal stages and a $44.5-\mathrm{mm}(1.75$-inch) space between the last tooth and the second brush seal.

Brush seals, seal holders, and a new test rig rotor were designed, manufactured, and installed in the steam deposition test rig. Modifications were made to the steam piping system to accept larger steam flow. Orifice plates and additional instrumentation were added in order to measure flow through the unsegmented and segmented brush seals. The data acquisition 
system was modified to record additional test parameters for the brush seal test. The brush seal test is currently underway.

\section{Plans For Next Quarter}

The dynamic leakage test will be completed and the durability of the seal design will be verified. Wear data from the brush seal will be obtained. Layout of the brush seals in the ATS turbine steam gland will be completed.

\section{Technology Application}

The brush seals will be used in the first machine by nesting the brush seal within the labyrinth seal packings. A slot will be machined in the labyrinth seal to accept the brush seal. On subsequent machines, the steam gland can be shortened to take advantage of improved sealing and reduce the manufacturing cost of the steam gland.

\section{Section 2.2.4.15 (GTMTAR) Airfoil Repair}

\section{Objective}

Existing techniques will be evaluated and adapted for the material/geometry combinations unique to the ATS turbine airfoils to extend component life.

\section{Progress 4Q96 through $3 Q 97$}

Efforts continued to examine the repair of single crystal alloys. Samples representative of two alternative processes were created. Initial results were collected on mechanical tests. Additional development work scope was established.

\section{Plans for Next Quarter}

Studies will continue to evaluate repair methods for single crystal alloys with selection of process and subsequent optimization of parameters.

\section{Technology Application}

The ability to repair airfoils will result in more cost-effective flowpath components.

\section{Section 2.2.5 (GTTT) Thermal Barrier Coating Technology}

\section{Section 2.2.5.1 (GTTTSD) Coating System Development}

\section{Objective}

Plasma spray TBC coating processes will be developed for specific ATS combustion and turbine components. Both axisymmetric and non-axisymmetric plasma gun and part motions will be developed. Coating evaluations will consist of metallography, property measurements, and thermal cycling exposure. Computer simulations, motion trials on part replicas, and spray trials on parts will be used for improving robot path planning accuracy. Improved process monitoring will be developed to increase process repeatability and control. 
The TBC manufacturing technologies portion of the task will focus on integration and compatibility between TBC processing and other component manufacturing steps. Techniques to prepare components for spraying will be defined. Fixturing and masking will be developed. Surface finishing techniques will be developed.

The TBC process and diagnostics portion of the task will focus on achieving a better fundamental understanding of the TBC application process. Specific process conditions critical to the thickness and properties of the TBC system will be evaluated. Continuing work will focus on identifying critical-to-process characteristics (CTPs) for the ceramic top coat and metallic bond coat. The CTPs will be those directly controllable aspects of the coating process that most strongly influence process variability and TBC quality.

The TBC nondestructive evaluation (NDE) portion of the task will develop NDE techniques to measure attributes and properties of TBCs on turbine hardware that are relevant to manufacturing. The primary focus will be on development of methods to measure coating thickness. A secondary focus will be on development of methods to evaluate coating microstructure

\section{Progress 4Q96 through 3Q97}

Robot Motion Control and Part Programming Methods for Airfoils

The three FANUC Robotics M710i/RJ2 systems (two development systems located in Schenectady, NY; one production system located in Greenville, SC) were configured to assure matched performance. This included mechanical alignment, kinematics calibration, RJ2 controller setup, ROBCAD model setup, and STP motion programming.

Four methods for robotics motion control and programming were fully developed and tested. The first two methods are based on FANUC Robotics products called Teach Pendant (TP) and Karel programming. These two approaches are forms of Tool Center Point (TCP) motion control and require stationary targets in order to define motion (paths) along the 3D part surface. Motion development and testing have proven that these two approaches are inadequate because of the geometric complexity of the ATS hardware. Both nozzles and buckets require simultaneous movement of the spray tool and part motion to properly access all part surfaces and to satisfy the process requirements for surface velocity, standoff distance, and spray angle.

The other two methods are forms of inverse time motion programming which accounts for simultaneous movement of the spray tool and part motion. The first is a FANUC Robotics product called Segment Time Programming (STP) which utilizes the built-in path planning capabilities of the RJ2 controller. The second is a custom form of Inverse Time (IT) developed for GE by FANUC Robotics. Both STP and IT demonstrated motion control performance within the requirements for the ATS program. STP motion control/programming is preferred because it is a stanclard product from FANUC Robotics and is fully supported in industry.

Two off-line robotics motion modeling/programming systems were developed and tested. The first system is a Tecnomatix product called ROBCAD, which supports full 3D modeling of robotics motion with capabilities for detecting motion limits (position and velocity) and collisions. The standard ROBCAD product supports TP and Karel motion programming (TCP 
motion only). ROBCAD efforts focused on complete development and testing of inverse time modeling capabilities based on FANUC Robotics STP. The ROBCAD/STP programming tools are in place and motion development for actual ATS hardware is underway.

The second programming approach is through a custom product being developed by CRD, called Coordination through Short Motion Programming (CSMP). CSMP models robotics motion based on TP, Karel, STP, and IT programming approaches. CSMP takes into account the robotics system capabilities for motion position, velocity, and acceleration based on equipment characterization studies performed at CRD. The CSMP model incorporates the measured performance limits for the M710i/RJ2 robot system, including motion dynamics for each axis (position, velocity, and acceleration limits). The M710i/RJ2 robot system is performing very systematically and gives excellent agreement with the CSMP model. Experiments included both constant and variable speed motions performed on both a 2D airfoil replica shape and a pre-production ATS turbine nozzle. TBC process requirements relating to surface-relative velocity and gun standoff distance were met or exceeded in nearly all tests.

An ATS nozzle replica, fixture, and turntable platen were developed to support development of motion control and path programming techniques. The nozzle replica was enhanced to permit evaluation of various motion control strategies. A Visible Laser Measurement System was developed for use by the robot operator during motion verification. Precision laser targets were developed and tested for measuring velocities on buckets and nozzles. The current design works well for both airfoils and platforms; however, additional development is required to accurately measure velocities in fillets.

ATS bucket replica airfoils and fixturing were designed and drawings prepared. Three types of airfoils were designed: one for surface velocity measurements, one with internal cavities to simulate an actual bucket, and one solid bucket to determine how thermal mass affects coating quality.

Initial motion programming approaches for nozzles and buckets were selected. Designed experiments are being used to optimize motion programming for different parts.

\section{TBC Process Development for Transition Pieces}

Work was resumed on developing a process for plasma-spray production of a thick TBC for ATS transition pieces. Baseline process data were obtained using two experimental matrices, and critical process parameters were identified. Based on this information, process conditions were adjusted to obtain a range of TBC microstructures on flat plates. Improvements in TBC properties (to nearly $5 \mathrm{X}$ ) over baseline production coatings were achieved. A preliminary set of processing parameters was selected based on these results.

An ATS transition piece to be used for combustion testing was coated in the production spray cell using the preliminary process parameters. Metallography confirmed that the microstructural features of the TBC were significantly improved over conventionally processed transition piece coatings.

Funding of TBC development for transition pieces was subsequently transferred from the ATS program to an internal program in order to focus more resources toward refinement of the TBC processes for airfoils. 


\section{Bond Coat Process Development}

Testing and evaluation of protective bond coats on substrate materials to be used for first- and second-stage airfoils, shrouds, and transition pieces continued with additional furnace cycling and oxidation rig hours accumulated. Based on the data received to-date, bond coats for the first ATS hardware were selected, and specifications were written for the materials and techniques chosen.

Experiments to increase the aluminum (Al) content of the air plasma spray (APS) NiCrAlY bond coat near the substrate in order to improve oxidation resistance were conducted. Al enrichment was accomplished without formation of a continuous brittle beta-phase interlayer. The bond coats were examined in the as-processed condition and after vacuum heat treatment. Specimens were metallographically polished, examined optically, and the Al composition profile determined using a SEM microprobe. The technique was successful in enriching the Al content of the bond coat in the vicinity of the bond-coat/substrate interface. It is expected that the Al enrichment will enhance the environmental protection to the substrate while maintaining the excellent TBC durability exhibited by APS NiCrAlY bond coats.

\section{TBC Manufacturing Technologies}

A new gun tooling system was developed to provide precise and repeatable gun mounting. The gun tooling systems were installed in the three airfoil spray cells.

Evaluations and calibrations of non-robotic booth equipment were performed to assure equivalency between sites. A survey of the three sites was conducted to identify the differences in the spray procedures being used to apply TBC. The survey covered 142 different spray parameter, equipment, or procedural choices. Differences were found in the choices used for twenty of these parameters. Common settings for these twenty parameters were subsequently identified.

To establish whether the differences in spray practices caused a variation in TBC mechanical properties, sample plates were sprayed at the three GE sites. These plates were coated using the spray practices in place at each site prior to the standardization. Site-to-site differences in mechanical properties were found, but these were not ascribed to differences in spray practices between sites.

Controlled TBC surface finishing methods are being developed to ensure both acceptable surface finish and uniform material removal over all regions of the airfoils, fillets, sidewalls (nozzles), and platforms (buckets). Smooth TBC surface finish has two benefits: (1) it lowers TBC and metal temperatures by reducing hot side heat transfer, and (2) it enhances machine performance by reducing aerodynamic losses.

Sample plates and airfoil shapes were coated and used to evaluate various surface finishing techniques. Conventional techniques, such as tumbling and grit blasting, had difficulty in uniformly finishing all areas of the airfoil geometries and cannot maintain dimensional control because of the differences in removal rates at different locations (e.g., fillets and leading edges of airfoils). Continued development is focusing on machining operations such as grinding, belting, and milling. Another technique, which utilizes part-specific soft tooling and conformable abrasive media, also showed good initial results and is being further evaluated. 
The profilometer settings for the measurement of TBC surface finish were completed. Two sets of calibration plates were created at various TBC finishes, ranging from as-sprayed to fully finished. These were evaluated by the profilometer manufacturer, and recommended profilometer settings and measured surface finish were provided. Calibration curves for profilometers used by various (GE sites will be created in order to correlate surface finish measurements to reference measurements made by CRD (reported in Section 2.2.3.6, Surface Roughness and Combustor-Generated Flow Effects on Heat Transfer).

Several processes for applying bond coat and top coat to the welded joint of the second-stage nozzle doublets are being evaluated. These nozzles are cast as singlets and welded into doublets following application of TBC to the nozzle airfoil and sidewall surfaces. Metallurgical evaluation showed that the weld process has minimal effect on the TBC structure. However, access to the weld joint is not adequate for the application of advanced TBC using the standard spray equipment. As a result, three approaches were investigated: (1) use of an air plasma mini-gun for top coat and, possibly, bond coat deposition; (2) use of a braze alloy for the bond coat and a slurry-applied ceramic for the top coat; and (3) use of an HVOF bond coat process.

Information for various plasma guns was collected, and suggested process conditions were requested from the gun vendors. A search to find a gun small enough to coat the entire weld joint with enough power to achieve required coating properties led to one prime candidate. A physical model was generated to simulate the space restrictions for a plasma gun when the two nozzles are welded together. Work with the nozzle model showed that this gun could easily pass through the nozzle cavity. However, initial work to determine the quality of the coating from this gun showed extremely poor deposition efficiency. Designed experiments were performed that significantly improved the deposition efficiency and led to acceptable microstructures for both the bond coat and TBC. Further experiments were performed to evaluate the potential for overheating the part if the gun motion had to be stopped on the part and reversed. Experiments showed that temperatures were well below those expected to degrade the mechanical properties of the substrate material. However, masking will be needed in these regions in order to produce acceptable TBC microstructures.

The first gun evaluated showed lower than acceptable reliability for manufacturing, however. Problems of gun reliability were overcome by use of a new gun, which was shown to be capable of achieving good TBC microstructures with high reliability and low maintenance. Mechanical properties of the TBC were lower than those of TBC sprayed using the standard gun but are considered adequate. Furnace cycle tests (FCT) were recently completed and the results are being analyzed.

Initial trials on brazed bond coats were promising and further development is planned. Slurryapplied ceramic top coats were evaluated, but that approach was abandoned because of the poor mechanical properties of the ceramic.

An HVOF spray process is being evaluated for application of the bond coat to the weld joint. Although the HVOF gun will not fit in the area between the nozzle airfoils, that is not expected to be a significant limitation because the process uses a much longer standoff distance and is more tolerant of off-angle spray than the APS process. 
Techniques for applying TBC over strain gauges were evaluated. Trial plates were fabricated by applying a standard TBC bond coat and top coat followed by a heat treatment. The TBC was then locally removed by the gauge vendor for installation of the strain gauge. A ceramic overcoat was applied by the vendor to restore thermal protection in the gauge region.

\section{TBC Process and Diagnostics}

Statistical analysis of over ninety designed experiments conducted between 1994 and 1996 was completed. All coatings were applied to flat plates. Ten process variables were included in the analysis. TBC properties considered were tensile strength, modulus, and thickness per pass. Process models were developed at a confidence level of $95 \%$ to predict $77.7 \%$ of tensile strength variation, $88.6 \%$ of modulus variation, and $99.5 \%$ of thickness variation. Process models were used to define process windows to achieve specific coating properties. A preliminary summary of APS bond coat experiments was completed. Pareto diagrams were generated to show the relative importance of process variables to the coating characteristics.

Plasma guns that operate at longer standoff distances and higher powder injection rates are desired for manufacturing. Information was collected for various alternate plasma guns, and suggested process conditions were obtained from the gun manufacturers. Experiments were performed to evaluate coatings sprayed using two alternate guns. Measurements of particle temperature and velocity were taken for reference and to optimize plasma conditions for each gun. A design of experiments (DOE) was performed with one of the guns to determine process effects on coating properties. Preliminary analysis of the data suggests this gun has the capability of achieving TBC properties similar to the present plasma gun at much longer standoff distances and up to $4 \mathrm{X}$ higher powder injection rates.

A protocol for measuring preheat and deposition temperature will be specified using the Inframetrics IN760 Infra-Red (IR) thermal imager. Good agreement was observed between IR temperature measurements and thermocouples attached to production buckets. Accuracy of IR pyrometry temperature measurements on semitransparent TBCs was evaluated, and accuracy limits were determined as a function of thermal gradient and TBC thickness. Initial experiments comparing $\mathbb{R}$ temperature measurements with a surface melting point standard indicated that the temperature error resulting from TBC translucency was acceptable for moderate through-thickness temperature gradients. Emissivity for an isothermal TBC was measured as a function of thickness by sequential thinning operations, and a lower thickness limit for TBC temperature measurement was determined. A radiative heat transfer model was developed to allow computer simulation of the effect of thermal gradient and thickness on temperature measurement accuracy. Development of several types of calibration specimens for determining TBC surface temperature was begun.

An assessment was made of the ease-of-use of commercial software for automated temperature data recording. Use of the software is currently limited by restrictions on the amount of data that can be recorded.

Evaluation of a gas-fired auxiliary heating source in the production spray cell showed significant improvement in part temperature control over plasma gun preheating alone. Strategies to control the gas torches, as well as use the gas torches in conjunction with the plasma gun, were evaluated. 
Evaluation of methods for surface preparation prior to performing local APS TBC repairs was begun.

\section{Nondestructive TBC Thickness Measurement}

An automated hybrid top coat thickness measurement system using a flexible eddy current probe in combination with a multi-axis scanner was developed. Installed Coordinate Measuring Machines (CMMs) in Schenectady and Greenville will be used as the scanning devices. The other elements of the system include a redesigned eddy current probe and probe holder, a Nortec 24 eddy current instrument, a Pentium computer, motion control software, and a modified version of the eddy current software being used for manual eddy current measurements.

Installation and checkout of the Mark 1 system was begun. An additional VALISYS software module was purchased and installed to support programming the system. Beta testing of the system was delayed because of difficulties with integration of the PC-based software into the UNIX-based site systems.

It was determined that complete inspection coverage of nozzles and buckets is not possible using the Mark 1 automated system because of the high contact force required by the flexible eddy current probe, which significantly restricts the angular degree of freedom for the probe holder. Further system development will focus on use of miniaturized rigid eddy current probes. The flexible probe was developed primarily to improve measurement reproducibility when performing manual eddy current measurements. Measurement reproducibility is not expected to be degraded by using rigid probes in combination with a CMM scanner.

Several new sets of reference specimens are being constructed that employ recently developed bond coats. Some specimens will be used as eddy current thickness calibration pieces. Others will be used for designed experiments to determine the effect of processing parameters on eddy current thickness measurements.

\section{Nondestructive TBC Evaluation}

A program to apply laser ultrasonics for nondestructive evaluation of TBC elastic (Young's) moduli was begun. Current techniques use mechanical resonance to extract the coating modulus indirectly. The laser ultrasonic approach uses a Nd:YAG laser to produce a shaped source beam onto the target coated substrate generating an ultrasonic Lamb wave which predominantly propagates in the coating. A laser interferometer senses the Angstromamplitude propagating wave signal, which is stored on a computer and analyzed for frequency dispersion content. With the coating thickness known, the Young's modulus can be calculated once an analytic model of the system has been constructed.

The coatings contain anisotropy (e.g., in-plane versus through-thickness) and are not adequately described by a single number. Inversion tools for extracting all relevant moduli are under development, and a cooperative agreement for study of this problem has been worked out with CNRC/IMI (Canadian National Research Council). A numerical model for calculation of dispersion properties from mechanical constants was developed. This model indicates that dispersion properties are sensitive to coating mechanical properties and not to the bond line. In addition, preliminary laser ultrasound data were acquired for an existing set of samples that produce results consistent both with our model and with mechanical resonance 
measurements. A new approach for extracting complete multiple mode dispersion curves was developed.

\section{Plans for Next Quarter}

\section{Robot Motion Control and Part Programming Methods for Airfoils}

Robot motion equivalency tests at each site using the enhanced ATS Nozzle Replica, gun tooling, and ROBCAD/STP programming tools will be completed. Laser Target development and testing for measuring robot motion performance on ATS buckets and nozzles will continue.

ROBCAD/STP patch and continuous motion development based on constant and variable velocity trials on ATS hardware and replica shapes will continue. A subset of the CSMP functionality will be transitioned to GE Power Systems to enable off-line evaluation of robot motions.

\section{TBC Manufacturing Technologies}

Booth equivalency tests at three GE airfoil coating facilities will be completed.

Development and manufacturing trials on machining processes for surface finishing TBCcoated airfoils will be conducted. The trials will include selection of appropriate machine tools, motion programming for specific airfoils, and machining trials.

Process development for coating of the second-stage nozzle weld joint will continue. HVOF bond coats will be applied at various process parameters and subsequently coated with TBC by mini-gun. Mechanical properties and thermal cycling tests will be conducted.

A manufacturing upgrade to production status including masking, instrumentation, machining, and coating parameter activities will be supported.

\section{TBC Process and Diagnostics}

Evaluation of the alternative plasma guns will continue. More experiments will be performed to better understand the capabilities of these guns to achieve coating properties at higher feed rates and longer gun-to-work distances.

Accuracy of IR pyrometry will be further verified for larger through-thickness temperature gradients by comparison with complementary pyrometry techniques. An in-house software package will be evaluated for automated pyrometry data collection. Specifications for an accurate, easy-to-use deposition temperature measurement protocol will be established.

Experiments to evaluate APS repair of a new make TBC will be completed. This activity may be deferred until 1998.

\section{Nondestructive TBC Thickness Measurement}

Integration of the motion control computer and software with the scanning hardware for the automated Mark 1 eddy current ceramic coating thickness scanner will be completed.

Metallographic measurements of bond coat thickness on specimens with eddy current measurements will be correlated using the flexible probe system. Compound curvature specimens will be built. 
Use of the HP analyzer will be expanded to develop a method to measure bond coat thickness. Nondestructive TBC Evaluation

Further evaluations will be deferred to 1998.

\section{Technology Application}

The process for applying APS TBC to ATS combustion and turbine components will be defined. This process will define the baseline upon which coating durability will be evaluated and evolutionary improvements will be made.

\section{Section 2.2.5.2 (GTTTRR) TBC Risk Reduction}

\section{Objective}

TBC durability will be evaluated under conditions very similar to the surface temperature, thermal gradient, and stress state of TBCs in ATS applications. An E-beam rig capable of inducing high thermal gradients will be used to assess the relative durability of various TBCs, and the controlling mechanisms of TBC failure will be characterized. TBCs with a spectrum of microstructures will be tested to determine the role of TBC thickness on stress development and failure mode in high thermal gradient conditions, the failure modes of various TBCs of different microstructures and deposition techniques, the role of number of cycles and hold times at high temperature on TBC failure mode, and the role of bond coat composition and roughness on TBC life and failure mode. The effects of environmental contaminants on TBC performance in high thermal gradient conditions will be investigated. Numerical modeling will be used to determine the stress, strain, and thermal gradient conditions in the various TBCs during the tests.

\section{Progress 4Q96 through 3Q97 \\ Standard (Flat) Tophats}

Two TBC-coated tophats were furnace aged to $50 \%$ and $75 \%$ of expected ATS TBC life. These tophats were then tested under full ATS conditions for 100 hours and 2500 cycles. No hot spots were observed during testing and no TBC damage was observed by cross-sectional metallographic evaluation. Test specimens for residual mechanical property measurements were machined from these two tophat samples. No systematic decrease in the residual mechanical properties was measured as a result of the 100-hour, 2500-cycle full ATS condition testing.

\section{Fillet Tophats}

A PtAl-coated fillet tophat was tested under moderate conditions to produce tophat stress and temperature maps. This information was needed to determine instrument locations for fullcondition testing. A fillet TBC endurance sample was prepared for testing.

\section{Plans for Next Quarter}

Fillet TBC endurance samples will be tested at full ATS conditions. These samples include samples furnace aged to $0 \%, 50 \%$, and $75 \%$ of expected ATS TBC life. 
The third CMAS sample will be tested. Testing will continue up to 250 cycles or until a TBC hot spot is observed.

\section{Technology Application}

Durability of the baseline TBC in an environment simulating that of the ATS baseline will be evaluated. These results will establish confidence that the TBC will provide acceptable minimum durability for safe and reliable operation of the ATS turbine within the time frame of the first inspection interval.

\section{Section 2.2.5.3 (GTTTDD) TBC Design Data and Life Analyses}

\section{Objective}

Thermomechanical failure modes in advanced TBCs will be identified, classified, and defined using empirical methods. Experiments will be performed to find key relationships among plasma spray processing variables, coating microstructure, coating physical and mechanical properties, and coating performance under simulated ATS conditions.

The relative contribution of oxidation and cyclic damage to the failure of two TBC systems will be evaluated in order to estimate the TBC life under the ATS gas turbine conditions. This will be accomplished by furnace cycle testing TBC systems using a series of dwell times per cycle $\left(0.1\right.$ to 20 hours/cycle) and dwell temperatures $\left(1037^{\circ} \mathrm{C}-1093^{\circ} \mathrm{C}\left[1900^{\circ} \mathrm{F}-2000^{\circ} \mathrm{F}\right]\right)$, and incorporating the results into an existing cumulative damage model. In support of this modeling approach, microstructural features of the bond coat and ceramic top coat will also be examined.

Numerical analyses will be performed to determine TBC stress states expected in ATS turbine components and in laboratory thermal cycling tests. The influence of the TBC stresses on TBC failure modes will be examined. Specially developed finite elements will be used for modeling the behavior of the interface cracks and free-edge stress singularities. The effects of bond coat roughness on TBC stress state, crack driving forces, and delamination failure will be examined. Parametric studies to determine the effects of bond coat and top coat properties on the TBC stress states will be performed.

The spatial and run-to-run variability of TBC thermal conductivity will be evaluated. Improved understanding of this variability is essential because the variation in TBC thermal conductivity can be several times greater than that seen in metals due to variations in TBC microstructure, and can therefore lead to design inaccuracy. Various methods of measuring thermal diffusivity and conductivity on flat and curved samples will be evaluated. The gas pressure dependence of thermal conductivity as a function of temperature will be measured. The results will be used to estimate the thermal conductivity of TBCs at ATS conditions. The effect of thermal aging on TBC thermal conductivity will be quantified.

Information from this task will be used as input to other tasks. Appropriate data and modeling results from parallel GE programs will be incorporated. Design guidelines will be developed for TBCs on ATS components. Ultimately, a TBC life analysis methodology and a life predictive model will be developed. These will include effects of long-term exposure on top coat and bond coat physical and mechanical properties. 


\section{Progress 4Q96 through 3Q97}

\section{Furnace Cycle Test}

The furnace-to-furnace and site-to-site variability in furnace cycle tests (FCT) was thoroughly evaluated. An improved furnace calibration procedure was developed and incorporated into the test procedure.

Porous and dense vertically cracked (DVC) TBC specimens were furnace cycled at $1148^{\circ} \mathrm{C}$ $\left(2100^{\circ} \mathrm{F}\right)$ and $1093^{\circ} \mathrm{C}\left(2000^{\circ} \mathrm{F}\right)$ using dwell times of $0.1,0.75$, and 10 hours per cycle. The majority of specimens were cycled to failure, although some specimens were removed at intermediate times for tensile adhesion testing. A small number of specimens were intentionally exposed to two different dwell times in order to test the influence of thermal history on remaining TBC life.

Three main conclusions have been drawn to date. (1) Analysis of the test data at $1148^{\circ} \mathrm{C}$ $\left(2100^{\circ} \mathrm{F}\right)$ indicated equal contributions of bond coat oxidation and ceramic fatigue to TBC system life; whereas, visual examination of failed specimens suggested that bond coat oxidation ultimately limits TBC system life. In both the DVC and porous TBC, the pooled standard deviation in TBC life was approximately $10 \%$ of the average life. (2) There was a statistically significant difference in DVC TBC life at $1148^{\circ} \mathrm{C}\left(2100^{\circ} \mathrm{F}\right)$ between the five N5 plates tested. It was hypothesized that this difference was due to minor changes in process conditions between spray runs. No such difference in life was observed for the porous TBC system. (3) Analysis of the test data at $1093^{\circ} \mathrm{C}\left(2000^{\circ} \mathrm{F}\right)$ indicated an increasing contribution of bond coat oxidation to TBC system life; whereas, visual examination of failed specimens revealed ceramic fatigue to be an increasing contribution.

\section{Thermal Conductivity}

\section{(A) Planar samples}

Measurements were made in nitrogen and in vacuum up to the highest temperatures of interest for the ATS design. Good agreement of the data with a gas pressure model was obtained. Extrapolations of the model to full ATS conditions are considered accurate. It was confirmed that the radiation contribution to TBC thermal conductivity is small up to the highest temperatures of interest.

Acceptable measurement reproducibility was obtained after storing specimens for a twomonth period. The primary objective during this reporting period was to produce refined design data for TBC thermal conductivity as functions of temperature and aging time. The three furnaces needed to conduct aging to at least 1,000 hours were profiled using calibrated thermocouples. The temperatures in the region for sample placement are uniform to $\pm 1^{\circ} \mathrm{C}$. Enhancements were made to the furnaces for improved reliability.

Free-standing TBC samples (12 mm diameter) were prepared for furnace aging. Both sides of the samples were ground flat and smooth. Samples were aged in air for 1,000 hours at $1038^{\circ} \mathrm{C}, 1204^{\circ} \mathrm{C}$, and $1316^{\circ} \mathrm{C}\left(1900^{\circ} \mathrm{F}, 2200^{\circ} \mathrm{F}\right.$, and $\left.2400^{\circ} \mathrm{F}\right)$. These samples will be compared with corresponding samples aged for short times $(<100$ hours). There was no measurable change in TBC density as a result of aging. 


\section{(B) Curved TBC samples from parts}

Measurements on curved and flat tape cast samples were made to test the laser flash method for various radii of curvature. The results for all samples were identical (within experimental error), verifying that this technique is useful for most regions on parts.

Sections from production first-stage buckets were evaluated. Eight samples were prepared from each of two sections, each section corresponding to a different APS run. In each section, two parts with small radius of curvature and two with large radius of curvature were taken from both concave and convex locations. Changes in radius of curvature were noted after sample removal, in some cases by a significant amount. The final radii of curvature were used for density determinations by weight and volume. There was no trend in density corresponding to subclassification (e.g., run-to-run, convex vs. concave, large vs. small radius of curvature). Sample thickness was measured using a micrometer and corrected for the effect of roughness.

There was higher scatter in the thermal conductivity compared to planar samples, consistent with a larger error in thickness and density compared to planar samples. Within the measurement uncertainty, there was no trend in thermal conductivity corresponding to subclassification (e.g., run-to-run, convex vs. concave, large vs. small radius of curvature). However, the absolute value of thermal conductivity was slightly lower than the values measured previously on corresponding planar samples.

\section{Plans for Next Quarter \\ Furnace Cycle Test}

Exposures at $1038^{\circ} \mathrm{C}\left(1900^{\circ} \mathrm{F}\right)$ will begin. These exposure tests and further evaluations of the previously aged samples will be deferred to 1998 .

\section{Thermal Conductivity}

Thermal conductivity of aged planar samples will be measured and incorporated into the design databases. A robust method for measuring sample thickness and density for unpolished samples or samples polished on one side only will be developed. This will allow more accurate thermal conductivity measurements to be made from part sections.

\section{Technology Application}

A database will be established that will link TBC properties and durability in laboratory tests to TBC durability in the ATS turbine. Ultimately this database will be used to predict TBC life as a function of temperature and strain at specific locations on ATS turbine components. The database will also be used to identify process improvements to the baseline TBC that result in improved properties and durability.

\section{Section 2.2.5.3.1 (GTFFTB) Bucket TBC Roughness and Spall Characterization}

\section{Objective}

This task will quantify the external airfoil heat transfer coefficients associated with the roughness characteristic of TBCs. This task places specific attention on the roughness 
associated with TBC structure, which can be very different from that of metallic surfaces or coatings.

Typical average roughness measurements made on surfaces cannot fully distinguish between metal finishes, artificial rough surfaces, and applied or polished TBC surfaces. While the measured average roughness values of such surfaces may be the same, the effect on external heat transfer may be quite different due to the specific character of the roughness. This task will use CRD's Transient Heat Transfer Cascade to test an airfoil coated with TBC that has been polished to various levels, and assess the effect of TBC-type roughness.

\section{Plans for Next Quarter}

This task has been completed.

\section{Technology Application}

The results from this task will be analyzed for consistency among the various roughness levels tested. The results will also be compared to other similar tests run in the same facility that used metallic rough surfaces. If the complete available data show a consistent and clear effect of TBC surface roughness on external heat transfer, these data will be used to determine an equivalent TBC roughness for use in the design heat load predictions on the ATS turbine airfoils.

\section{Section 2.3 (CC) Combined Cycle Integration}

\section{Section 2.3.1 (CCUA) Unit Accessories}

\section{Objective}

Development of four new unit accessories-fuel heating, cooling-air cooling, steam cooling, and clearance control-is critical to the development of the ATS gas turbine in order that the gas turbine meet its performance goals and function properly. The ATS turbine employs a DLN 2.6 combustion system that requires the gas fuel to be heated in order to achieve the overall ATS efficiency goal. The cooling-air cooling system is required to maintain temperature in sections of the gas turbine within acceptable limits. The steam cooling system is required to cool the turbine hot gas path parts while meeting performance goals for the ATS turbine. The clearance control system enables the turbine to operate at a higher efficiency than would be possible without it. The exhaust diffuser will be designed so that maximum possible pressure recovery will be realized, thus increasing the performance of the ATS gas turbine. Designs of remaining accessory systems will be conventional.

Design of the heat exchanger and piping for the hot fuel will take into consideration the need to avoid coking. Deposit formation will be investigated. The effectiveness of coke barrier coatings, which have been under development for liquid-fueled systems, will be evaluated in long-term tests.

\section{Progress 4Q96 through 3Q97}

During this period, the engineering design team developed the unit accessories from the conceptual design phase well into the preliminary design phase. 


\section{Fuel Heating}

The final Process \& Instrumentation Diagram (P\&ID) for the gas fuel heating systemincluding mechanical and electrical schematics and temperature, pressure, and flow information-was completed. All device nomenclature for the gas fuel heating system was defined and included in the overall advanced gas turbine device summary. Preliminary functional specifications defining the gas fuel heating system components were completed in order to begin the detailed component design work with potential suppliers.

\section{Cooling-Air Cooling System}

A cost study of the high-pressure (HP) water cooling-air cooling (CAC) system design developed in 1996 revealed that the HP configuration would yield a very high overall system cost. Subsequently the HP configuration was scrapped and an intermediate pressure (IP) water CAC system configuration was developed. This resulted in a system with a significantly lower cost, higher reliability, and less complexity.

A preliminary P\&ID was completed for the IP water CAC system configuration. The P\&ID included a mechanical schematic, definition of necessary devices (to be included in the advanced gas turbine device summary), and temperature, pressure, and flow information developed through a Flowmaster system model.

A preliminary functional specification was completed that defined the components of the overall system. This was used to start work with suppliers to define the design of the system components.

During 3Q97 further component reductions were realized for the cooling-air cooling system based on the change from an HP system to an IP system. The devices required for the system were defined and added to the overall advanced gas turbine device summary. Using the preliminary P\&ID and functional specification completed in the $2 Q 97$, preliminary definition of the system components with suppliers was started.

\section{Steam Cooling System}

The steam filter vessel configuration was redesigned to a simpler, more compact, and lower cost vessel that can also be maintained more easily. The system P\&ID was completed, defining the system temperatures, pressure, and flows throughout the system in addition to the system layout. Based on the P\&ID, outline drawings for the steam filter, valves, and flow meter were developed with suppliers, defining the preliminary detail design of these components.

Revision of the steam flow requirement for the steam cooling system in $3 Q 97$ resulted in the need to resize all components of the steam cooling system. In addition, several design reviews were held to develop a design for a steam measurement system. Five concepts were developed, four involving steam flow measurement and one involving measurement of the temperature of the steam-cooled components. By the end of $3 Q 97$, this was narrowed down to two concepts with the intention of deciding between the two during $4 \mathrm{Q} 97$.

\section{Clearance Control System}

A transient model of the clearance control system was created that resulted in changes to the system design requirements in order to simplify and reduce the cost of the system. Based on 
the changes to the design requirements, the method of pressurizing the system was changed from using plant instrument air to using reciprocating compressors. The reciprocating compressors will be added to the clearance control system to pressurize the system prior to startup and to provide makeup air during normal operation. A preliminary system P\&ID and preliminary functional specification were completed in order to begin specifying the system components with suppliers.

The final system P\&ID, device summary, and functional specification were completed. These documents were used in several reviews with suppliers in order to choose the best supplier for each component of the system (including the skid itself). During the selection process, further cost reductions were realized through competitive bidding. A failure modes and effects analysis (FMEA) of the system was completed, which resulted in changes to the system configuration in order to improve the system reliability.

\section{Exhaust Diffuser}

A scaled model test of the advanced gas turbine exhaust diffuser was conducted at $\mathrm{CRD}$. The first model test results during the $1 \mathrm{Q} 97$ and $2 \mathrm{Q} 97$ were inconclusive. A preliminary outline drawing and functional specification were developed for the exhaust diffuser. These documents were used with suppliers so they could begin the preliminary detail design of the exhaust diffuser.

The second model test was conducted at CRD using a more refined diffuser model. The tests were completed at the very end of 3Q97. It appears from preliminary test results that the diffuser configuration adequately meets its design requirements so that it will be possible to begin the detail design of the exhaust diffuser with suppliers during 4Q97.

\section{Plans for Next Quarter}

\section{Cooling-Air Cooling System}

A final system review of the cooling-air cooling system will be held in order to enable completion of the final P\&ID and final functional specification. Once complete, an advance purchase order will be written so as to start suppliers on the detail design of the system components. In addition, the system FMEA will be completed .

\section{Steam Cooling System}

The preliminary design of the steam flow measurement system will be complete with the selection of one of the two remaining measurement system concepts. The system P\&ID will be updated to show the measurement system and to reflect the new steam flow requirement issued during 3Q97. New outline drawings for the steam valves and steam filter will be completed based on the new steam cooling flow. Outline drawings will be created for the steam measurement system flow meters.

\section{Clearance Control System}

Suppliers will be selected to design and fabricate the clearance control system components and skid package. Design reviews will be held with the suppliers during 4Q97 and 1Q98 as they develop the detail design of the system components. The clearance control skid will be completed and shipped to the gas turbine test facility in 1Q98 for use in the full speed, no load (FSNL) test being conducted during 2 Q98. 


\section{Exhaust System}

The full report from the CRD diffuser model test is expected early in 4Q97. If the results are satisfactory (as preliminary test results suggest [Section 2.2.2.6.1]), the detail design of the exhaust diffuser can begin in $4 Q 97$. This will involve several design reviews with suppliers as they develop the diffuser detail design with the GE exhaust diffuser engineer. Further testing may also be required to study the acoustic effects of the exhaust gas flow through the diffuser.

\section{Technology Application}

Development of the fuel heating system, the cooling-air cooling system, the steam cooling system, the clearance control system, and the exhaust diffuser system are all critical to successful operation of the ATS gas turbine. Each system is also critical to the high efficiency rating that the ATS gas turbine will achieve. Therefore development of these systems will continue in order that the ATS gas turbine meet these design goals.

\section{Section 2.3.2 (CCCL) Controls}

\section{Objective}

An integrated plant control system will be developed and designed that will be suitable for the advanced gas turbine combined cycle power plant. Specifications of control equipment requirements will be prepared. Control and protection strategies will be developed for gas turbine steam cooling and integration with the steam turbine and heat recovery steam generator (HRSG). Control system dynamic behaviors will be studied by dynamic simulations. Specifications of control algorithms will be prepared for implementation in the control system program.

\section{Progress 4Q96 through 3Q97}

Control and protection strategies were developed for most of the gas turbine systems. Models of the major equipment components and the control system were developed for dynamic studies. The development of the integrated control system progressed into the design and manufacturing phases.

Control system models were developed and are being used in an ongoing study of the dynamics of the combined cycle, the combined cycle components, and the control system. The control sequences for startup and shutdown were studied, including the continued development of valve transition logic for management of air and steam flows to the gas turbine. Other control loop dynamic studies include gas turbine clearance control, fuel heating control, and steam cooling control. Development of algorithms for the protection of the ATS gas turbine continues, focusing particularly on the protection of hot gas path components. Design and manufacturing processes for the prototype control panels of the integrated control system are underway. Prototype field testing of the control components is ongoing.

\section{Plans for Next Quarter}

Study of control loop dynamics will continue. Software algorithms and sequence logic for the gas turbine will be coded into control programs. Verification of the control programs will 
begin using equipment models and actual control panels. Manufacture of the prototype panel for gas turbine control will be completed.

The integrated plant control system conceptual design for the STAG $109 \mathrm{H}$ configuration will be very similar to that of the STAG 107H ATS plant.

\section{Technology Application}

The integrated plant control system conceptual design for the STAG $109 \mathrm{H}$ configuration will be very similar to that of the STAG 107H ATS plant.

\section{Section 2.3.3 (CCRA) Reliability, Availability, and Maintainability (RAM) Analysis}

\section{Objective}

An evaluation of the reliability, availability, and maintainability (RAM) of the $7 \mathrm{H}$ equipment will be performed. The basis for the work will be the EPRI High Reliability Controls and Accessories Study. The RAM analysis will include: the flange-to-flange gas turbine, heat recovery steam generator, steam turbine, controls and accessories, electrical generator, and balance of plant equipment. A failure modes and effects analysis (FMEA) will be included.

\section{Progress 4Q96 through $3 Q 97$}

The majority of activity during this period was restricted to FMEAs.

Gas Turbine Flange-to-Flange - Turbine and Compressor

FMEA development continued on all conventional and unconventional aspects of the turbine and compressor. Over 60 FMEAs were identified to-date in Gas Turbine Flange-to-Flange. Ten FMEAs were completed: steam gland, third-stage bucket cooling delivery, exhaust frame cooling systems Nos. 1 and 2, steam delivery bore tube, compressor rotor/cooling, variable guide vane (VGV) components, outer turbine shell arrangement, outer turbine shell, piping (generic), and turbine base. Twenty-five more are underway, many in the final steps to completion. These include all 4 bucket castings, all 4 shrouds, all 4 nozzles, inner shell and clearance control, steam piping, first-stage nozzle support ring, first-stage nozzle joint lifing, steam delivery adapter, second-stage rotor, and 7 in steam delivery-cross tubes, cross tube sleeve, manifold cover plate, radial spring tube, aft shaft windage cover, manifold spring, and radial spring.

\section{Plans for Next Quarter}

FMEA development will continue on the following: stator system, combustion, stator structures, steam delivery system, rotor, and assembly FMEAs involving interface of Turbine Design Engineering and Compressor and Structures Design Engineering. Efforts will be made to start and complete the remaining 26 FMEAs in 4 Q97.

\section{Technology Application}

The FMEA results will be applied to the design of the $9 \mathrm{H}$ and $7 \mathrm{H}$ hardware, with special emphasis on the components involved with the steam-cooling aspects of the design. 


\section{Section 2.3.4 (CCSD) Combined Cycle Systems Design}

\section{Objective}

Optimization analyses will be performed and the combined cycle system will be configured to optimize cost/performance characteristics of the total plant. Steady-state modeling will be used to calculate the detailed plant performance. Dynamic modeling of load change sequences (e.g., startup and load rejection) will be used to specify control system design. Operability will be assessed.

\section{Progress 4Q96 through 3Q97}

The steady-state performance model (SSPM) for the STAG 107H was updated for improved maintainability and platform portability. Extension of both the STAG $109 \mathrm{H}$ and $107 \mathrm{H}$ performance models to include automation of design point calculations was started. Vendor evaluation for compliance of STAG $109 \mathrm{H}$ heat recovery steam generator (HRSG) functional specifications was completed. Definition of machine operating limits for use in STAG 109H system design and implementation into the control system are on schedule for the full speed, no load (FSNL) test.

The ATS gas turbine Cycle Deck performance model was updated and incorporated an updated steam bottoming cycle model into the first major update of the $107 \mathrm{H} / 109 \mathrm{H}$ reference plant SSPMs. The rotor clearance control (CC) system was studied and optimized.

Preliminary optimization of the fuel heat exchanger to include cost was completed. The SSPM was updated to include an optimized design of the cooling-air cooling system and gas fuel heating system. The Clearance Control conceptual design for interaction with the steam cycle was revised.

The STAG 109H thermal dynamic model (TDM) was successfully extended to simulate Unit Trip, Flying Restart, Hot Restart, and Load Change transients which were released for general design purposes. This completes the first release of transient runs for dynamic modeling. System response to rapid transients was studied and communicated to Gas Turbine Engineering. TDM results and findings were incorporated into FMEA analysis for transient behavior of H-machine-specific new systems, which include: gas turbine steam cooling, cooling-air cooling, and gas fuel heating systems. A higher fidelity gas turbine model was incorporated into the TDM, and preliminary tests at full speed, full load (FSFL) were successful.

Generation of Design Standards and Guidelines Documentation for use by Combined Cycle Applications Engineering is in progress and about $15 \%$ complete.

Three process improvement projects directly linked to the ATS gas turbine models were started and will be worked on through the end of 4 Q97. The targets of these quality projects are the SSPM and the TDM. Ore project targets the speed of convergence of the SSPM. The second targets automation of Heat Balance reports for ATS project proposals. The third targets the verification of a new and more robust software and platform for use with the thermal dynamic model. 


\section{Plans for Next Quarter}

Extension of the performance model to include automation of design point calculations will continue. Work will continue on machine operating limits and control strategy definition for use in the $9 \mathrm{H}$ gas turbine prototype. Design Standards and Guidelines Documentation generation for use by Combined Cycle Applications Engineering will continue. The dynamic model upgrade to a higher fidelity gas turbine model will be further tested for optimal computational speed and part-load verification.

\section{Technology Application}

Operability evaluation of the STAG $109 \mathrm{H}$ configuration will be directly applicable to the STAG 107H ATS plant. Cooling-air cooling and fuel heating system conceptual designs will be very similar for the STAG $107 \mathrm{H}$ ATS plant.

\section{Section 2.4 (MF) Manufacturing Equipment and Tooling}

\section{Objective}

The materials, equipment, tooling, and processes required to produce the $7 \mathrm{H}$ and $9 \mathrm{H}$ turbines will be identified, designed. and procured. Manufacturing schedules will be established to support ATS pre-commercial demonstration goals. Manufacturing schedules and cost will be defined.

\section{Progress 4Q96 through 3Q97}

Forging operations were completed on the IN718 turbine rotor forgings, which were shipped to the machining supplier for sonic inspection and machining. Seven forgings were sonic inspected successfully, the results were evaluated, and the forgings are currently in various stages of machining. Development of steam system components for the rotor cooling system progressed through manufacturing process definition. TBC process qualifications for H-machine airfoil coating continued and the Greenville, SC, coating facility became operational for airfoil components. Design of a test stand for full speed, no load (FSNL) testing of $\mathrm{H}$ design gas turbines has progressed to a point where site preparation has begun and components are on order to support completion by April 1998.

\section{Plans for Next Quarter}

The IN718 forgings and steam system components for the first $9 \mathrm{H}$ machine will complete manufacturing and be delivered to Greenville for assembly of the turbine rotor. TBC process qualification will be completed for airfoil components; construction of the FSNL test stand will begin.

\section{Technology Application}

Development of the turbine wheel forging dies and the ultrasonic inspection techniques are the first application in forgings of this size and will be used to provide high-strength, hightemperature material that is compatible with the steam cooling environment in the ATS turbine rotor. The mockups are being used to assure fit-up of all components in very restrictive areas of the turbine. An electronic simulation of these areas is being done in parallel to develop simulation technology for future applications. The TBC robot controllers will 
provide the thickness control for the TBC coating that is required for proper heat transfer properties in the steam-cooled turbine airfoil components.

\section{Section 2.5 (IG) Integrated Gasification and Biomass Fuel}

\section{Objective}

An assessment of the ATS will be performed as part of an efficient and environmentally compatible integrated gasification combined cycle (IGCC) power generation system. Modifications to the gas turbine to accommodate the high mass flow resulting from the low heating value fuel gas and nitrogen injection for low NOx emissions will be identified. Analyses will be run to optimize the integration of the steam cycle with one oxygen-blown entrained flow gasifier and gas cleanup system and integration of the gas turbine with the air separation unit. IGCC system performance will be analyzed for one coal composition at ISO ambient air conditions.

\section{Progress 4Q96 through 3Q97}

There was no activity associated with this task under the ATS Phase 3 Cooperative Agreement during the current reporting period.

\section{Plans for Next Quarter}

There is no activity planned for this period.

\section{Section 2.6 (DE) Pre-Commercial Demonstration}

\section{Objective}

A commercial proposal will be prepared and submitted to the host utility.

\section{Progress 4Q96 through 3Q97}

Commercial activity remains high. Excess of generating capacity in the domestic market continues to delay project approvals; however, commercial discussions (equity, price, shipment requirements, insurance premiums, performance levels, construction financing, and service agreements) with potential host utilities and power marketers continue to intensify.

The fifth and sixth Utility Advisory Board (UAB) meetings were held. UAB members were updated on the status of ATS gas turbine performance, operability, maintainability, reliability, availability, plant arrangements, and installed cost.

\section{Plans for Next Quarter}

The next UAB meeting is planned for $4 \mathrm{Q} 97$. 


\section{Section 2.7 (PM) Program Management}

\section{Objective}

Within GEPG Engineering, an ATS Program Office will be established and a Program Manager and a Contract Administrator will be assigned. The Program Manager will direct the overall activities of the Program Office, and will have responsibility for reporting to DOE and ensuring that the program goals are achieved. The Program Office is responsible for communicating contract requirements, authorizing applied labor and expenses for material and services, scheduling monitoring, and reporting cost and technical performance. Additional responsibilities include coordinating ATS activities with CRD and GEAE. The assigned Contract Administrator will support the Program Manager in all administrative matters. All materials and equipment acquisitions will be closely monitored by the Program Office with support from the Finance and Sourcing organizations.

Actual scope, schedule, and budget will be tracked against plan. An integrated program plan will be maintained, including a detailed Work Breakdown Structure, that accurately describes the planned work, reflecting all changes in work scope or schedule. The integrated program plan includes the implementation and coordination of all program support procedures and initiatives such as Target Costing, Key Quality, and Design for Manufacturing.

Reports will be prepared to serve both DOE and GE needs for oversight and monitoring, including quarterty reports, annual reports, and topical reports. A final report will be prepared at the completion of the cooperative agreement. Reports specified in the Cooperative Agreements Financial Assistance Reporting Requirements Checklist will be supplied. Technical papers will be submitted for presentation to professional society meetings. Open communications will be maintained with DOE and the Industry Advisory Board.

\section{Progress 4Q96 through $3 Q 97$}

In response to a request from DOE FETC, the GE ATS Program Office led the preparation of a proposal to restructure the current ATS Phase 3 program, continuing the engineering development and component testing activities of the original Work Breakdown Structure with the addition of a catalytic combustion conceptual task and a factory full speed, no load (FSNL) test of the GE model $7 \mathrm{H}$ gas turbine. All other Phase 4 activities relating to the full-scale pre-commercialization testing of the Advanced Turbine System in a combined cycle power plant with a host utility were eliminated.

The work scope required to meet the FSNL test was defined, and manpower and purchased services for each task were determined. Input from GE Power Systems Engineering and Manufacturing, GE Aircraft Engines, and GE Corporate Research and Development was inchuded in the proposal, was delivered in 3Q97.

An Advanced Turbine Systems Program Review was held for DOE/FETC on August 25, 1997, at GE Power Systems and GE Corporate Research and Development. Topics reviewed inchuded: $\mathrm{H}$ program status, gas turbine component (turtine, compressor, combustor) design status, material review, thermal barrier coatings status, nondestructive evaluation inspection techniques, steam purity test results, and lab tours showing technical efforts in materials technology, thermal barrier coatings, spoolie testing, heat transfer, combustion, advanced seals, E-beam demonstration, and aerodynamic testing.

\section{Plans for Next Quarter}

The proposal submitted in $3 Q 97$ will be negotiated. 